

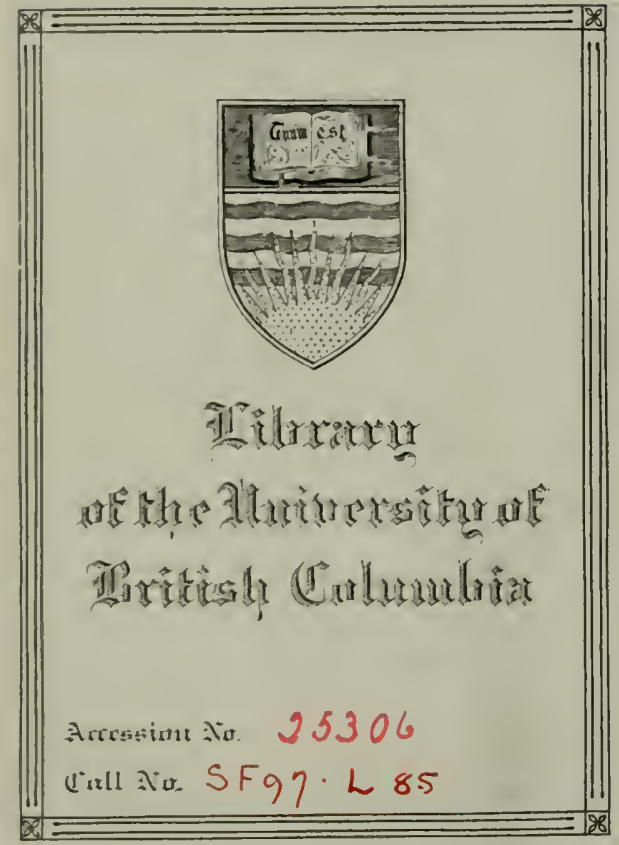


Fi@e; 

CAMBRIDGE AGRICULTURAL MONOGRAPHS

\section{PLANTS POISONOUS TO LIVE STOCK}




\section{CAMBRIDGE UNIVERSITY PRESS}

C. F. Clay, Manager

Zlondon: FETTER LANE, E.C.

EDinburgb: 100 PRINCES STREET

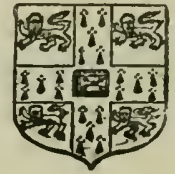

lonvon: H. K. LEWIS AND CO. LTD., 136, GOWER STREET, W.C.

Condon: WILLIAM WESLEY AND SON, 28, ESSEX STREET, STRAND

fero gork: G. P. PUTNAM'S SONS

Sombag, Calcutta and fladras: MACMILLAN AND CO., LTD.

Torento: J. M. DENT AND SONS, LTD.

Cokño: THE MARUZEN-KABUSHIKI-KAISHA 
Digitized by the Internet Archive in 2010 with funding from University of British Columbia Library 


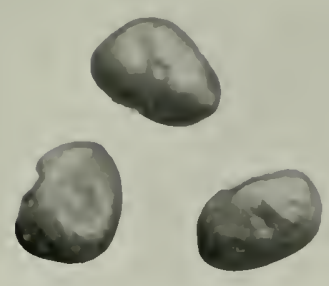

a

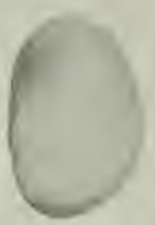

C
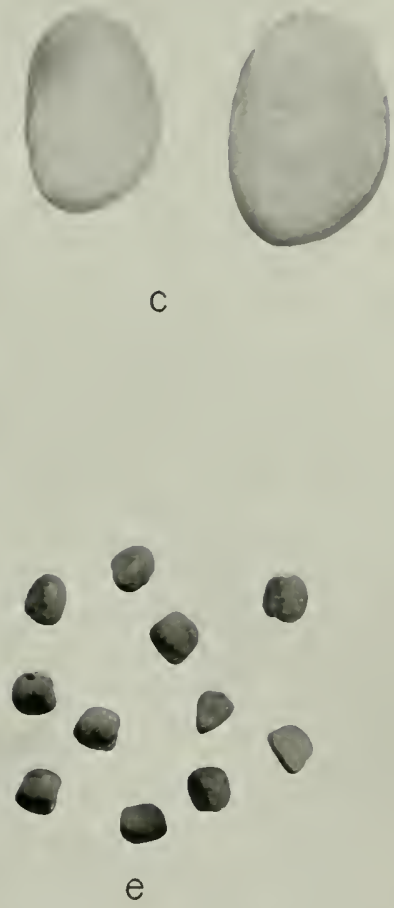

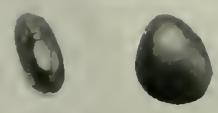

b
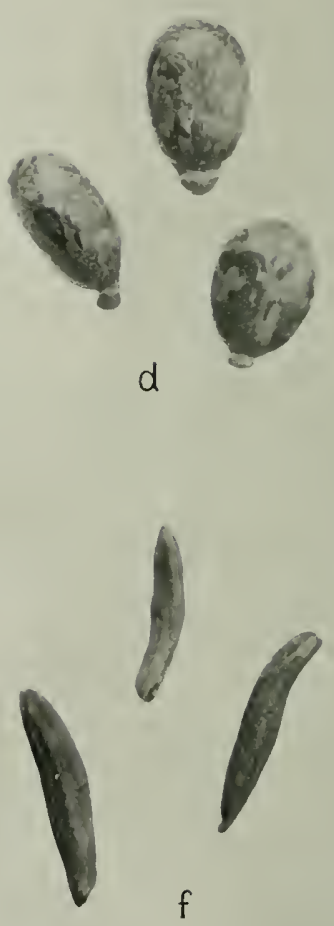

"Reddish-brown to reddish-purple "Java" Beans (Phascolus lunutus); b" Red Rangoon" Beans (I'. Inmatus); c "Large White" Beans ( $P$. lenetus); $d$ Castor Oil Beans (Ricimus communis); $e$ "Indian Peas" (Lathyrus salivus), from Bombay; $f$ Ergot (Claviceps purpurea), from Spain. All natural size. 


\section{PLANTS POISONOUS TO LIVE STOCK}

BY

HAROLD C. LONG, B.Sc. (Edin.)

of the Board of Agriculture and Fisheries

Author of Common Weeds of the Farm and Garden

Cambridge :

at the University Press

I 9 I7 



\section{PREFACE}

$\mathrm{A}^{\mathrm{S}}$ in the case of a previous volume, Common Weeds of the Farm A and Garden, the preparation of this handbook was undertaken because of the great lack of readily available and reliable information on the subject in English scientific literature. Many of the facts were known to a few interested persons, but many others were so scattered here and there in technical reports and journals that they were scarcely known even to expert chemists and botanists. The bringing of this information together in some sort of order has involved considerable labour extending over several years, but if the volume be found helpful to those for whose use it has been prepared I shall feel more than gratified.

That the subject is of importance is fully realised by farmers and veterinary surgeons alike, for the annual loss of stock due to poisonous plants, though not ascertainable, is undoubtedly considerable. It was felt that notes on mechanical injury caused by plants and on the influence of plants on milk might usefully be included, as in some degree related to poisoning; this has therefore been done. On the other hand, a number of cultivated plants (e.g. Rhus, Wistaria) which are poisonous have not been included because exotic and hardly likely to be eaten by stock. Fungi generally also find no place in the volume, as they are sufficiently extensive to deserve a volume to themselves, and are far less readily identified than flowering plants.

The dividing line between plants which are actually poisonous and those which are only suspected is far from clear, but a division was considered desirable for the convenience of the reader, and an endeavour has been made to give a sound but brief statement as to the present information on plants poisonous to live stock in the United Kingdom, with symptoms, toxic principles, and a list of the more important references to the bibliography in relation to each plant included in Chapters ir to vi (the numbers corresponding with the numbers in the Bibliography).

Regarding symptoms it is to be regretted that in many cases they appear to be the result of injections of the toxic extracts, and not observations made after natural poisoning by ingestion of the plants. 
Further, there may frequently be doubt as to the identification of the plant suspected of causing poisoning; indeed, in some cases it is possible that the identification rests on the veterinary surgeon or the stockman thinking a certain plant is the cause. The most complete and systematic account of European poisonous plants is that of Cornevin (1887), and references to poisonous plants in the ordinary literature are heavily indebted to him. In so far as the toxic principles of the plants are concerned, however, his book is in many instances no longer reliable.

The chemical formulae, quoted for the use of students and research workers, have been checked by consulting works by the following authors, the reference to the bibliography being given in brackets: Henry (128), Dunstan (76), Allen (4), Haas and Hill (114), Thorpe (240), Van Rijn (252), Kobert (161), Esser (81), and Beilstein (16).

Apart from the literature consulted I desire to acknowledge my great indebtedness to the Board of Agriculture and Fisheries for kind permission to make use of official records; to Mr F. W. Garnett, M.R.C.V.S., for kindly reading the proofs from the veterinary standpoint; to very many Experiment Stations, State Departments of Agriculture, and other authorities in Australasia, America and the Continent of Europe, for assistance given and literature sent; to Sir David Prain and members of the staff at Kew for much friendly advice, and aid in consulting the Kew library; to Sir James Dobbie for permission to spend some time at the Government Laboratories to consult certain volumes; to Mr T. H. Middleton, C.B., Dr E. J. Russell, Professor W. Somerville, Sir Stewart Stockman, Professor T. B. Wood, and others, for information and many helpful suggestions; to my friend Mr W. A. Whatmough, B.Sc. (Lond.), for many suggestions and kindly reading the proofs; and to my colleague Mr W. R. Black for invaluable help in preparing notes, checking data and reading proofs. To all these, and many others who are not mentioned by name, I tender my sincere thanks.

For any shortcomings I crave the indulgence of my readers, only requesting that they be friendly enough to spare a moment to call my attention thereto.

H. C. LONG.

Surbiton,

October, 1916. 


\section{CONTENTS}

CHAP.

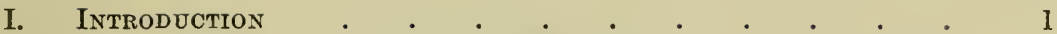

What is a Poisonous Plant? Harm done by Poisonous Plants. Circumstances in which Poisoning occurs. Effect of Soil, Climate and Cultivation on the Toxic Properties of Plants. Variation in the Poisonous Parts of Plants. Eradication of Poisonous Plants. Treatment of Poisoned Animals. Tests with Suspected Plants. Legal Aspect of Plant Poisoning. The Toxic Principles of Plants.

II. Ranunculacez. Papaveracex. Cruciferet. Caryophyllace.z. Hypericinez. Geraniaceze . . . . . . . . 9

iil. Celastracee. Rhamnacea. Papilionacez. Rosacele. Cu-

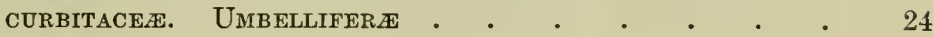

iV. Araltacez. Caprifoliacez. Compositer. Ericacez. Primulaceza. Oleacez. Convolvulacez. Solanaceze . •

V. Scrophularinez. Polygonacez. Thymelacee. Euphorbiaceze. Amentacem. Coniferem. Aroidefe . .

VI. Dioscorideez. Liliacex. Graminez. Equisetaceza. Filmces. FUNGI . . . . . . . . . . . 78

ViI. Plants suspected of Being Poisonous • • • • . 92

ViII. The Effects of Plants on Mirlk. Plants which cause Mechani-

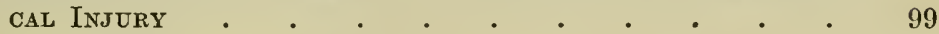

IX. Classification of Potsons . . . . . . . . 103

Bibliography . • • . . . . . . . . 106 INDEX . . . . . . . . . . . . 114

Photograph of three varieties of Phaseolus beans, of Castor

Oil Beans, Indian Peas, and Ergot . . . . Frontispiece 



\section{CHAPTER I}

\section{INTRODUCTION.}

What is a Poisonous Plant? As will be shown later, so-called "poisonous" plants differ widely in "degree of harmfulness," and it is highly probable that under ordinary conditions many of the plants commonly reputed to be poisonous are really almost or quite harmless. It is possible, however, that a plant usually unsuspected may on occasion prove noxious-for example, Nepeta Glechoma (p. 96), included as suspected of poisoning horses. For these reasons, no line of demarcation can be drawn to separate actually poisonous plants from those which are suspected or are almost certainly quite harmless; and a large number of species is included in Chapter vII as suspected, many of them, however, being almost certainly more or less poisonous in certain circumstances. In many cases it is practically impossible to come to any conclusion as to the degree of toxicity of a plant, owing to the want of exact information. Many plants are quite harmless except when affected by fungi, moulds, etc.

A really poisonous plant may be defined as one a small quantity of which when eaten induces some form of indisposition with irritant, narcotic, or nervous symptoms, with serious or even fatal consequences either immediately or by reason of cumulative action of the toxic property.

Harm done by Poisonous Plants. A perusal of the following pages will afford convincing proof that the question of the general "wholesomeness" of wild plants is worthy of serious consideration by all who are interested in the practice of agriculture. Still more important is a satisfactory knowledge of the extent to which plants are actually poisonous - that is, sufficiently injurious when eaten in small or large quantities to induce more or less severe indisposition, illness or death, with the consequent losses which such bring in their train-loss of milk and meat production in the case of cattle, of meat and wool production in sheep, of power in the horse, of expenditure in attendance and veterinary treatment generally, and possibly total loss by death of the animals concerned. 
The losses due to Poisonous Plants in Great Britain happily afford no comparison whatever with the immense losses sustained in some other countries, such as the cases of lupine poisoning mentioned at p. 29, but deaths are sufficiently numerous to make it certain that financial losses are in the aggregate very heavy. In this connection it may suffice to refer to the many cases of yew poisoning, the losses due to Umbellifers (pp. 36-42), and the instance reported in the Staffordshire Weekly Sentinel in relation to meadow saffron and water hemlock (p. 80). Further, it appears to be extremely likely that many losses due to unascertained causes are really due to plant poisoning. For this reason veterinary surgeons will be well advised always to consider this possibility and, if need be, to obtain the services of a trained botanist to survey the farm or field involved, with the object of deciding whether poisonous plants are present.

Circumstances in which Poisoning occurs. It may be assumed that many plants are to a considerable extent protected from animals by the fact that they have an unpleasant odour, are acrid or bitter to the taste, or are actually toxic in character, just as others assume such protective devices as spines. In a state of nature animals appear to avoid instinctively such plants as are toxic or "unwholesome," and to be less readily poisoned than are domesticated animals living under artificial conditions. Indeed, it has been remarked that farm stock reared in a locality where certain poisonous plants abound are much less likely to be injured by these plants than animals imported from a district where they do not occur.

The individuality of stock is also a factor which may be responsible for poisoning, some animals having what may be described as a depraved appetite for unusual and unappetising food plants. It would appear that animals are often tempted to eat dark-green plants of luxuriant growth which are soft and succulent. This is especially true when the plants are young and tender, particularly as regards sheep, which, however, usually avoid tall, old rank-growing and coarse herbageunless absolutely pressed by hunger. Cattle, however, are not so particular, and will commonly eat large coarse-growing plants.

Sheep have been observed to be particularly variable in their choice of food plants, not only individually in the flock, but from day to day. Chesnut and Wilcox remark ${ }^{1}$ that "there seems to be no way of accounting for the appetite or taste of stock. This statement is perhaps

1 "The Stock-Poisoning Plants of Montana," V. K. Chesnut and E. V. Wilcox. Bul. No. 26. U.S. Dept. Agric., Div. Bot., 1901. 
especially true of sheep. We have often observed sheep eating greedily on one day plants which they could scarcely be persuaded to eat on the following day on the same range." In the case of one flock of sheep on a foothill range at an altitude of $4,600 \mathrm{ft}$. " a few of the sheep were observed eating large quantities of wild sunflower (Balsamorhiza sagittata), a few ate freely of false lupine (Thermopsis rhombifolia), some confined their attention largely to the wild geranium, while others ate false esparcet (Astragalus bisulcatus) almost exclusively. Two sheep were seen eating the leaves of lupine, and about fifty ate a greater or less quantity of Zygadenus venenosus, while the majority of sheep in the band fed exclusively upon the native grasses on the range."

Horses also have been known to acquire in America a depraved appetite for horsetail and loco-weed.

The different species of live stock are often quite differently affected by poisonous plants, some being very susceptible to a given plant while others may be little or not at all susceptible. One species (e.g. the pig) may readily vomit the poison of a plant which is emetic, while another (e.g. the horse) may be unable to do so and hence be the more seriously injured. The variability of the different classes of live stock in this respect is frequently brought out in Chapters II to vi. Poisonous effects may also vary with the individuality and age of animals of the same species.

At certain periods of the year-e.g. in early spring, and during dry summers,- - there may be a scarcity of green herbage, and this may induce animals to eat any green plants which are especially early, including poisonous ones, which they would otherwise refuse.

In some cases poisonous plants which do not lose their toxic properties on drying (e.g. meadow saffron) may be included in hay, and hence find their way to stock in such a form that they may not be distinguished. It has been found, however, that some poisonous plants or parts of them are refused by stock when mixed with good herbage in hay. Care should be exercised that poisonous plants are not included with hay or green fodder, and in cases of poisoning all forage should be examined.

Animals may also be poisoned by certain toxic seeds (e.g. corn cockle) fed to them with cereal grains, in feeding stuffs generally, or in the refuse seeds from the sources mentioned. Here again judgment is necessary, and it is probably advisable on all counts to burn the weed seeds and similar refuse from the sources mentioned. Poisonous seeds may occur in low quality feeding stuffs, and poisonous seeds of 
foreign origin are occasionally sold for food purposes owing to the mistaken idea that they are a valuable addition to the ration (e.g. the poisonous "Java" beans). In any case in which an animal is believed to have been poisoned purchased feeding stuffs should always be considered as a possible source of injury and be submitted to examination.

Clippings and trimmings from gardens and shrubberies have proved a more or less common cause of live stock poisoning, such material being too often carelessly thrown out for animals to pick over. In such circumstances it may quite easily happen that the animals get yew, daphne, privet, rhododendron, azalea, solanums, and other plants of a poisonous character. For this reason it is better to destroy such trimmings, etc., by burning them, or by adding them to the compost heap as the case may be.

A further source of poisoning must be noted here-fleshy and parasitic fungi (toadstools, rust fungi), moulds and similar organisms. Many toadstools are directly poisonous when eaten, but the microscopic organisms are probably in themselves harmless, though taken with food which they are responsible for injuring (bad hay, cakes, etc.), the poisoning being due to the changed and damaged feeding stuffs, or possibly to poisonous principles directly elaborated by the microscopic fungi. Fungi and related organisms cannot be dealt with in this volume, but it may at least be said that the use of mouldy hay and similarly affected feeding stuffs is attended with some danger, which is not yet very clearly defined.

Effect of Soil, Climate and Cultivation on the Toxic Properties of Plants. In general, wild poisonous plants are richer in either alkaloids or glucosides than the same species when cultivated, though there are exceptions. In many cases it is found that plants vary considerably in toxicity, or the percentage content of the poisonous principle, according to soil, light, moisture, etc. Solanaceous plants in particular vary in this way, and one or two instances may be given as examples. Solanum nigrum varies so much that it has been regarded as harmless in one country and quite poisonous in another (p. 52).

Experiments conducted at the Arlington Experimental Farm, Virginia, showed that in 24 first-year plants of Atropa Belladonna grown in 1910 the alkaloid contents of the leaves varied from 0.334 to 0.700 per cent., and averaged 0.547 per cent. In 1911 the alkaloid contents (usually the average of five pickings) of the leaves of 59 plants varied from 0.306 to 0.766 per cent., and averaged 0.532 per cent. In 1912 the alkaloid contents (commonly the average of 5 pickings) of the 
leaves of 57 plants varied from 0.352 to 0.768 per cent., and averaged 0.545 per cent. In individual plants at a single picking the highest alkaloid content in 1911 was 0.925 and the lowest 0.200 , and in 1912 the highest was 0.882 and the lowest 0.292. (Jour. Agric. Res., I. 2, Nov., 1913.)

The variation in the percentage of poisonous principle was well shown in several papers read at the International Congress of Applied Chemistry held at Washington and New York in 1912 (see Chemist and Druggist reports). For example, Carr stated that at the Wellcome Materia Medica Farm, Dartford, Kent, the effect of manuring on medicinal plants has been tested for some years, and the effect of the more common fertilisers on Atropa Belladonna was shown by the following table :-

\begin{tabular}{|c|c|c|c|c|c|c|c|}
\hline \multirow[b]{2}{*}{ Fertiliser } & \multirow[b]{2}{*}{$\begin{array}{l}\text { Time of } \\
\text { Application }\end{array}$} & \multirow[b]{2}{*}{ Per acre } & \multicolumn{5}{|c|}{$\begin{array}{l}\text { Percentage of Alkaloid } \\
\text { in Dry Stem and Leaf }\end{array}$} \\
\hline & & & $\begin{array}{c}1906 \\
\text { 3rd } \\
\text { year's } \\
\text { plants }\end{array}$ & $\begin{array}{c}1907 \\
4 \text { th } \\
\text { year's } \\
\text { plants }\end{array}$ & $\begin{array}{c}1910 \\
\text { lst } \\
\text { year's } \\
\text { plants }\end{array}$ & $\begin{array}{c}1911 \\
\text { 2nd } \\
\text { year's } \\
\text { plants }\end{array}$ & $\begin{array}{l}1912 \\
\text { 3rd } \\
\text { year's } \\
\text { plants }\end{array}$ \\
\hline $\begin{array}{l}\text { Main crop } \\
\text { Farmyard manure } \\
\text { Nitrate } \\
\text { Calcium cyanamide } \\
\text { Basic slag } \\
\text { Superphosphate } \\
\text { Potash }\end{array}$ & $\begin{array}{c}-\overline{\text { March }} \\
\text { March \& April } \\
\text { Do. } \\
\text { Do. } \\
\text { Do. } \\
\text { Do. }\end{array}$ & $\begin{array}{l}50 \text { loads } \\
2 \mathrm{cwt} . \\
1 \mathrm{cwt} . \\
2 \mathrm{cwt} . \\
5 \mathrm{cwt} . \\
5 \mathrm{cwt} .\end{array}$ & $\begin{array}{l}0.54 \\
0.54 \\
0.52 \\
-\overline{0.61} \\
0.46 \\
0.61\end{array}$ & $\begin{array}{l}0 \cdot 34 \\
0 \cdot 34 \\
0 \cdot 23 \\
- \\
- \\
- \\
0 \cdot 40\end{array}$ & $\begin{array}{l}0.61 \\
0.61 \\
0.54 \\
0.69 \\
0.65 \\
0.81 \\
0.75\end{array}$ & $\begin{array}{l}0 \cdot 59 \\
0 \cdot 53 \\
0 \cdot 46 \\
0 \cdot 49 \\
0 \cdot 56 \\
0 \cdot 49 \\
0.53\end{array}$ & $\begin{array}{l}0.68 \\
0.71 \\
0.64 \\
0.75 \\
0.84 \\
0.76 \\
0.69\end{array}$ \\
\hline
\end{tabular}

In considering these results it must be remembered that the soil is naturally suited to the plant, and the percentage of alkaloid obtained without added fertilisers is already high. The low figures obtained in 1907 were probably due to the seasonal conditions. Atmospheric conditions have a modifying influence.

It was also shown that the Belladonna root of commerce varies greatly in alkaloid strength. "In a number of analyses made of commercial roots, variations from 0.27 to 0.69 per cent. have occurred. The average of twenty-one analyses of German and Austrian commercial roots was 0.40 per cent. Other observers have recorded similar results. Chevalier (Compt. Rend., 1910, 150, 344) gives the following figures for Continental roots: French, 0.300 to 0.450 per cent; Austrian, 0.251 to 0.372 per cent.; Italian, $0 \cdot 107$ to 0.187 per cent. Henderson has 
shown the average of thirty samples of foreign root to be $0 \cdot 3$ per cent. It is interesting to observe that the average of nine samples of root grown at Darenth is 0.54 per cent. In order to determine whether this rariation was due to collecting at different times of the year, roots from the same plot, derived from second year's plants, which were sown at the same time, were dug up at intervals and dried. The following is a record of the analysis of these samples:-

\begin{tabular}{|c|c|c|c|c|c|}
\hline March, 1911 & $\ldots$ & .. & . & 0.56 & per \\
\hline May, 1911 .. & .. & $\ldots$ & & 0.59 & , \\
\hline June, 1911 .. & . & . & & 0.53 & $"$ \\
\hline August, 1911 & .. & $\cdots$ & & 0.50 & $"$ \\
\hline December, 1911 & .. & . & . & 0.59 & , \\
\hline
\end{tabular}
small."

"The amount of variation throughout the year is thus seen to be very

Dunstan (Bul. Imp. Inst., 1905) has shown that Hyoscyamus muticus grown in India yielded 0.3 to 0.4 per cent. of hyoscyamine, but that the same species grown in Egypt produced 0.6 to 1.2 per cent.

According to Esser no coniine is found in Conium maculatum growing in the far north. The same authority says that the root of Hyoscyamus niger is quite free from toxic properties in winter.

Variation in the Poisonous Parts of Plants. As will be shown in succeeding chapters, many plants (e.g. meadow saffron) are poisonous in all their parts, though the amount of the toxic substance may differ according as to whether the seeds, leaves, stem or roots are severally considered. In other cases one part of the plant alone is toxic (e.g. the seeds, as in corn cockle). Further, some species vary in the percentage of the toxic substance in the leaves before and after flowering. Frequently the root is the most toxic portion of the plant. This point may be usefully recollected in relation to poisoning of live stock, which are in general affected by the foliage or ripe seeds.

Eradication of Poisonous Plants. Wherever poisonous plants are found, particularly in quantity, where they are liable to be eaten by live stock, an attempt should be made to eradicate them. They may be simply dealt with as weeds as may be necessary according to the species concerned. When any difficulty is experienced in regard either to determination of the species or to methods of eradication the advice of the Board of Agriculture and Fisheries (Whitehall Place, London, S.W.) should be requested. Stock should at once be removed from a suspected pasture, which should be immediately and thoroughly 
examined by a competent botanist. Harmful plants should be eradicated and their place. filled by better herbage.

Treatment of Poisoned Animals. This volume makes no pretensions to deal with the veterinary treatment of cases of plant poisoning. Whenever poisoning is suspected the services of a veterinary surgeon should be sought without delay; the text books at his disposal will aid him in the treatment of any case which presents unusual difficulties. The symptoms indicated in the following pages, together with the possible discovery of a suspected plant, may be utilised in diagnosis.

Tests with Suspected Plants. The action of plants on animals may be ascertained (1) by observing the effects in cases in which it has been established that the plants have been eaten, or (2) by direct experimental feeding of animals with the plant. In the first case the results may be accurate and satisfactory if observations have been made from the outset.

As regards (2) the results may or may not be satisfactory according as the plan pursued is sound or otherwise. For example, it cannot be considered altogether reasonable and satisfactory to extract the principles present in the plant, inject them into the blood stream, and conclude from any ill effects that the animal may exhibit that the plant is poisonous, since the substance extracted may be poisonous under such conditions but little or not at all harmful when the plant is eaten in the small quantities commonly taken by animals. Again, it cannot be held satisfactory to feed an animal on a heavy and exclusive diet of the suspected plant for a considerable period. The real test would, in general, consist in a feeding trial in which the suspected plant occupied a place in the ration in reasonable quantity-such a quantity as might well be taken in natural circumstances, in view of its relative abundance in regard to other food available; and if considered likely that the plant would be eaten daily it may be fed regularly for some days. Should such a test prove negative it may generally be held that the plant is not poisonous, or only so in exceptional circumstances.

Legal Aspect of Plant Poisoning. There is clearly some legal liability in regard to poisonous plants which may, by hanging over a boundary, cause injury to a neighbour's stock. The only cases known to the author are in relation to the yew. In the case of Crowhurst v. Amersham Burial Board (48 L. J., Ex. 109; 4 Ex. D., 5) a Burial Board was held liable for the loss of a horse poisoned by eating leaves of a yew tree planted in the cemetery owned by the Board, the tree having grown through and over their fence and projected on to the 
meadow occupied by the plaintiff. In Ponting v. Noakes $(63$ L. J. B. 549 ; (1894) 2 Q.B., 281) the defendant was not held liable for the death of a horse which ate off the branches of a yew tree, because the tree did not extend up to or over the plaintiff's boundary, though it overhung a ditch, the edge of which was the boundary, and was hence accessible to the plaintiff's stock.

The Toxic Principles of Plants. The poisonous substances in plants may be grouped either (1) according to their physiological effects on certain organs; (2) according to the principal outward and perceptible symptoms caused; or (3) in accordance with their chemical relationships.

In regard to (1) the poisons may be nerve, heart, blood-poisons, etc. (2) The poisons may be acrid, narcotic, or both. Acrid poisons are those which cause irritation or inflammation of the digestive tract (Euphorbia, Ranunculus, Daphne, etc.); narcotic poisons affect only or chiefly the brain (Agrostemma, Papaver, Atropa) or chiefly the spinal cord (Claviceps purpurea, Lolium temulentum); acrid-narcotic poisons induce to a greater or less extent the symptoms of both the foregoing groups (Taxus, Colchicum, Cicuta, Solanum, etc.).

(3) As the accounts of the individual plants will show, the toxic principles of many plants are not yet well understood, either as regards chemical constitution or symptoms caused. Many poisons may be driven off by heat (boiling, drying), and some plants may thus be rendered harmless.

Most of the toxic principles of our native poisonous plants are Alkaloids or Glucosides. The former all contain nitrogen, differ considerably in molecular constitution, and are usually combined with widely distributed organic acids. In the pure state they are colourless and usually stable, crystalline or amorphous solids, or readily volatile liquids; they usually have a burning taste. In general the same base is confined to species of the same order-e.g. Solanine to the Solanacece. The alkaloids include the most powerful poisons.

The term "Glucoside" indicates a group of substances which by the action of an acid or enzyme are split up into a sugar (grape sugar, galactose or rhamnose) and other substances (alcohol, aldehydes, acids). They have a bitter taste and are generally readily soluble in water. Related to the glucosides are also the Saponins, remarkable for the fact that they induce an exceedingly frothy condition in water; the prussic acid yielding compounds or cyanogenetic glucosides (e.g. Amygdalin and Phaseolunatin) also belong to this group. Other substances will be mentioned in the succeeding chapters. 


\section{CHAPTER II}

\section{RANUNCULACEAE.}

Traveller's Joy (Clematis Vitalba L.). The extent to which this species is poisonous is not clear, though all parts are stated to be poisonous, acrid and narcotic, while the juice tends to blister the skin. It is remarked by Cornevin that it is less poisonous in spring, when the ass and goat browse on it to a considerable extent without serious trouble, than later, when it cannot be eaten without danger.

Toxic Principle. Traveller's Joy appears to contain strongly poisonous substances which have not been closely investigated. Greshoff found a Saponin in the leaves ${ }^{1}$. The poison is dissipated by heat.

Symptoms. When eaten in quantity the young shoots are diuretic, violently purgative, causing dysentery, and in rare cases death. Applied to the exterior it is irritating and even vesicatory. (Cornevin.)

REFERENCES.

63, 81, 101, 130, 161, 233.

Anemone (Anemone sp.). Both our native species of Anemone appear to be more or less poisonous in character: the Wood Anemone or Wind Flower (A. nemorosa L.), and also the Pasque Flower ( $A$. Pulsatilla L.). These plants, the former of which grows in woods and damp shady spots in fields, and the latter on chalk downs and limestone pastures, may on occasion be taken by stock in early spring, when green herbage is not too plentiful, but deaths appear to be rare, even if they have occurred. All parts of the plants contain a toxic principle, which is volatile and destroyed by drying.

Toxic Principle. The toxic substance is stated to be Anemonecamphor (oil of Anemone) which imparts a bitter taste to the plants,

1 Kobert states that various species of Clematis, Ranunculus, Anemone, and also Caltha palustris and Trollius europaeus, contain Anemonal or Pulsatilla-camphor, which causes strong local irritation, burning and swclling in the mouth, vomiting, intestinal inflammation, etc. 
and itself gives rise in the plant to Anemonic acid and Anemonin $\left(\mathrm{C}_{10} \mathrm{H}_{8} \mathrm{O}_{4}\right)$, a very poisonous, narcotic substance, stated to be neither a glucoside, nor an alkaloid, but a ring ketone with the properties of an acid anhydride.

Symptoms.-The symptoms recorded by Cornevin in the poisoning of animals by the fresh plants are nausea, coughing, vomiting (if possible), stupefaction, muscular tremors, and violent colic, accompanied at times by hæmaturia and always by diarrhœa and dysentery. There are pronounced respiratory and heart troubles.

Pott confirms the symptoms of hæmaturia, diarrhœa, and inflammation of the stomach and intestines in the case of $A$. Pulsatilla when fed in the green condition. According to Esser, the plant poison affects the spinal cord and the brain, the symptoms being similar to those produced by Aconitum Napellus.

\section{REFERENCES.}

$16,63,81,191,197,198,213,233,240$.

Buttercups (Ranunculus sp.). A number of species of Ranunculus are acrid, irritant or severely poisonous, as the case may be. There are variations in the poisonous character according to the season, and some parts of the plant are more toxic than others. At the time the young shoots develop in the spring but little of the poisonous principle is present, and some (e.g. R. Ficaria) are not then poisonous, but a larger quantity of the poisonous principle forms later, and some species are especially dangerous at the time of flowering, after which the toxicity decreases with the maturity and state of dryness of the plant. The flowers are the most poisonous, and then the leaves and stem. It does not seem to have been demonstrated that the seeds of any species are dangerous, though Henslow states that the fruits of some species, when green, appear to be most intensely acrid.

Some species of Ranunculus are especially harmful ( $R$. sceleratus, $R$. Flammula, and $R$. bulbosus), while others are less so (R. lingua, $R$. Ficaria, $R$. acris). The toxic principle is volatile, and buttercups are easily rendered innocuous by drying or boiling-so much so that when dried in hay they may be regarded as a nourishing food for stock, and are readily eaten. Indeed, $R$. repens is scarcely, if at all, injurious even when green, though a case of fatal poisoning to sheep said to be due to this species was reported in the Veterinarian in 1844 . Fresh $R$. aquatilis is held to be quite harmless, and has been used as a fodder. "Along the banks of the Hampshire Avon, and other places in the same neigh- 
bourhood, it is used by the peasantry as fodder. They collect it in boats and give it to their cows and horses, allowing the former about twenty to thirty pounds a day. One man is said to have kept five cows and a horse, with little other food but what they could pick up on the heath, using no hay but when the river was frozen. Hogs eat it and will live upon it alone until put up to fatten." (Johnson and Sowerby-Useful Plants of Great Britain.)

R. sceleratus L., or Celery-leaved Buttercup, is probably the most toxic species, and it is stated that in man a single flower may cause poisonous symptoms resembling those due to Anemone and Colchicum. It is considered especially dangerous to cattle, and has caused many losses: among its French names are Mort aux Vaches, and Herbe sardonique. Poor people have been known to eat the young shoots when boiled, heat dispelling the poison.

$R$. Flammula L., the Lesser Spearwort, has repeatedly proved fatal to horses and cattle.

$R$. bulbosus L., the Bulbous Buttercup, is somewhat variable in toxicity, and is least dangerous after the flowers have dropped their corolla, and the bulb-like rootstock is most harmful in autumn and winter. The flowers are the most dangerous part.

R. Ficaria L., Lesser Celandine, varies in toxicity with locality and season, being most harmful at the flowering period. It is stated that wood-pigeons eat the roots with avidity, and that the young shoots have been eaten as a saiad in Germany, as they are not toxic. An English veterinary surgeon (Flower) recorded that three heifers were poisoned by it (Vide Cornevin).

R. acris L., Acrid Buttercup or Tall Crowfoot, is a frequent cause of poisoning in cattle, and Cornevin says it is perhaps the species which causes the most accidents.

Toxic Principle. The buttercups contain an acrid and bitter juice, the chemical properties and composition of which are not well known, but it is believed that the substance is identical with the Anemonin of the Anemone sp. (q.v.). Beckurts isolated Anemonin and Anemonic acid from $R$. acer. Pott, however, states that the poisonous species contain the two alkaloids Aconitine and Delphinine.

Symptoms. The buttercups are acrid, burning and narcotic, causing irritation of the mucous membrane, with inflammation of the intestinal tract.

Cornevin shows that $R$. sceleratus induces gastro-enteritis, colic, diarrhœa with excretion of black foul-smelling fæces, vomiting when 
possible, falling-off in milk yield in cows, nervous symptoms, reduction in pulse, and stertorous respiration, dilation of the pupils, enfeebled condition, difficult mastication, spasmodic movements of the ears, lips, etc.,-followed in serious cases by convulsions, sinking of the eye in its socket, possibly stoppage, and death in 6 to 12 hours after convulsions first appeared.

In the horse symptoms substantially similar to the above have been recorded (Lander).

In cows, Pott records hæmaturia, and reddish or bitter milk.

Sheep after eating $R$. repens have been noticed to fall suddenly in the field; their eyes rolled, and some animals showed dizziness, and died with the head inclined over the left flank (Lander).

REFERENCES.

$47,63,81,112,130,140,145,170,203,204,205,213,233,235$.

Marsh Marigold or King-Cup (Caltha palustris L.). Like the species of Ranunculus, the Marsh Marigold is to some extent poisonous in character, and both animals and man have suffered. Cattle have died from eating it, and Müller records the poisoning of many horses, one of which died. In general, animals refuse it, but may possibly eat it when pressed with hunger in times of scarcity of green herbage. Cornevin states that it has little or no acrid properties when very young, but that it is toxic by the time of flowering-acridity increasing with age.

Toxic Principle. The toxic character of the Marsh Marigold has not been fully investigated, though the presence of an alkaloid has been determined, and A. B. Smith states that the toxic properties are due to the alkaloid Jervine $\left(\mathrm{C}_{26} \mathrm{H}_{37} \mathrm{O}_{3} \mathrm{~N}_{2} \mathrm{H}_{2} \mathrm{O}\right)$ and the glucoside Helleborin $\left(\mathrm{C}_{36} \mathrm{H}_{42} \mathrm{O}_{6}\right)$. On drying-e.g. in hay-the plant becomes harmless, as in the case of most species of Ranunculus.

Symptoms. Cornevin records that cattle have died from inflammation of the digestive tract, and gives the symptoms as those of Ranunculus poisoning. There seem to be digestive troubles, diarrhœa, and loss of milk production, even (according to Rusby) when fed with hay. In the horse, there is colic, bloating, and inflammation of the bladder, while the urine is dark red. According to Cornevin, the symptoms are similar to those produced by Ranunculus sp. Pammel quotes Friedberger and Fröhner as stating that the plant causes hæmaturia. Five persons who ate it as a herb were "seized with violent sickness and pain 
in the abdomen, followed by diarrhœa and general œdematous swelling over the whole body," but they recovered (Johnson and Sowerby).

REFERENCES.

$63,81,140,190,203,213,233$.

Hellebores (Helleborus sp.). Two poisonous species of hellebore may on occasion be taken by live stock, though rarely-Stinking Hellebore ( $H$. foetidus L.) and Green Hellebore ( $H$. viridis L.). The much esteemed Christmas Rose (H. niger) is also toxic, but unlikely to be eaten by stock. In no case should trimmings of these plants from shrubberies, etc., be thrown to stock-cows have died from eating such trimmings. The two species first mentioned are equally toxic, all parts are poisonous, and drying does not render them innocuous. Cornevin records that animals have been killed by $H$. foetidus, and says that $9 \frac{1}{2} \mathrm{oz}$. of the fresh root or $2 \frac{1}{2} \mathrm{oz}$. of the dried root are poisonous doses to the horse, while 120 to 150 grains are fatal to sheep. It was recorded in 1847 (Veterinarian) by Mayer that a horse was fatally poisoned through eating five half-pints of the chopped-up leaves of this species in two days in a bran mash. In regard to this species also Johnson and Sowerby write: "The Bear's-Foot has been used as a vermifuge ever since the days of Hippocrates, notwithstanding its dangerous qualities. Every part of the plant is a violent cathartic, but far too uncertain in the degree of its action to be safely administered."

Toxic Principle. Both species contain the poisonous glucosides Helleborin $\left(\mathrm{C}_{36} \mathrm{H}_{42} \mathrm{O}_{6}\right)$, a highly narcotic and powerful poison; Helleborein $\left(\mathrm{C}_{26} \mathrm{H}_{44} \mathrm{O}_{15}\right)$; and the alkaloid Jervine $\left(\mathrm{C}_{26} \mathrm{H}_{37} \mathrm{O}_{3} \mathrm{~N}_{2} \mathrm{H}_{2} \mathrm{O}\right)$.

Symptoms. The Hellebores are cathartic, narcotic, and drastically purgative. Stupor is followed by death with spasms in the case of $H$. viridis (Pammel). In general there is in the horse and ox bloody purgation, salivation, attempts to vomit, and excessive urination, according to Lander, who cites Mayer as noting violent straining and the discharge of frothy mucus, but no effort to vomit, the heart action resembling that observed in Digitalis poisoning, showing periodic intervals of arrest in systole.

Müller gives the symptoms in cattle and sheep after eating the leaves as loss of appetite, nausea, and even vomiting, salivation, grinding of teeth, wind, colic, bloody diarrhœa, decrepitude, giddiness, loss of sensation, convulsions, and not seldom death.

Affected cows are stated to give bitter milk which has purgative effects (Pott). 
The poisoning of two cows by $H$. viridis came under the notice of Cornevin. There was observed loss of appetite, diarrhœa, tenesmus, violent attempts to evacuate, which after 5 or 6 days resulted only in the expulsion of glareous blackish matter; to the end the pulse was slow and intermittent. The heart beats were weak, and after 5 or 6 beats there was a stop equal in duration to at least a beat and a half. A remarkable fact was the very gradual loss of condition, while the milk secretion was maintained until the last day. In one case death occurred after 12 days and in the other after 28 days.

\section{REFERENCES.}

$63,81,130,140,170,190,203,205,213,233,254$.

Larkspur (Delphinium Ajacis Reich.). In the United States of America certain species of Larkspur are exceedingly harmful to live stock, and it has been said that "with the exception of the Loco weeds there is probably no poisonous plant on the cattle ranges of the West that has caused such heavy losses to stockmen as has larkspur" (Far. Bul. 53, U. S. Dept. Agric.). D. Ajacis is the only British species, occurring in cornfields in Cambridgeshire, Sussex and elsewhere, and, like the Continental species $D$. Consolida, must be regarded as poisonous and fatal to cattle, while horses and sheep may also suffer. Sheep and goats, however, appear to resist the poison unless taken in considerable quantity. Wilcox fatally poisoned a yearling lamb within an hour of administering per os the extract from less than $1 \mathrm{oz}$. of the dried leaves of an American species. The seeds are the most dangerous part of the Larkspur, and should never be ground up with wheat should the two plants grow together. The seeds of $D$. Staphisagria are used in medicine.

Toxic Principle. The species D. Ajacis has been little studied, but $D$. Consolida and D. Staphisagria contain the alkaloids Delphinine $\left(\mathrm{C}_{31} \mathrm{H}_{49} \mathrm{O}_{7} \mathrm{~N}\right)$, very poisonous and having a bitter taste; Delphisine $\left(\mathrm{C}_{31} \mathrm{H}_{49} \mathrm{O}_{7} \mathrm{~N}\right)$, which is extremely poisonous; Delphinoidine $\left(\mathrm{C}_{42} \mathrm{H}_{68} \mathrm{~N}_{2} \mathrm{O}_{7}\right)$, which is poisonous; and Staphisagrine.

Symptoms. The seeds are stated to be emetic and purgative, and D. Consolida is stated by Pott to be an acute narcotic poison to horses and cattle. In general the symptoms appear to resemble those produced by Aconitum (p. 15). There is salivation, vomiting, colic, convulsions, and general paralysis (Müller).

REFERENCES.

$16,63,93,128,130,190,203,204,205,213,233$. 
Monkshood (Aconitum Napellus L.). The extremely poisonous character of this plant has been recognised since ancient times, and it is mentioned by Pliny, Dioscorides, etc. It is not common in the wild state in Britain-chiefly occurring in some Welsh and one or two West of England counties-and is not very liable to cause poisoning of live stock in Britain. Cases of poisoning of horses, cattle, sheep and pigs have been recorded on the Continent, however (Cornevin), and cows died in Victoria. Linnæus says that it is fatal to cows and goats when they eat it fresh, but that when dried it does no harm to horses. Medical works record many cases of human poisoning, particularly in cases where the root has been mistaken for horse radish-from which, however, it markedly differs. The leaves at first taste insipid and then sharply burning; the root when fresh smells like the radish and has a slightly sweetish taste, which is succeeded by characteristic tingling of the tongue and a sensation of numbness in the mouth.

Toxic Principle. Monkshood is very poisonous, and though all parts are toxic the root is the most dangerous, and next the seeds and leaves. The plant seems to vary in toxicity with age and climate, being but slightly active when very young, most active just before flowering, and at the minimum of activity when the seeds ripen. The cultivated form is stated to be much less poisonous than the wild one. Drying removes a part of the toxic substance, and boiling removes most of it. The plant contains the toxic alkaloid Aconitine $\left(\mathrm{C}_{34} \mathrm{H}_{45} \mathrm{NO}_{11}\right)$, and also Aconine $\left(\mathrm{C}_{25} \mathrm{H}_{39} \mathrm{NO}_{9}\right)$. The root contains 0.17 to 0.28 per cent. of Aconitine, but the leaves and flowers less.

Symptoms. The chief symptoms are those of depression, and are manifested through the nervous system and the circulatory and respiratory organs. Tetanic symptoms are also present. There is loss of appetite, salivation, inflammation of the mucous membrane of the mouth and jaws, grinding of teeth, nausea and vomiting, great restlessness and colic; the animal groans and walks with an uncertain gait owing to bodily weakness, giddiness and paralysis of hind feet or of all limbs; there is also a notable slackening in the pulse, breathing becomes difficult, consciousness is lost and the pupils are dilated. Death ensues in most cases within a few hours, and after convulsions.

Kaufmann (quoted by Cornevin) observed in the horse champing of the jaws, salivation, fibrillous contraction of the muscles of the olecranon, then of the buttocks, then of the whole body. The intestinal pains were shown by the blows of the animal's hind feet under and at the back of the belly. There was also observed an intense and painful 
contraction of the muscles in the inferior cervical region, the hyoid and the abdomen; an increased sensibility; repeated evacuations; at first congestion, then great paleness of the mucous membranes; diminution in the volume of the arteries; faint whinnyings at the moment of the contraction of the muscles of the neck, shoulders and stomach; muscular rigidity of the posterior limbs; uncertain gait; laboured breathing; and finally paralysis of motion, respiration and senses.

Lander in giving similar symptoms for the horse notices also choking movements of the œsophagus, eructation of frothy matter, dilatation of pupils and low temperature.

Kaufmann gives the poisonous doses of powdered root for the horse and dog as 13 to $14 \mathrm{oz}$. and $\frac{1}{6} \mathrm{oz}$. respectively.

\section{REFERENCES.}

$4,16,63,78,81,128,130,153,161,170,203,205,213,233$.

\section{PAPAVERACEAE.}

Poppies (Papaver sp.). Poisoning by the two common poppies ( $P$. Rhoeas $\mathrm{L}$. and $P$. dubium $\mathrm{L}$.) is not common, but Cornevin says that the former is poisonous in all its parts, and sufficiently so to cause accidents every year. Animals may be affected by eating the plant when mixed with green fodder, or by ingesting the seeds and capsules with waste material after the winnowing and grading of cereals. Stock, however, will most likely reject the plants, owing to their unpleasant odour and taste, but cattle have been poisoned by eating unripe heads of $P$. Rhoeas when the plant was mixed with clover and sainfoin. $P$. dubium has caused poisoning of horses, cattle and pigs.

Toxic Principle. Both species contain the alkaloids Morphine $\left(\mathrm{C}_{17} \mathrm{H}_{19} \mathrm{NO}_{3}\right)$ and Rheadine $\left(\mathrm{C}_{21} \mathrm{H}_{21} \mathrm{NO}_{6}\right)$, which are present in the milky juice of the plant. The latter, which was isolated by Hesse, is believed to have no narcotic effects. The toxic principle is not destroyed by heating, and the plant is therefore poisonous both in the green state and when dried in hay.

Symptoms. It is remarked by Cornevin that cattle poisoned by $P$. Rhoeas at first exhibit symptoms of excitement, shown by continual movement, by pawing of the soil or litter, increased respiration and more rapid pulse; this is followed by stoppage of the digestive functions, sometimes a little swelling of the eyelids, and coma, one affected animal 
appearing to sleep while standing, remaining motionless, and if forced to move walking in an unsteady manner. Finally, the animal falls, and if a fatal result is likely (which is unusual) it remains stretched on the ground; respiration becomes slower, the temperature falls, and after a few convulsive movements death occurs owing to asphyxia.

Müller notes excitement, wildness of look, dilatation of pupil, convulsions; then coma, loss of sensation and symptoms of depression replace those of excitement. There is salivation, bloating, constipation, and in many cases also bloody diarrhœa. Death, however, is rare.

Pott gives stupidity, retention of urine, colic, with sickness and diarrhœa, convulsions, and epileptic symptoms, the animals falling over and rolling.

\section{REFERENCES.}

$4,16,63,128,190,205,213,262$.

Greater Celandine (Chelidonium majus L.). This common plant exhales an unpleasant odour, and when bruised or broken shows the presence of a yellowish acrid juice, which becomes red immediately on exposure to the air. It is an old medicinal drug plant, but is dangerous, being emetic and purgative, with a strongly irritating effect on the digestive tract. Animals are but rarely likely to take it, and no record of the death of domesticated animals has been found.

Toxic Principle. Among the substances contained in the Greater Celandine may be mentioned the bitter alkaloid Chelidonine $\left(\mathrm{C}_{20} \mathrm{H}_{19} \mathrm{NO}_{5}\right.$ $+\mathrm{H}_{2} \mathrm{O}$ ), which, especially occurring in the root, does not appear to be poisonous, or is of feeble activity; the alkaloid Chelerythrine $\left(\mathrm{C}_{21} \mathrm{H}_{17} \mathrm{NO}_{4}\right)$, which is poisonous; and Protopine $\left(\mathrm{C}_{20} \mathrm{H}_{19} \mathrm{NO}_{5}\right)$. It is stated by Cornevin that the toxic substance is not removed on drying, but Pott (1907) remarks that the dried plant is harmless to animals, the poisonous alkaloid being volatile and disappearing on drying.

Symptoms. The action of this plant is acrid, irritant and narcotic, emetic and purgative. Esser remarks that when Chelerythrine is introduced on the nasal mucous membrane it causes violent sneezing, and taken internally causes vomiting. Müller says that poisoning of domesticated animals is not recorded, but that according to old accounts 500 grammes (about $1 \mathrm{lb}$.) of the fresh plant eaten by the horse will at most cause slight diabetes. 


\section{CRUCIFERE.}

Charlock (Brassica Sinapistrum Boiss.), also known as B. Sinapis Visiani and Sinapis arvensis L., may be regarded as harmless in the young state, but liable to cause injury after flowering, when the seeds have formed, when it may occasion serious accidents if eaten by live stock. A case in which rape cake containing the seeds of charlock caused poisoning was recorded in 1875 (Jour. Roy. Agric. Soc.). The seeds only are dangerous.

Toxic Principle. The seeds contain minute quantities of volatile Oil of Mustard or Allyl-isothiocyanate $\left(\mathrm{C}_{3} \mathrm{H}_{5} \mathrm{NCS}\right)$, the alkaloid Sinapine $\left(\mathrm{C}_{16} \mathrm{H}_{23} \mathrm{NO}_{5}\right)$, and the alkaloidal glucoside Sinalbin.

Symptoms. Ingestion of the seeds may cause inflammation of the stomach and intestines (with loss of appetite, wind, colic, and diarrhœa); inflammation of kidneys (difficult, excessive or bloody urination); and nervous symptoms, with great exhaustion, uncertain gait, paralysis of limbs and in isolated cases convulsions (Müller).

Pott also records increased salivation.

In the horse Cornevin records great depression, difficult and accelerated respiration, yellowish mucus and convulsive cough. A characteristic symptom is the emission of frothy liquid through the nostrils (as much as 10 litres in one hour). Death often occurs from asphyxia in a fit of coughing.

In cattle, cake containing the seeds caused inflammation of the intestines, exhausting diarrhœa, and unquenchable thirst.

The cultivated Mustards may induce similar effects, and Lander records the following symptoms as caused by Brassica nigra:-In the horse, bronchial symptoms, marked by difficulty in breathing and the discharge of great quantities of yellowish frothy matter from the nose; in cattle, uneasiness, restlessness and intense colic, with frantic rushing about and mania, ending in exhaustion, falling, struggles and collapse; in a recent case there were dullness, coldness, some tympany, laboured respiration, staggering and falling, and in fatal cases, immobility and a semi-comatose condition.

\section{REFERENCES.}

$4,16,63,76,127,170,190,205,213,219$.

Wild Radish (Raphanus Raphanistrum L.). As in the case of charlock, the seeds of wild radish are very acrid, and susceptible of introducing intestinal troubles if eaten by animals when mixed with cereals. 
Garlic Mustard (Alliaria officinalis Andrz.) and Treacle Mustard (Erysimum cheiranthoides L.). The seeds are stated to have properties similar to Brassica Sinapistrum (p. 18) owing to a pungent oil; and when eaten in quantity to induce poisoning, inflammation of the digestive tract and of the kidneys, as well as nervous symptoms (Müller).

\section{CARYOPHYLLACEE.}

Soapwort (Saponaria officinalis L.). This plant is more or less poisonous, but is rarely, if ever, eaten by stock, and no recorded case of the poisoning of stock has been met with.

Toxic Principle. The whole plant, especially the root, contains the poisonous glucosidal Saponin $\left(\mathrm{C}_{18} \mathrm{H}_{28} \mathrm{O}_{10}\right)_{4}$, a peculiar substance which causes intense frothing when stirred in water.

Symptoms. No symptoms of animal poisoning by the plant are recorded, but the action of Saponin in the blood stream is to induce dissolution of the red cells, with stupefaction and paralysis, as in the killing of fish by poisoning. It also causes vomiting and purging. Taken by the mouth it causes inflammation of the alimentary tract, the contents of which are fœtid and mixed with blood.

\section{REFERENCES.}

$16,63,76,81,203,235$.

Corn Cockle (Agrostemma Githago L.). This well-known plant of corn-fields must be regarded as poisonous, though experiments and reports as to its effects on the different classes of live stock vary widely. Though a poisonous principle is found in nearly all parts of the plant, the plant in the green state appears to be innocuous, and is in any case rarely likely to be eaten fresh by stock, which probably refuse it on account of its hairy character. The seeds, however, are by no means harmless. They are rather large, and somewhat troublesome to separate from cereal grains. When ground up with wheat they both discolour the flour and impart a grey tint and disagreeable odour to bread made from it. Further, flour containing a considerable quantity of cockle must, owing to the poisonous character of the latter, be held to be unfit for consumption. Fatal results have followed the use of bread containing Corn Cockle. 'The toxic principle therefore is not destroyed by heating, even in an oven in baking. 
As regards domestic animals, Corn Cockle seeds have frequently been mixed with feeding stuffs and have caused many deaths. Cornevin's experiments in feeding calves, pigs and fowls led to fatal results. $\mathrm{He}$ was able to say that the announts of cockle flour necessary to cause death were :-

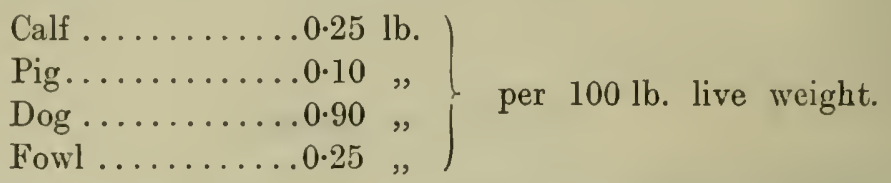

Among other cases, Kornauth and Arche found that in their feeding trials pigs were not killed, but albuminoid metabolism was diminished and fat production increased. In 1893 pigs died in Germany with symptoms of acute poisoning, when fed on tailings containing six per cent. of cockle. In 1903-4 experiments showed that with the cow, sheep, pig and goat, cockle is not poisonous when fed in amounts usually found in feeding stuffs. Millspaugh gives a case in which two calves died on being fed with two lots of $14 \frac{1}{2} \mathrm{oz}$. each of wheat flour containing 30 per cent. and 45 per cent. of cockle seeds. About 1892 Nevinny concluded that six grammes of cockle seed consumed in 1200 granmes of bread were beyond doubt poisonous in effect, and that the sale of grain or flour containing it should be forbidden. Kobert held that the sale of feeding stuffs containing cockle should be forbidden by law. An extensive study of this question was made by Pesch, who concluded that "Under certain conditions Corn Cockle is injurious to domestic animals. The amount of the poisonous substance in the seed is variable, depending probably upon the season and the soil. Animals become accustomed to it, so that amounts of seed which at first cause sickness, later have no injurious effect. The susceptibility of animals to the poison varies both with the species and the individual. Young animals are more readily affected than older ones. It is believed that rodents and sheep are not susceptible, and, as far as is known, grown cattle are only slightly or not at all affected by the poison. Calves, swine, horses, and especially dogs, are more or less susceptible. Concerning birds and fowls there is some doubt."

Though animals are reputed to become tolerant of the poison if the cockle is only taken in small regular doses, yet there appears to be a chronic form of poisoning due to this cause and termed Githagism, while there is an acute poisoning due to the ingestion of large quantities of the seeds which may cause death in 24 hours or less. 
It is clear that the evidence is quite sufficient to warrant the statement that the ingestion of more than a very small quantity of cockle seed is dangerous, and the consumption of even small quantities should be avoided. Thus care should be taken to remove the seeds from cereal grains.

Toxic Principle. The dangerous substance contained in cockle seeds is the glucoside variously known as Githagin, Saponin, Agrostemmin, Sapotoxin, Agrostemma-Sapotoxin, or Smilacin $\left(\mathrm{C}_{17} \mathrm{H}_{26} \mathrm{O}_{10}\right)_{2}$. This principle appears to occur chiefly in the seeds, which contain up to 6.56 per cent., but it has been found in small quantities in other parts of the plant. It is very freely soluble in water, in which it froths like soap when shaken up, and it has a sharp taste and no odour.

Symptoms. A sufficient quantity of the toxic substance may cause nervous debility and dysentery-according to Chesnut "intense irritation of the digestive tract, vomiting, headache, nausea, vertigo, diarrhœa, hot skin, sharp pains in the spine, difficult locomotion, and depressed breathing. Coma is sometimes present and may be followed by death. In animals chronic diarrhœa and gradual depression."

The chronic form, which occurs when small doses are repeated over a long period (practically the only form found in human beings, but never in animals, except perhaps in the pig) is characterized by gradual wasting away, loss of breath; loss of strength, chronic diarrhœea, and nerve troubles, death taking place in marasmus and decline. The active principle acts as an irritant on the digestive tract, causing colic, diarrhœa and enterorrhagia.

Cornevin describes the symptoms in the acute form of the poisoning in the case of horses, cattle, pigs and dogs.

In the horse, if a small quantity only is taken, there is yawning, heavy colic, stamping and evacuation of rather soft fæces. If larger quantities are taken, the symptoms, which commence in about an hour, are salivation, frequent yawning and turning of the head, colic, pale mucus, hurried and weak pulse, rise in temperature and accelerated respiration. Some time later there are muscular tremors succeeded by pronounced rigidity, and the fæces are diarrhœic and fœtid. The animal lies down, and getting up is painful; it falls into a kind of coma, stretches itself to the utmost, and death takes place without convulsions.

In cattle, the symptoms observed one hour after eating are restlessness, salivation, and grinding of the teeth. Excitement and colic are followed sometimes by coughing, this state lasting from five to eight hours. There is then a period of coma, characterized by permanent decubitus, 
repeated fotid diarrhœea, hurried and plaintive respiration, accelerated and gradually weakening pulse, a gradual loss of motor and sensory powers, and a progressive decline in temperature. Death occurs in twenty-four hours.

In the case of pigs, the animal grunts, lies down and remains thus with its snout embedded in the straw. There is vomiting, more or less violent colic and diarrhœa, the evacuation consisting of bad-smelling, spumous fæcal matter. At times there are clonic contractions. Young pigs are most susceptible.

Pott cites cases in which abortion was a feature of the poisoning, both in cows and pigs. The results of numerous experiments which he quotes (among others some carried out for the Prussian Ministry of Agriculture) are very contradictory, a small quantity causing death in some animals, while others of the same species were left unharmed by large quantities. He ascribes this to the very variable proportions of the poison present in the seeds.

REFERENCES.

$4,16,28,46,52,53,63,76,81,82,144,161,172$,

184, 190, 203, 205, 213, 249.

\section{HYPERICINEEE.}

St. John's Wort (Hypericum perforatum L.). There appears to be no record of poisoning of live stock by this plant in Britain, but Cornevin records that it injured breeding mares fed on lucerne containing it in large proportion. Drying in converting into hay did not render it innocuous. It is only poisonous if eaten in considerable quantity, and in general animals are not likely to eat much of it voluntarily, owing to its resinous odour when crushed, and a bitter and slightly saline taste.

Toxic Principle. The poisonous properties of St. John's Wort have not been fully investigated, but it is stated to contain an oil and an acrid bitter resin. Ewart says that it "contains an oil whose medicinal value was formerly highly esteemed; but this oil, and the woody nature of the plant, render it somewhat injurious in fodder." Summers says (Journ. Agric. S. Australia, Sept. 1911, p. 144) that "it is reported to be decidedly injurious, causing horses who eat it to break out in sores, while milk cows have a tendency to dry off owing to its effect on the system." 
Symptoms. In mares, dullness, sinking of head, loss of appetite, slackening of pulse and respiration, dilatation of pupils, defective sight, and lips purple (Müller).

REFERENCES.

$63,82,11 \bar{i}, 190,203$.

\section{GERANIACEF.}

Wood Sorrel (Oxalis Acetosella L.). Though rarely likely to be eaten by stock this plant must be mentioned here, as it is considered dangerous on account of its high content of oxalates, which may cause serious illness and diarrhœa, and in the case of sheep even be fatal. Pott says that the milk of cows eating it is with difficulty converted into butter.

REFERENCE.

213. 


\section{CHAPTER III}

\section{CELASTRACEXE.}

Spindle Tree (Euonymus europceus L.). According to Cornevin the spindle tree is poisonous in all its parts, especially the fruits, which are emetic and strongly purgative. Sheep and goats have been injured from eating the leaves, and children have suffered from eating the fruits.

Toxic Principle. This plant does not appear to have been closely studied from the toxicological point of view; contrary to the statements generally made in the literature Van Rijn remarks that this species does not contain the doubtfully classed Euonymin.

Symptoms. Ingestion of the plant induces symptoms and lesions such as are due to violent vegetable purgatives.

\section{REFERENCES.}

$63,81,205,252$.

\section{RHAMNACEE.}

Buckthorn (Rhamnus Catharticus L.) and (R. Frangula L.). The berries of both species are toxic and purgative, but both are uncommon and rarely eaten by stock.

Toxic Principle. The berries and bark contain the glucosides Frangulin $\left(\mathrm{C}_{21} \mathrm{H}_{20} \mathrm{O}_{9}\right)$ and Rhamnetin $\left(\mathrm{C}_{16} \mathrm{H}_{12} \mathrm{O}_{7}\right)$.

Symptoms. The berries are purgative, and there is some danger from large quantities, which may induce super-purgation. The leaves are astringent and may arrest milk secretion (Cornevin). Müller states that the inflammation of the stomach and intestines may terminate fatally.

\section{REFERENCES.}




\section{PAPILIONACEÆ.}

Laburnum (Cytisus Laburnum L.). The well-known and much admired Laburnum must be regarded as one of the most poisonous species of British plants. By numerous experimental researches Cornevin proved that all parts of the plant are poisonous-root, wood, bark, leaves, flowers, and seeds, especially the seeds. In his experiments the horse, ass, sheep, goat, dog, cat, fowl, duck and pigeon, were utilized, seeds being given. He found that 80 centigrammes per kilogramme live weight would be necessary to kill a horse (say $1 \mathrm{lb}$. for an animal of $1200 \mathrm{lb}$. live weight), 60 centigrammes per kilogramme live weight to kill an ass (say $6 \mathrm{oz}$. for an ass weighing $600 \mathrm{lb}$ ); and 6 grammes in the case of a fowl (say $0.4 \mathrm{oz}$. for a fowl weighing $4 \frac{1}{2} \mathrm{lb}$.). The sheep and goat he was not able to kill, as they refused the food after a certain point; the dog and cat he was not able to kill because they so readily vomited; and the duck and pigeon vomited with extreme facility.

Many cases of the poisoning of children have occurred through the ingestion of the fiowers and seeds. In 1908 a case was recorded by the Board of Agriculture and Fisheries, in which two horses were alleged to have been poisoned in North Wales by laburnum seeds, a very small quantity of which was found in their stomachs after death.

Müller states that in Dalmatia goats which had eaten Cytisus Weldeni, though themselves uninjured, produced milk which was poisonous to man.

Toxic Principle. All parts contain the toxic alkaloid Cytisine $\left(\mathrm{C}_{11} \mathrm{H}_{14} \mathrm{~N}_{2} \mathrm{O}\right)$, said by Moer and Partheil to be identical with Ulexine; it is found in the seeds to the extent of 1.5 per cent. Cornevin states that the root, wood and bark are nearly constant in toxicity, but that the leaves and pods present remarkable seasonal variations owing to the migration of the poison into the seeds. The toxic property is not destroyed by drying of the plant.

Symptoms. Laburnum poisoning is of the acrid, narcotic type, with, in man, nervous symptoms, abdominal pain, vomiting, purging, tetanic spasms and convulsions.

Cornevin's observations show that the symptoms occur in three consecutive stages,-(1) excitement, (2) coma and inco-ordination of movement, and (3) convulsions. The order of the appearance, their duration, and the association of each with the others depend upon the susceptibility of the animal and the quantity ingested. Thus the 
symptoms of excitement may be present alone if only a small quantity is eaten; the duration of the symptoms in this case is never considerable, and the normal is gradually regained. In general, however, the symptoms are associated in pairs; thus when an average quantity is fed there is excitement and coma but no convulsions; when large quantities are fed the first stage is suppressed or is so short as to be almost imperceptible, the coma and convulsions being present simultaneously. As regards temperature, there is, in stage (1) a rise, in stage (2) a drop, and in stage (3) a rise again near death. In stages (2) and (3) there is a slackening of respiration, the arterial tension is raised, there is an increase in the number of pulsations and a modification of the rhythm. In stage (3) near death there is a lowering of the arterial tension, and the pulsations become gradually less perceptible, but with a uniform rhythm; there is a slackening in respiration, and by the time this finally ceases the heart beats have become imperceptible.

When horses, asses or mules have eaten a small quantity of the seeds or leaves, there is simply yawning and uncertain gait, these symptoms lasting for two hours, and the normal being regained after urination. Considerable (but not fatal) quantities cause unsuccessful attempts at vomiting, sometimes opisthotonos in asses, sweating, muscular tremors, and then a deep coma which may last 15 hours. Fatal quantities cause yawning, sexual excitement, accelerated and noisy respiration, wheezing, muscular tremors followed by contractions which commence in the posterior limbs and spread to the anterior limbs, facial contractions, staggering and copious sweating. A rapid fall in temperature follows, but there is a slight rise during the period of convulsions; the pulse is at first quicker and stronger, but the number of beats rapidly comes back to the normal, to rise again shortly before death; the rhythm of the pulse is at first regular (in groups of 2,3 or 4 ) but becomes irregular again just before death. The animal at length falls, and cannot get up, the nostrils are distended, the mouth is wide open, respiration becomes gradually slower, and death takes place in great agony.

In cases of poisoning of horses and asses noticed by Pott animals that could not vomit died very quickly. The symptoms were excitement, nausea, coma, slower breathing, convulsions, paralysis of the motor nerves, and finally cessation of the action of lungs and heart.

Ruminants are much less susceptible than horses. Cornevin's attempts at poisoning failed through their refusal of the plant. Müller observed in a case of cattle poisoning, bloating, paralysis of the limbs (especially fore limbs), sleepiness, dilatation of pupils, and later salivation, 
nausea, coma and occasional convulsive movements of the muscles of the extremities. These symptoms persisted through several days and then disappeared.

\section{REFERENCES.}

$4,16,63,64,81,128,144,161,190,205,213$.

Broom (Cytisus Scoparius Link.). This very plentiful and widely distributed plant is undoubtedly to some extent poisonous, though perhaps only feebly so in the quantities likely to be eaten by domestic animals. Blyth records 400 cases of poisoning from it, however. Very hungry animals might eat too much of it, and hence show symptoms of poisoning.

Toxic Principle. The plant contains the alkaloid Cytisine $\left(\mathrm{C}_{11} \mathrm{H}_{14} \mathrm{~N}_{2} \mathrm{O}\right)$; also the volatile alkaloid Sparteine $\left(\mathrm{C}_{15} \mathrm{H}_{26} \mathrm{~N}_{2}\right)$, a single drop of which, according to Blyth, killed a rabbit, which showed symptoms similar to those of nicotine poisoning.

Symptoms. Taken in sufficient quantity broom induces narcotic poisoning, with symptoms resembling those caused by Coniine, with central nervous paralysis.

Cornevin gives the symptoms as similar to those due to C. Laburnum. REFERENCES.

4, 16, 82, 128, 203.

Indian Peas (Lathyrus sativus L.). A type of poisoning that deserves attention here is that known as Lathyrism, since it is due to the consumption of peas of the genus Lathyrus, the most dangerous being the "Indian Pea," L. sativus. The peas of this plant (see Frontispiece) are small and dark-coloured, and are imported largely from India and other countries under the general name of Mutter peas, a name which they share with the ordinary pea Pisum sativum. In addition to the seeds of this species the seeds of two South European and North African species-L. Cicera and L. Clymenum-have commonly caused poisoning both in man and in animals, not infrequently leading to fatal results. Horses, cattle, sheep and pigs have been affectedhorses particularly so-and many cases have been recorded in the veterinary journals since 1885. Very heavy losses have occasionally resulted from the use of the raw peas as a food for stock. For example, in 1884 Messrs. Leather of Liverpool had 35 out of 74 cart horses ill through eating Indian peas at the rate of 3 to $4 \mathrm{lb}$. per head per day. Of the 35 no less than 19 died, and 2 were slaughtered, while 
14 recovered. In the famous Bristol Tramways case (1894) 123 out of 800 horses became ill owing to being fed on the peas of $L$. sativus, and many died. There are few records of harm to cattle, sheep and pigs, and Watt quotes Don to the effect that pigeons lose their power of flight by feeding on the peas. Very large quantities of the peas are used for feeding purposes, and the fact that the losses are not larger is probably because the peas only comprise a small proportion of the ration or are cooked before use.

After boiling or roasting the peas appear to be less harmful, as they are eaten in India when cooked, or ground into flour and converted into bread-though Cornevin states that drying and cooking does not destroy the toxicity, while boiling for some time showed that at any rate part of the toxic substance passed into the water, which became toxic and caused death, the boiled seeds losing the greater part of their poisonous property and not causing accidents when the water was rejected. MacDougall states that as far as experimental evidence was available (1894) it seemed to show that boiling the seeds before use renders them innocuous.

Lathryism usually only supervenes when the use of the peas for food is prolonged, and the peas are taken in considerable quantity, but it is possible that there is wide variation in the toxicity of different samples, owing to differences in soil, climate, and other factors. In man, Lathryism is stated to be common in Spain, Italy, Russia and India, owing to continued use of bread from flour of the three species of Lathyrus mentioned above. It is said especially to affect males.

Toxic Principle. Nothing certain as to the poisonous properties is known, attempts to isolate the toxic substance having failed (Kobert), though Smith gives it as prussic acid, apparently indicating a cyanogenetic glucoside. This, however, can hardly be so, as the poison is cumulative, and may not show its effects for weeks or months, or, in man, even years-according to the quantity of peas eaten.

Symptoms. Lathyrism is only produced when the ration consists largely of the pea for a considerable period (see above); in the horse fed exclusively on the pea, the tenth day; but when one or two quarts are given daily, only towards about the 80 th day. Moreover, the malady may declare itself as long as fifty days after the cessation of the pea feeding (Lander).

In general Lathyrism is marked by paralysis of the lower extremities in man and the hind limbs in animals, owing to the degeneration of the muscle fibres, and possibly to affection of the nerves. In horses there 
is paralysis of the hind limbs, dyspnœa and roaring-with paralysis of the recurrent laryngeal nerve, and transverse myelitis. The horse thus shows weakness of the hind quarters, staggering in the effort to stand, difficulty in breathing, abnormally fast and irregular pulse, open mouth, distended nostrils. Tracheotomy often gives almost immediate relief.

Lander mentions in cart horses grinding of teeth, and convulsive movements of the eyes, recalling epilepsy. In one outbreak there was thick wind, staggering gait, weakness of hind quarters, and general signs of intoxication; and sudden violent attacks of laryngeal paralysis and dyspnœa during which there was palpitation, frothing, tongue protruded, eyes staring, bluish tint of buccal membranes, and palpitation. Paroxysms sometimes proved fatal.

An attack among 125 lambs is mentioned by Cornevin. The lambs could not stand on their fore legs and were obliged to go down on their knees. On setting them up again, they were only able to keep up while motionless or moving slowly. There was loss of sensibility in the front members. In spite of this the eye was alert, they were attentive to everything that went on around them, and were easily frightened.

In pigs paralysis of posterior members has been observed.

In cattle there was staggering, blindness, and stiffness of the lower joints. In sheep and pigs there was also paralysis of the hind limbs.

REFERENCES.

$63,82,137,170,179,190,203,205$.

Yellow Vetchling (Lathyrus Aphaca L.). To what extent this vetchling is poisonous to stock is not clearly known, but it is cultivated in India as a fodder for cattle. The seeds, however, are not altogether safe when ripe, and MacDougall says "The seeds and pods have been known to be used in soup in their young state and without harm resulting, but the ripe seeds are narcotic and cause sickness and headache."

Lupines (Lupinus sp.). Different species of Lupinus have been found to cause poisoning of live stock, more particularly sheep, which, when fed largely on lupines, develop a chronic type of poisoning known as Lupinosis, or poisoning may be acute and rapid in its effects, as in the United States. Records of large numbers of sheep being affected at a time date from 1872, in various parts of the German empire. In Europe by far the most harmful species is the Yellow Lupine (L. luteus), which has been the cause of heavy losses of sheep, though horses, cattle and goats may also be affected. The Blue Lupine ( $L$. angustifolius) 
and White Lupine ( $L$. albus) may also be toxic. $L$. luteus has caused lupinosis in Germany since 1860, and Cornevin states that in 1880 no less than 14,138 out of 240,000 sheep fed upon it (or $5 \cdot 89$ per cent.) died. Of 44 horses affected 11 died.

It must not be thought that all crops of lupine are poisonous, as lupines are extensively grown on the Continent for fodder purposes and are usually harmless. Even where Lupinosis occurs, considerable quantities of the lupine must be ingested to cause poisoning. The toxicity appears to vary according to soil and certain indefinite conditions, and sometimes even a kilogramme $(2 \cdot 2 \mathrm{lb}$.) of the plant would suffice to kill a sheep. Poisonous symptoms may sometimes be observed after a single meal. Desiccation does not render the plant innocuous, the seeds and hay being poisonous.

In the United States species of Lupinus have caused great loss. In 1898 no fewer than 1,150 of a flock of 2,500 sheep died from eating one species; one sheep farmer lost 700 sheep from the same cause; and 1,900 out of 3,000 sheep died from Lupine poisoning in Montana in 1900 . Lupine hay is found to be less harmful to horses and cattle, and Chesnut and Wilcox suggest that this is possibly because as a rule they avoid the pods, while sheep eat them. Lupines in America are very rapid in their action on sheep, which may often die in one-half to three-quarters of an hour after eating a quantity of the pods. Further, there is evidence that sheep may gradually become immune to the poison by eating Lupines regularly, since sheep fed regularly on hay nearly half lupine were unaffected, but others eating the same hay for the first time died in considerable numbers. The lupines are certainly far the most dangerous when they bear ripe seeds-cut and made into hay before the pods form they are much less dangerous.

In regard to L. luteus Lander says: "According to the German authorities a daily ration of 1 pound of the whole plant, $\frac{3}{5}$ pound of empty pods, or $\frac{1}{3}$ pound of seeds, will produce poisoning."

Various means have been tried to render Lupines harmless, and success is stated to follow heating with steam under a pressure of 2 to $2 \frac{1}{2}$ atmospheres.

Toxic Principle. A very full account of Lupine poisoning is given by Pott, and from this a brief summary may be made. Siewert and Wildt (1879) found two substances very like the alkaloids of Conium maculatum-one like Coniine and the other like Conhydrine, the former only being proved to be very poisonous. Baumert states that in $L$. luteus there are only two bitter alkaloids, Lupinine $\left(\mathrm{C}_{10} \mathrm{H}_{19} \mathrm{ON}\right)$ and 
Lupinidine $=$ Sparteine $\left(\mathrm{C}_{15} \mathrm{H}_{26} \mathrm{~N}_{2}\right)$. Many investigators (e.g. Kühn at Halle) held that lupinosis was not identified with the presence of lupine alkaloids. Then, in 1883, Arnold and Schneidemühl caused the disease (lupinosis) in sheep with lupines freed from all alkaloids, and they isolated from the seeds a substance they named Lupinotoxin, which they found to be poisonous. The nature of the poison cannot yet be said to be fully understood. The Lupine does not always appear to be poisonous-only under certain conditions which are not too well defined. One farmer had Lupines on the same soil for twelve years without ill effects when fed to sheep, and then of 450 sheep 120 were severely ill, and 80 died; they had had unthrashed Lupine, not quite ripe, to the extent of one-fourth of the ration. It is held to be definitely established that the presence of this poison is due in turn to the presence of a saprophytic fungus; when the fungus is absent or only present in small quantity the lupine is not at all or only slightly poisonous.

Symptoms. The disease is either acute or chronic according to the amount of poison ingested. Most writers describe the disease in sheep, but symptoms given vary somewhat.

In the acute form sheep become ill suddenly. There is loss of appetite, dyspnœa, intense fever, hæmaturia, circulatory and digestive troubles, grinding of teeth and trembling, which may pass into spasmodic contractions. Vertigo is sometimes present. Jaundice then appears and is evidenced by the yellow colour of the mucous membranes. Tumefaction of the eyelids, lips and ears is common, but not invariably present. Micturition is frequent, but not abundant, and the urine contains albumen; the excrements are few and dry. There is collapse, and loss of condition progresses rapidly, death occurring on the fourth to the sixth day after the commencement of the illness.

In the chronic form the interstitial hepatitis predominates. Tumefaction of the head may also appear as in the acute form. Digestive troubles indicate chronic gastro-enteritis. This condition lasts for from 15 to 20 days, during which the cephalic œdemæ are eliminated by gangrene and the animals remain listless and without appetite. The illness in sheep is grave, and affected animals are rarely completely cured. The mortality in other species does not seem to be less than in sheep. (Cornevin.)

In describing the acute form of lupinosis Pammel adds that the initial temperature may be as high as $104^{\circ}$ to $106^{\circ} \mathrm{F}$., but that it is intermittent and gradually falls just before death. The pulse may reach 130 per minute and the respirations 100. A bloody froth may 
issue from the nostrils. Animals apparently prefer the recumbent position, extend the head on the ground, and seem entirely oblivious to all surroundings. At first there is constipation, but later diarrhœa may set in and the excreta be tinged with blood. In the chronic form the symptoms are not so violent. Jaundice may be entirely absent, and emaciation and anæmia may be the chief signs.

Chesuut and Wilcox record a case in which two sheep were each given 150 medium-sized pods of a native lupine, and seemed to like them. In 45 minutes, however, they became frenzied and died an hour later. They give the symptoms as practically the same as those caused by European species of Lupinus; acute cerebral congestion, with great mental excitement, the sheep rushing about and butting into things; following is a stage characterized by irregularity of movement, violent spasms, and falling fits; in most cases collapse and death occur within half-an-hour to an hour and a half; the pulse is strong and regular; the convulsions resemble to some extent those caused by strychnine; the excretion of the kidneys is much increased and sometimes bloody. In post-mortem examination the kidneys are found affected, the lungs slightly congested, the cerebral membranes in all cases congested, and in violent cases small blood vessels are ruptured in different parts of the body.

\section{REFERENCES.}

\section{$4,16,20,21,42,57,63,69,82,93,128,161$, $166,170,190,203,213$.}

"Java" Beans (Phaseolus lunatus). Though not native to Great Britain, the so-called Java Beans have been imported in considerable quantities for stock feeding, and in the past nine years have caused the death of a large number of animals. For example, in March, 1906, the Board of Agriculture and Fisheries published an account of the poisoning of animals by these beans at eight centres; at six of the centres 133 cattle were involved and 43 died. The beans are of varying origin, and pass under the name of Java beans, Rangoon beans, Burma beans, Lima beans, and Paigya beans. They are considerably different in colour according to origin, the Java beans being pale brown to almost black; Rangoon, Burma or Paigya beans smaller, plumper, and lighter in colour ("red Rangoon beans" are pinkish with small purple splotches, and "white Rangoon beans" are pale cream); and Lima beans are much larger than the last-named and pale cream or white in colour (see Frontispiece).

It has long been known that beans of certain forms of Phaseolus 
lunatus are poisonous, and the fact is noted by Church (Food Grains of India, 1886), and by Watt (Dictionary of the Economic Products of India, 1889-96). The coloured forms, and particularly the wild forms, are the most dangerous, the white types being in general safe for stock feeding. Some forms have a general similarity to butter beans and haricots, and have hence been favourably regarded by farmers, but it is a sound plan to purchase under a guarantee beans with such names as those given.

Toxic Principle. It was shown in 1903 (Proc. Roy. Soc., Vol. 72) that the seeds of $P$. lunatus, uncultivated in Mauritius, contained a cyanogenetic glucoside, Phaseolunatin $\left(\mathrm{C}_{10} \mathrm{H}_{17} \mathrm{O}_{6} \mathrm{~N}\right)$. This glucoside, under favourable conditions, such as are present when the beans are moist, masticated and ingested at the temperature of the animal body, gives rise to prussic acid, which is the direct cause of poisoning. The seeds of the wild forms yield, like bitter almond seeds, considerable quantities of prussic acid, while the cultivated forms resemble sweet almonds in yielding only traces of the acid, or none at all. Determinations of the yield of prussic acid by various investigators show percentages of from 0.027 to 0.137 in Java beans, and 0.004 to 0.02 in Burma beans. The largest proportion therefore occurs in the coloured beans, while the white forms contain much less or none at all, and may be generally regarded as safe for stock.

Symptoms.-The symptoms given by Damman and Behrens (Veterinary Journal, 1906) were vertigo, tympany, and falling, with death in most cases. Mosselmann (Vet. Jour., 1908) observed the symptoms due to the ingestion of a small quantity of the beans by six head of cattle. They were: great excitement, salivation, swelling, slight diarrhœa, quick pulse and respiration, muscular spasms, and paralysis of the hind quarters in one instance; all recovered rapidly.

REFERENCES.

$$
5,38,76,77,107,109,125,129,144,255 .
$$

Castor Oil Plant (Ricinus communis L.). The beans (see Frontispiece) of this exotic are toxic, and poisoning is only likely to occur if they are sold in error as a feeding stuff, or from the use for feeding purposes of the press-cake after the extraction of the well-known castor oil, a purgative commonly used medicinally, of which the beans contain about 50 per cent. According to Cornevin four seeds suffice to cause accidents in man, eight lead to very grave results, and beyond that number death may ensue. Pigs and poultry have been poisoned by the seeds, and 
M. Audibert (near Beaucaire) reported the death of 80 sheep from eating the press-cake, which is stated to have more pronounced properties than the oil. It has been found as an impurity in linseed cake and maize meal. (Jour. Roy. Agric. Soc., 1892.)

Toxic Principle. The toxic properties of the bean are due to Ricin, a toxin which is similar to bacterial toxins, and the activity of which is destroyed by heating to $100^{\circ} \mathrm{C}$. The beans also contain the alkaloid Ricinine $\left(\mathrm{C}_{8} \mathrm{H}_{8} \mathrm{O}_{2} \mathrm{~N}_{2}\right)$, the toxic properties of which are regarded as doubtful. (See Deane and Finnemore, Yearbook of Pharmacy, 1905, p. 473.)

Symptoms. These usually appear some days after the ingestion of the beans or press-cake. There is generally purging. Broad observed in an affected horse loss of appetite, shivering, cold extremities, dejection, abdominal pain, constipation, temperature $103^{\circ} \mathrm{F}$., pulse 70 , and death in about three days.

\section{REFERENCES.}

$4,16,66,73,128,205$.

\section{ROSACEE.}

Cherry Laurel (Prunus laurocerasus L.). This exceedingly common ornamental shrub has caused the poisoning of numerous cattle and sheep on the Continent, but is apparently less harmful in Great Britain -and in any case animals are not much given to eating the foliage of this shrub, the strong smell of the leaves when bruised affording a warning of its unwholesome character. Gerlach recorded the intoxication of 25 sheep. Bibbey also records the poisoning of 15 sheep by laurel, some of them dying (Farmer and Stockbreeder, Jan. 29, 1912). On the other hand, Henslow wrote of his cows that they "completely ruined a long laurel hedge adjoining the field in which they lived; but this abnormal food did no harm either to themselves or the milk they produced."

Toxic Principle. So long ago as 1803 Schrader showed that the cherry laurel contains a substance yielding prussic acid. The leaves contain the cyanogenetic glucoside Prulaurasin $\left(\mathrm{C}_{14} \mathrm{H}_{17} \mathrm{O}_{6} \mathrm{~N}\right)$, and an enzyme-emulsin which, by its action on the cyanogenetic glucoside, induces the formation of prussic acid, which is the actual cause of poisoning. The percentage of the glucoside appears to be greatest about July and August. By a microchemical examination Peche has clearly localised hydrocyanic acid compounds in the leaf parenchyma.

Symptoms. In poisoning by Cherry Laurel there is bloating, inability to rise, loss of sensation, difficult breathing, convulsions and 
dilatation of pupils, and the results may be fatal if unattended to, prussic acid being formed.

In the case of poisoning of ewes Aggio observed (Veterinary Journal, 1907) loss of appetite, vomiting, and inability to rise, followed by several deaths. In 1871 Adsetts described (Veterinarian, 1871) symptoms of poisoning in the horse: indistinct and feeble pulse; congested mucous membranes, difficult respiration, uneasiness, prostration, coldness of the extremities, loss of appetite, constipation, diminished urination, and acute pain, eventuating in death in three days. In sheep Bibbey observed salivation, grinding of teeth, brain symptoms, paralysis in the back, coma, and death.

REFERENCES.

$4,16,73,76,81,128,129,130,132,170,205,232,254,255$.

\section{CUCURBITACE王.}

Bryony (Bryonia dioica L.). This widely distributed hedge climber, which produces large quantities of scarlet berries, is a highly irritant plant, with an unpleasant odour and a nauseous juice. The large fleshy tuberous rootstocks have caused the poisoning of whole families who have eaten them in mistake for turnips and parsnips. The berries may tempt children, and cases of poisoning have occurred. Cornevin estimated that 15 berries would cause the death of a child and 40 that of an adult. No deaths of domestic animals have been observed in searching the literature, but animals may possibly eat it along the hedgerows at times when grass is scarce. Pigs might possibly eat sufficient of the rootstock, or poultry of the berries, to cause poisoning.

Toxic Principle. The plant contains the bitter and poisonous glucoside Bryonin $\left(\mathrm{C}_{34} \mathrm{H}_{48} \mathrm{O}_{9}\right)$.

Symptoms. The symptoms are those resulting from inflammation of the stomach and intestines, together with convulsions. According to Cornevin consumption of the plant promotes sweating, and causes a livid hue, nausea, diuresis and abundant painless, watery defæcation, to which are added in cases of poisoning nervous symptoms of stupor and tetanic convulsions. There may be super-purgation or a suppression of defæcation.

Lander states that $2 \mathrm{lb}$. of fresh or 6 to $8 \mathrm{oz}$. of dried root given to horses did not cause purging, but there was abdominal pain, loss of appetite, accelerated breathing, fever, dullness and copious urination.

Cases may end fatally.

\section{REFERENCES.}

$73,76,81,141,170,233$. 


\section{UMBELLIFEREE.}

Cowbane or Water Hemlock (Cicuta virosa L.). This plant is undoubtedly exceedingly poisonous, and fatal cases have occurred in both man and farm live stock. It has been mistaken by man for parsley, celery or parsnip, with fatal results, many persons having succumbed to it. The rootstock is attractive to children on account of its sweetish taste. Pott says that either fresh or dry it is poisonous to all animals when only a small quantity is eaten, and often causes rapid death. Sheep and goats appear to be less readily affected than other domestic animals, and cattle to be most sensitive. The loss of eleven animals in Brittany was noted in the Veterinarian in 1877, and a number of cattle died in Ireland (Veterinary News, 1911), death in both cases being due to Cowbane. It is clearly dangerous to grazing animals which have easy access to it, especially if ordinary herbage is scarce. Hedrick (Canada) is quoted as stating that a piece of the root about the size of a walnut is sufficient to kill a cow in about fifteen minutes; and Müller says that the quantity of dried plant sufficient to kill a horse appears to be about $1 \mathrm{lb}$. According to Kanngiesser the mortality in human poisoning due to this plant amounts to 45 per cent. of the cases.

Toxic Principle. The poisonous character of Cowbane has not been fully investigated, and the toxic principles are given as the alkaloid Cicutine, with Oil of Cicuta, and Cicutoxine. The last is a bitter resinous substance classed by Cushny in the picrotoxin group; it occurs in the dry root to the extent of 3.5 per cent. The toxicity is stated to vary with season and climate; the rootstock is most poisonous in spring.

Symptoms. In man the yellow poisonous juice in the rhizome induces epileptic convulsions, followed by death. The cicutoxine gives acrid narcotic symptoms quickly followed by fatal results. The symptoms usually appear within two hours, and death ensues in half-an-hour to several hours. The symptoms which appear in an hour or so are given as loss of appetite, salivation, vomiting (in swine), nausea, colic (in horse), bloating (in cattle), diarrhœa, irregular pulse and heart, dilatation of pupils, rolling of eyeballs, vertigo, reeling in circles, twisting of neck, falling down, automatic movement of limbs, opening and shutting of mouth, and death, usually with convulsions, in from half an hour to an hour after first manifestation of symptoms.

For cattle, Lander gives hurried respiration, collection of froth at the mouth and nostrils, and tympanites. The limbs are extended and alternately stiffened and relaxed. 
In his description of the symptoms Esser states that swallowing is difficult, the tongue is stiffened, there is salivation, and death takes place after loss of consciousness and convulsions.

\section{REFERENCES.}

$31,73,81,123,141,151,170,190,203,205,213,233,238$.

Water Parsnip (Sium latifolium L.). The leaves and especially the root of this species are regarded as poisonous, and the plant is described as "poisonous" by Strasburger.

According to Müller the symptoms resemble those produced by Chorophyllum (p. 40). After eating the roots cows showed symptoms of excitement, leading, in some instances, very quickly to death. The milk, according to Cornevin, is of a disagreeable flavour.

The related $S$. angustifolium has also been mentioned as objectionable. As regards the toxic principle these plants have not been closely studied, and it is not possible to give detailed symptoms.

\section{REFERENCES.}

$73,81,190,235$.

Water Dropwort (Oenanthe crocata L.). This weed of marshes, ditches, and similar wet spots, has been a frequent cause of loss of stock. Cases of fatal human poisoning have also occurred, owing to the leaves having been mistaken for celery and the rootstock for parsnips. Several cases of the poisoning of cattle have been recorded in the veterinary journals, and sheep and cattle died on a farm near Bristol (Jour. Roy. Agric. Soc., 1898). Horses have also been poisoned. Johnson and Sowerby (1861) record the poisoning of 17 convicts near Woolwich, the leaves and roots being eaten in mistake for celery and parsnips respectively. Nine suffered from convulsions and became insensible; one died in five minutes, a second in a quarter of an hour, a third in an hour, and a fourth a few minutes later, while two more died during the next few days.

Cornevin says that this plant causes the poisoning of animals every year-they eat it willingly, showing an enfeebled instinct owing to domestication. The plant is poisonous in all its parts, the root being the most toxic, and drying does not destroy the toxic property. Cornevin gives the following quantities of the fresh root as necessary to poison various animals:- 
Horse $\ldots \ldots \ldots+0 \cdot 100$ per cent. of the live weight.

$\mathrm{Ox} \ldots \ldots \ldots \ldots \cdot 0 \cdot 125$

Sheep ..........0.200

Pig.............. $0 \cdot 150$

Rabbit .......2. 2.000

$\begin{array}{lll}\because & , & , \\ , & , & , \\ , & \text {, } & \text { ", }\end{array}$

Holmes described Oenanthe crocata as the most dangerous and virulently poisonous of all our native plants (Pharm. Jour., 1902).

Other species of Oenanthe are also poisonous in a less degreee.g. O. fistulosa L., and O. Phellandrium Lamk.

Toxic Principle. Poehl (1895) obtained from the root of this species an amorphous neutral product which he designated Oenanthotoxin. The latest investigation is that by Tutin, who examined entire dried plants collected in early spring, and the experiments confirmed the conclusion arrived at by Poehl, that the toxic principle is a neutral resin. A darkcoloured, viscid resin, insoluble in water, and equal to 3 per cent. of the weight of the plant, was extracted, and it is stated that the neutral portions of the petroleum and ether extracts of this resin represent the toxic principle of the plant. As there is no evidence of the homogeneity of this product, and it is probably complex in character, it was given no name or formula. The fact that it has poisonous properties was ascertained by administering the various products to guinea pigs per os.

Symptoms. In poisoning by $O$. crocata the symptoms generally appear very quickly, and in serious cases death may follow in from one hour to a few hours. In Tutin's experiments on guinea pigs the extracts referred to above rendered the animal hypersensitive in two to four hours, while marked convulsions, with trismus soon appeared; the heart-beat became very noticeably slow and the convulsions persisted until death ensued. There is great restlessness, difficult breathing, convulsions, loss of sensation, blindness and stupefaction (Müller); Lander says the symptoms recall hemlock poisoning, with the addition of green fœtid diarrhœa.

In cattle, one hour after eating, there is depression and accelerated respiration; the conjunctivæ are injected, the eye turns in its orbit, the pulse is weak but rapid, and there is foaming. Later, there is colic. and spasmodic contractions of limbs and jaws. If the quantity ingested is sufficient to cause death, the animal falls, but still moves its limbs. There is bellowing, contraction of pupils, insensibility, and death in convulsions-or, if not fatal, cattle may remain paralysed.

In the horse, the appearance of the symptoms and the course of the illness are much more rapid and the nervous symptoms are accentuated. 
If the pig has consumed only a small quantity it soon gets rid of the poison by vomiting; but if the quantity is considerable there is no vomiting and death is as rapid as with cyanide poisoning (Cornevin).

REFERENCES.

$10,14,73,81,141,146,170,190,205,209,213,235,246$.

Fool's Parsley (Aethusa Cynapium, L.). Much has been written about the toxic properties of this weed of cultivated fields, principally because, owing to the fact that the foliage has often been mistaken or misused for parsley and the roots for radishes (!), it has been the cause of human poisoning, though it seems to be one of the least active of the poisonous Umbellifers. Its poisonous character is undoubted, but it is unlikely to cause the poisoning of stock, which seem to refuse it. Some authors regard it as strongly poisonous, but others as more or less harmless. Johnson and Sowerby cite a case in which a child of five years old died within an hour after eating the root, and a second death (in Germany) within twenty-four hours from the use of the leaves in soup.

The most complete account of this plant is that by Power and Tutin, issued from the Wellcome Chemical Research Laboratories in 1905. Many authors since 1807 are cited as writing of its poisonous properties, and of cases of poisoning, two of which terminated fatally. Miller (1807) says that "most cattle eat it, but it is said to be noxious to geese." Bentley and Trimen write that "in all recorded experiments with it on animals, it has had poisonous effects." Dr. John Harley (1876 and 1880), after experiments on a child and adults, concluded that the plant was absolutely free from the noxious properties attributed to it. In 1904, however, a case of severe poisoning by it was recorded (Brit. Med. Jour., July 16, 1904, p. 124).

Toxic Principle. This has for many years been stated to be the alkaloid Cynapine. For their investigation Messrs. Power and Tutin collected the plant round London in July and August, with the fruits still green, and after thorough chemical examination found 0.015 per cent. of an essential oil of rather unpleasant odour; 0.8 per cent. of resinous substances; and an exceedingly small amount of a volatile alkaloid having the peculiar characteristic odour of Coniine. The amount of hydrochloride of the alkaloid obtained showed that if the base were Coniine it would correspond to only 0.00023 per cent. of Coniine in the plant. In a degree this confirms the statement by Walz (1859) that the fruit "contains a volatile base, very similar in odour and chemical 
behaviour to Coniine, and probably identical with it." The investigators suggest that the alkaloid is Coniine, and the small amount would justify the opinion, but there may be variation in toxic property according to stage of development and climate. The authors conclude that "it cannot be considered improbable that under favourable conditions of growth, the proportion of alkaloid may be increased to such an extent as to impart to the plant the poisonous properties ascribed to it."

Symptoms. In a child which died, there were abdominal pain, a feeling of sickness, and a tendency to lockjaw, and death supervened within an hour; and in a German case, vomiting, diarrhœa, lockjaw, and death in 24 hours. (Johnson and Sowerby.) The plant causes convulsions and stupor, with nausea and vomiting (Henslow).

The symptoms observed in cows are loss of appetite, salivation, fever, uncertain gait, and paralysis of hind limbs (Muiller).

Pott refers to a case which occurred in Guernsey among horses. Animals with white muzzles and feet had diarrhœa, while other horses remained healthy. All white places on the body were badly inflamed. Pammel states that the plant causes stupor, paralysis and convulsions in domestic animals.

\section{REFERENCES.}

$$
45,73,81,121,130,141,190,203,213,214 .
$$

Chervils (Chaerophyllum sp.). No investigation of these plants appears to have been undertaken, but $C$. sylvestre L., though eaten by some animals, including the ass and the rabbit, is stated by a German observer (vide Cornevin) to have caused the death of pigs. Müller states that according to the literature both cows and pigs have been poisoned, even fatally, by C. temulum L. The plants have a strong odour and acrid taste.

Toxic Principle. This, if any, appears to be unknown, though Muiller (1897) says that $C$. temulum contains in all its parts the little known Chaerophyllin (? alk.).

Symptoms. The pigs referred to above as having died were said to show paralysis, dilated pupils, and enteritis, and to refuse food. Postmortem examination showed acute gastro-intestinal inflammation. In the case of cows there are similar symptoms.

\section{REFERENCES.}


Hemlock (Conium maculatum L.). This plant, famous from ancient times as extremely poisonous, has a fetid, disagreeable odour-a mousy smell-especially noticeable when the plant is bruised. It has caused human poisoning in three ways: the seeds have been eaten in error for anise, the leaves for parsley, and the roots for parsnips.

Animals rarely appear to eat this plant, but cases have been recorded. It is stated that in the United States many domestic animals have been killed by it; and Ewart says that it is responsible for poisoning a number of cows in Victoria. Goats are believed to be largely immune to the poison, or are less harmed than other animals, and sheep are stated to eat the plant with impunity, though cases of poisoning are recorded. Johnson and Sowerby state that horses have occasionally swallowed considerable quantities without apparent effect, while Cornevin remarks that to cause death a horse would need to eat 4 to $5 \frac{1}{2} \mathrm{lb}$. of the fresh plant, or a cow $8 \frac{3}{4}$ to $11 \mathrm{lb}$.

Hemlock is probably most dangerous to live stock in the spring, when green herbage is least plentiful and the young shoots of hemlock are fresh and short. Chesnut says that the root is nearly harmless in March, April and May, but dangerous later, especially in the first year of growth; but Esser states that it is only poisonous in the spring. The foliage is more poisonous before flowering than after, when the poisonous principle passes to the fruits, which are more poisonous before ripening (three quarters ripe) than afterwards. Pott remarks that after eating hemlock cows give milk with a bad taste.

Toxic Principle. Early in summer the toxic principle appears to be chiefly contained in the foliage, but later in the fruit, particularly when still green. Among the substances contained in hemlock are the toxic alkaloid Coniine $\left(\mathrm{C}_{8} \mathrm{H}_{17} \mathrm{~N}\right)$, the poisonous Coniceine $\left(\mathrm{C}_{8} \mathrm{H}_{15} \mathrm{~N}\right)$, Conhydrine $\left(\mathrm{C}_{8} \mathrm{H}_{17} \mathrm{NO}\right)$, the alkaloid Methylconiine $\left(\mathrm{C}_{9} \mathrm{H}_{19} \mathrm{~N}\right)$, Pseudoconhydrine $\left(\mathrm{C}_{8} \mathrm{H}_{17} \mathrm{ON}\right)$. Coniine may be described as an oily, colourless, quite volatile liquid, quickly turning brown on exposure to the air, and giving a mousy odour to the whole plant. The amount of Coniine in the fresh leaves is given (Pammel) as 0.095 per cent., but in the ripe seeds 0.7 per cent. English fruits contain much more of the total alkaloids than imported fruits. Owing to the volatile character of the poisons hemlock largely loses its toxicity when dried in hay, and is therefore the less likely to prove injurious to domestic animals.

Symptoms. Hemlock is a dangerous narcotic plant. Even the smallest quantities may cause inflammation of the digestive organs, paralysis and death. The general symptoms are salivation, bloating, 
dilatation of pupils, rolling of eyes; laboured respiration, diminished frequency of breathing, irregular heart action; loss of sensation, convulsions, uncertain gait, falling, and at the end complete paralysis. Death occurs after a few hours. The poison acts on the motor nerve endings, causing paralysis, dyspnœe resulting from paralysis of the pectoral nerves, and acceleration of the heart from that of the inhibitory fibres of the pneumogastric.

Small quantities cause in the horse a little prostration, yawning, acceleration of pulse, dilatation of pupils and sometimes muscular spasms of the neck and shoulders. Large quantities cause nausea, unsuccessful attempts to vomit, gritting of teeth, accelerated respiration and dyspnœa, and muscular tremors commencing in posterior members and spreading to anterior members and spine. There is next difficulty of locomotion, sweating (but not continual), falling, paraplegia, then paralysis, loss of feeling, lowering of temperature, rapid pulse, increasingly difficult respiration, and death from stoppage of respiration.

With cattle there is ptyalism, cessation of digestion, bloating, constipation, weakness and stupor. Pregnant cows have been observed to abort; the milk of cows has an unpleasant flavour. There are bloody evacuations in some instances in the case of the ox. In cows Chesnut says that there was "loss of appetite, salivation, bloating, much bodily pain, loss of muscular power, and rapid, feeble pulse."

In sheep the abdomen is tucked up, the animal has a dazed appearance, there is dilatation of pupils, unsteady gait, the hind limbs being dragged, coldness, and death after a few convulsive movements.

In the pig there is prostration and inability to move, coldness, slow breathing, livid mucous membranes, imperceptible pulse, paralysis, particularly of the posterior members, and no convulsions.

\section{REFERENCES.}

4, 16, 52, 53, 73, 81, 82, 91, 128, 141, 161, 203, 205, 213, 238. 


\section{CHAPTER IV}

\section{ARALIACER.}

Ivy (Hedera Helix L.). The berries of the Ivy are said to be largely eaten by certain birds (e.g. blackbirds, thrushes, wood-pigeons), but have poisoned children. The plant has long been said to be poisonous, but no definite case of poisoning of live stock has been discovered; possibly farm live stock would need to eat a considerable quantity for serious effects to be induced. Indeed, when keep is short, it is quite common in some districts to see Ivy strewed on the fields for cattle and sheep to eat, and it is very frequently given to sick animals by country people (Garnett).

Toxic Principle. This has not been closely studied, but ivy contains a bitter principle which is strongly cathartic, emetic and purgative. Ivy contains a poisonous glucoside Hederin $\left(\mathrm{C}_{64} \mathrm{H}_{104} \mathrm{O}_{19}\right)$ and a resin (Gummi hederce).

Symptoms. As suggested above, it is doubtful whether animals have been poisoned by Ivy. Symptoms given appear to refer to children, and consist in sickness, diarrhœa, nervous symptoms, excitement at first, then convulsions and paralysis (Müller). Sickness and purgation (Esser).

Cornevin states that the symptoms are complex, emeto-purgative effects being present, with nervous symptoms resembling those of intoxication, viz. excitement, then coma, convulsions, uncertain gait, and stertorous respiration.

\section{REFERENCES.}

$73,76,81,130,208,240$.

\section{CAPRIFOLIACEE.}

Common Elder (Sambucus nigra L.) and Dwarf Elder (S. Ebulus L.). These two plants are usually avoided by stock, no doubt in view of their odour, more particularly in the case of the latter species. The bark, leaves and berries of both species were noticed by Cornevin as having pronounced purgative properties, and the berries of $S$. Ebulus as having poisoned turkeys. Esser remarks that the use of $S$. Ebulus by 
country folk as a purgative has caused fatal poisoning. The leaves of $S$. nigra have caused severe irritant poisoning in a child.

Toxic Principle. Some doubt exists as to the poisonous principle of the Elders, the leaves of which contain Sambunigrin $\left(\mathrm{C}_{14} \mathrm{H}_{17} \mathrm{O}_{6} \mathrm{~N}\right)$, a cyanogenetic glucoside; the alkaloid Sambucine; and a purgative principle. According to Cornevin drying reduces the toxicity but does not destroy it.

Symptoms. The symptoms are not very definite, but small quantities cause purgation, while large quantities induce depression and violent emetic and cathartic effects, with diarrhœa, abundant diuresis and acceleration of pulse. The leaves of $S$. Ebulus have caused vomiting, obstinate constipation and enteritis in a boy, and in the case of another boy the flowers caused vertigo and headache.

REFERENCES.

$4,73,81,203,233$.

\section{COMPOSITA.}

Tansy (Tanacetum vulgare L.). Live stock are most unlikely to eat this plant, as it is bitter and acrid. Cattle appear to have been poisoned by it in Germany, Kobert's opinion being that death had resulted from tansy. There have also been many serious cases of human poisoning.

Toxic Principle. Tansy contains the bitter, volatile and poisonous Oil of Tansy.

Symptoms. Tansy Oil has been employed as an abortifacient, and produces convulsions, violent spasms, frequent and feeble pulse, and paralysis of the heart and lungs, inducing a condition similar to that observed in rabies.

Pammel cites cases of the action of the oil from the plant on dogs. According to Pott the tansy imparts a bitter taste to the milk of cows which eat it.

\section{REFERENCES.}

161, 203, 204, 213.

Ragwort (Senecio Jacoboea L.). No suspicion appears to have been focussed on Ragwort in Britain, but it must be recorded here as the cause in Canada of the Pictou cattle disease, or hepatic cirrhosis, a somewhat fatal disease which has caused much loss during the last few years. In New Zealand also the same disease has been experienced, and has caused considerable mortality among sheep. In one case sheep 
were closely pastured on about 4000 acres with the object of eradicating the too prevalent weed, but after a year losses ensued. Gilruth concluded that if the weed does not monopolise the ground, sheep may, with few exceptions, eat it daily without suffering ill effects. Cattle and horses avoided it when possible.

It may be remarked that in Britain feeding the young shoots off with sheep, which seem to like the plant, is regarded as the best plan of reducing Ragwort in grass land. So far there seems to be no record of injury from this cause.

In South Africa cirrhosis of the liver in cattle (locally termed Molteno cattle sickness) has been traced to $S$. latifolius, 8 to $10 \mathrm{lb}$. of which in daily feeds of 2 to $6 \mathrm{oz}$. caused death in about six weeks. Another species, S. Burchellii, is similarly poisonous, $\frac{1}{2} \mathrm{lb}$. daily for four days having killed an ox on the fifth day; at Molteno half the quantity proved fatal. Both species are fatal to cattle and horses.

Toxic Principle. As regards S. Jacobøa nothing appears to be known as to any toxic principles, though an alkaloid has been isolated by Watt (1911), but not fully described. The South African S. latifolius, however, was examined at the Imperial Institute, and two new'crystalline alkaloids were isolated-Senecifoline $\left(\mathrm{C}_{18} \mathrm{H}_{27} \mathrm{O}_{8} \mathrm{~N}\right)$ and Senecifolidine $\left(\mathrm{C}_{18} \mathrm{H}_{25} \mathrm{O}_{7} \mathrm{~N}\right)-1.20$ per cent. being present in the plant before flowering and 0.49 per cent. after flowering.

Symptoms. As they may to some extent serve as a guide in relation to possible Ragwort poiscning in Britain the symptoms observed from poisoning by the South African species may be given: Severe and strained purging: fæces yellowish to dark brown; cows cease to give milk; abdominal pain, groaning; animal may go mad and charge anyone approaching, or lie with outstretched head, drooping ears, staring coat, and dull glaring eyes; death usual within three days from commencement of purging. The post-mortem shows an inflamed fourth stomach; hardened condition of the liver, often dull grey with spots in the interior; expanded gall bladder, with dull yellow viscid bile.

\section{REFERENCES.}

$43,128,195,260$.

Wild Lettuce (Lactuca sp.). Just how far the two species $L$. scariola $\mathrm{L}$. and $L$. virosa $\mathrm{L}$. are really poisonous is not clearly known, and it is probable that to be seriously harmful to farm live stock they would need to be ingested in considerable quantity, and this they never seem to be. They are certainly not actively poisonous, though Bailey 
and Gordon say that "we have been informed that this European plant -now a national pest-is sometimes eaten by cattle, on whom it has been observed to have had an injurious effect."

Toxic Principle. Authorities differ as to the substances to which the toxic property, if any, is to be attributed. According to Ludwig the milky juice, known as Lactucarium, includes Lactucone, Lactucin, and Lactucic Acid, the second of these being the narcotic substance. Nearly half the weight of Lactucarium (a form of dried juice) consists of the tasteless inodorous Lactucone or Lactucerin $\left(\mathrm{C}_{14} \mathrm{H}_{22} \mathrm{O}\right)$, and the bitter taste is due to Lactupicrine, Lactucin and Lactucic Acid. In the leaves of $L$. virosa, Dymond found traces of Hyoscyamine or a similar substance (Jour. Chem. Soc., 1892, Vol. 61, p. 90).

Symptoms. Intoxication is produced similar to that caused by poppy heads; the narcotic effects are dominant (Cornevin).

REFERENCES.

$11,73,81,130,213,240$.

\section{ERICACE王.}

Rhododendron (Rhododendron sp.). The literature points to there being no doubt as to the poisonous character of a number of species of Rhododendron, and indeed most species are suspected. Animals do not appear to eat Rhododendrons very extensively, but both English and Belgian veterinary surgeons have published records of poisoning of sheep and goats by $R$. ponticum. Suspected cases were recorded in the Journal of the Board of Agriculture (1907 and 1914); three cases of cattle poisoning in the Veterinary Record (1900, 1906, and 1907); one of calves in the Veterinarian (1859); and three of sheep-poisoning-one in the Veterinary Journal (1906), and two in the Veterinarian (1865); but these cases were not all fatal. The death of 19 out of 21 cross-bred Scotch lambs due to eating $R$. ponticum was reported by C. T. Baines in the Journal of the Land Agents Society (Aug. 1914, p. 373). The plant was eaten after a heavy fall of snow. Chesnut includes $R$. maximum as one of the thirty most poisonous plants of the United States. According to Cornevin, $R$. ferrugineum causes frequent poisoning of animals which graze on the plateaux where it grows-especially sheep and goats, the latter providing the most victims, as they willingly browse the young shoots and leaves. $R$. californicum is said to be poisonous to sheep in Oregon. R. Chrysanthum, the leaves of which 
have been used in Russia and Germany for rheumatism, has caused poisoning in man. $R$. punctatum and $R$. hirsutum appear to be not less poisonous.

Both leaves and flowers are narcotic, and even the honey in the flowers is regarded with suspicion. The following quotations are not without interest:-

"In these regions (Tungu) many of my goats and kids had died foaming at the mouth and grinding their teeth, and I have discovered the cause to arise from their eating the leaves of Rhododendron cinnabarinum ("Kema Kechoong," Lepcha ; Kema signifying Rhododendron); this species alone is said to be poisonous, and when used as a fuel it causes the face to swell and the eyes to inflame, of which I observed several instances." (Hooker, Himalayan Journals, ii. p. 150).

"Rhododendron arboreum becomes plentiful at 5000 to 6000 feet (East Nepal), forming a large tree on dry clayey slopes. . . . . In the contracted parts of the valley the mountains often dip to the riverbed in precipices of gneiss under the ledges of which wild bees build pendulous nests looking like huge bats suspended by their wings; they are two or three feet long and as broad at the top whence they taper downwards; the honey is much sought for except in spring, when it is said to be poisoned by Rhododendron flowers just as that eaten by the soldiers in the retreat of the Ten Thousand was by the flowers of $R$. ponticum." (l.c. i. p. 200).

Toxic Principle. The leaves and flowers contain a bitter poisonous glucoside, Andromedotoxin $\left(\mathrm{C}_{31} \mathrm{H}_{50} \mathrm{O}_{10}\right)$, which has been regarded as more poisonous than Aconitine. Other glucosides found in Rhododendrons are Ericolin $\left(\mathrm{C}_{34} \mathrm{H}_{56} \mathrm{O}_{21}\right)$, Arbutin $\left(\mathrm{C}_{12} \mathrm{H}_{16} \mathrm{O}_{7}\right)$, and Rhododendrin $\left(\mathrm{C}_{16} \mathrm{H}_{22} \mathrm{O}_{7}\right)$, but it is not clearly shown whether these are poisonous when ingested; Kobert, however, includes the two former among cerebro-spinal poisons.

Symptoms. In the case of goats Cornevin records intense pain, diarrhœa, discomfort, gritting of teeth, salivation, and frequently vomiting; while there is reduced lactation, trembling, spasms, vertigo, loss of power, and death. Lander notes similar symptoms in cattle and sheep.

According to Eve (Veterinary Record, 1907), a reddish colour was observed in the milk of a cow poisoned by Rhododendron.

REFERENCES.

$$
\begin{gathered}
4,16,53,63,73,76,81,144,161,170,203,205, \\
211,212,213, .231,252,264 .
\end{gathered}
$$


Azalea (Azalea sp.). A suspected case of poisoning was recorded in the Journal of the Board of Agriculture in 1907. No British record of poisoning has been found. Various species of Azalea (A. pontica, $A$. indica, $A$. arborescens, $A$. nudiflora, etc.) are stated to be very poisonous to all animals which browse on them in the East. Cuttings should never be thrown down where they can be eaten by stock.

Toxic Principle. Little work has been done on these plants, but they are believed to contain Ericolin, Arbutin, and Andromedotoxin as in the case of rhododendrons (p. 47).

Symploms. Azaleas appear to be narcotic, and to produce symptoms resembling those caused by Lolium temulentum (Cornevin).

REFERENCES.

73, 144, 190, 205.

\section{PRIMULACEE.}

Scarlet Pimpernel (Anagallis arvensis L.). Unless it occurs in very considerable quantity this little plant is unlikely to be eaten to an extent sufficient to cause definite poisonous symptoms, as it is a cornfield weed. It may be taken, however, if animals are allowed to run over stubble. Sheep are said to refuse it in general, but have died from eating it (see below).

There seems to be no doubt that if eaten in sufficient quantity it has a poisonous action, having an irritant action on the digestive tractthe intestines-as well as producing narcotic effects. Strasburger notes it as "slightly poisonous"; Bailey says "a dog is stated to have been destroyed by making it swallow three drachms of the extract," while according to Hyams the fluid extract in 4 drachm doses is fatal to dogs (the size of the dog is not mentioned!); at the Veterinary School at Lyons horses were intentionally killed by administering a decoction of the plant; in America Chesnut notes it as suspected of killing a horse; Ewart says it "has been reported to render the chaff from oat crops infested by the weed unpalatable to stock"; and Gilruth states that a year or two ago it was responsible for the death of a large number of sheep in Victoria, apparently acting as a narcotic poison (Amer. Vet. Rev., July, 1913, p. 383.). On the Pacific coast the plant is known as "Poison Weed." Grognier and Orfila are stated to have put its poisonous properties beyond doubt. 
Toxic Principle. The plant contains the glucoside Cyclamin $\left(\mathrm{C}_{20} \mathrm{H}_{34} \mathrm{O}_{10}\right)$, and a saponin-like substance (Pammel). Van Rijn says it contains two glucosides.

Symptoms. The plant has an irritating effect on the intestines and a stupefying effect on the nervous system. Cornevin states that it is never taken by the larger domestic animals in quantity sufficient to cause poisoning.

REFERENCES.

10, 73, 82, 190, 203, 235, 252.

\section{OLEACEÆE.}

Privet (Ligustrum vulgare L.). The facts as to the poisonous character of Privet are by no means clear, but Taylor records a case in which three children who ate the berries were attacked by violent purging, and a boy and girl died. Turner observed a case in which horses died after eating Privet.

Toxic Principle. The Privet is stated to contain the poisonous glucosides Ligustrin and Ligustron, not mentioned by Van Rijn, who says it contains Syringin $\left(\mathrm{C}_{17} \mathrm{H}_{24} \mathrm{O}_{9}\right)$, while Pammel (1911) adds the bitter glucosidal principle Syringopicrin $\left(\mathrm{C}_{26} \mathrm{H}_{24} \mathrm{O}_{17}\right)$.

Symptoms. In horses Turner observed loss of power in the hind limbs, with a pulse of 50 , temperature $102^{\circ} \mathrm{F}$., slightly injected mucous membranes, and dilated pupils, with death in 36 to 48 hours. The berries are stated by Müller to cause sickness and diarrhœa.

REFERENCES.

130, 190, 203, 233, 252.

\section{CONVOLVULACEE.}

Bindweeds (Convolvulus sepium L. and C. arvensis L.). The creeping rootstocks and foliage, as well as the seeds, are held to be more or less poisonous if eaten in quantity, and as long ago as 1872 Olver recorded (Veterinarian, 1872) that pigs which ate freely of Convolvulus died. These species, when eaten in considerable quantity, appear to be cathartic and purgative, causing symptoms resembling those due to jalap.

REFERENCES.

$82,141,190,203,254$.

L. 


\section{SOLANACEE.}

Thorn Apple (Datura Stramonium L.). This species is an escape from cultivation, but on occasion occurs plentifully in gardens, and if allowed to seed may escape to arable fields and find its way to stock, though it does not appear to have done so in Britain. Several species of Datura are recognized as virulent poisons in North America, where they are known as Jimson Weeds. All parts are poisonous, especially the seeds, which have a somewhat sweetish taste, and have frequently caused accidents to children who have eaten them. Cases are recorded in the United States in which cattle have been poisoned by eating the leaves of young plants in hay. Live stock, however, usually avoid the plant, which has an unpleasant odour and taste, while the seeds are enclosed in thorny capsules. Walsh states that the seeds are very fatal to young ostriches. Drying does not destroy the toxicity.

Toxic Principle. The Thorn Apple is usually stated to contain the highly poisonous narcotic alkaloid Daturine, but this appears to be a mixture of the two alkaloids Hyoscyamine $\left(\mathrm{C}_{17} \mathrm{H}_{23} \mathrm{O}_{3} \mathrm{~N}\right)$ and Atropine $\left(\mathrm{C}_{17} \mathrm{H}_{23} \mathrm{O}_{3} \mathrm{~N}\right)$, which, together with the alkaloid Scopolamine, or Hyoscine $\left(\mathrm{C}_{17} \mathrm{H}_{21} \mathrm{O}_{4} \mathrm{~N}\right)$, have been found in the plant, the principal constituent being Hyoscyamine. In some analyses as much as 0.33 per cent. of Atropine has been found in the seeds, and 0.2 per cent. in the leaves (Pammel). The three alkaloids occur together to the extent of 0.48 to 3.33 per cent. in the leaves, 0.43 per cent. in the flowers, and 0.1 per cent. in the root, Hyoscyamine predominating (Esser). An investigation conducted at the Imperial Institute (Bul. Imp. Inst., 1911) showed the amount of alkaloids in European specimens to be:-

$\begin{array}{llll}\text { Seeds } & \ldots & 0.21 \text { to } 0.48 & \text { per cent. } \\ \text { Leaves } & \ldots & \text { up to } 0.4 & \text { average } 0.22 \quad, \\ \text { Stems } & \ldots & \text { average } 0.17 \quad \text { ", }\end{array}$

Symptoms. The general effect of Datura poisoning appears to resemble that of Atropa Belladonna, but is by some considered more rapidly effective. There is paralysis, dilatation of the pupils, suspension of secretion and of the inhibitory fibres of the vagus, leading to rapid action of the heart (Lander). Poisoning may terminate fatally. Pammel quotes Winslow as stating that two grains of Atropine produce mild toxic symptoms in the horse; cattle are as susceptible as horses, though herbivora are not so easily influenced as carnivora. Chesnut gives the 
following symptoms: "Headache, vertigo, nausea, extreme thirst, dry, burning skin, and general nervous confusion, with dilated pupils, loss of sight and of voluntary motion, and sometimes mania, convulsions, and death." Walsh gives the toxic symptoms in ostriches as staggering gait, spasmodic jerking of the neck, stupor, and death in a comatose state.

REFERENCES.

$4,10,16,39,52,53,73,81,92,128,141,170,203,213,260$.

Henbane (Hyoscyamus niger L.). The poisonous character of Henbane is well known, but the plant is by no means common (except in Ireland), though found in parts of England, Scotland, and Wales. Poisoning of live stock may occasionally occur, but the disagreeable odour is likely to prevent all but abnormal or very hungry animals from touching it. The seeds are eaten by birds, apparently without injury, but poisoned chickens which ate the ripe seeds in Montana. Cornevin records that cows have been poisoned by eating the plant when given mixed with other herbage. There are numbers of cases of children having been poisoned by eating the seeds. The root has also caused accidents by being taken for other herbs, and the young shoots and leaves have been used in error as a vegetable. A case was reported in the press in 1910 in which 25 men and women visitors at a Davos pension suffered from the effects of eating the root of Henbane given in error for horse-radish, or mixed with it. All suffered from strange hallucinations, but with prompt and careful treatment all had recovered in twelve hours. Kanngiesser says that poisoning by this plant very seldom terminates fatally.

Welsby records a case in which animals were poisoned in a field in which Henbane was grown for medicinal use some years before (Veterinary Record, 1903). According to Rodet and Baillet (vide Cornevin) small quantities of the seeds are in some countries mixed with the food of fattening stock; if true that fattening is promoted, it is probably due to the inducement to quiet and repose caused by the narcotic properties of the seeds.

Toxic Principle. Poisoning by Henbane is due to the alkaloids Hyoscyamine $\left(\mathrm{C}_{17} \mathrm{H}_{23} \mathrm{NO}_{3}\right)$ and the closely related Hyoscine, or Scopolamine $\left(\mathrm{C}_{17} \mathrm{H}_{21} \mathrm{O}_{4} \mathrm{~N}\right)$. The glucoside Hyoscypicrin is also found in Henbane. The poisonous property is not eradicated by drying or boiling. The leaves of Henbane grown in Europe contain from 0.04 to 0.08 per cent. of total alkaloid, and the seeds 0.06 to 0.10 per cent. (Bul. Imp. Inst., 1911). 
Symptoms. Henbane is an anodyne, and hypnotic. The symptoms resemble those caused by Atropa Belladonna (p. 58). The important differences (Cornevin) are that there is here abundant salivation and no dryness of the mouth as in Atropa. There is dilatation of the pupils; and mydriasis, which is dissipated more slowly than in Belladonna poisoning.

Further differences in the action of the two poisons are given by Winslow (via Panmel): The tetanic stage succeeding spinal paralysis observed in Atropine poisoning does not ensue with Hyoscine. The latter alkaloid slightly depresses and slows the heart and does not paralyse the vagus terminations, nor depress the motor and sensory nerves or muscles. The circulation is but slightly influenced, and vasomotor depression only occurs in the later stage of lethal poisoning. Death occurs from paralysis of the respiratory centres. Poisoning in animals is exhibited by loss of muscular power, slowing and failure of respiration, stupor, and asphyxia. The pulse may be infrequent, the pupils are dilated, and the skin is moist rather than dry.

The following symptoms in animals are given by Welsby: Nervomuscular exaltation, eyelids and irides much dilated, eyes amaurotic and very bright, pulse full, temperature normal, respiration difficult and hurried, profuse salivation, muscles of neck and extremities in a state of tetanic rigidity, considerable abdominal distension, stercoraceous and renal emunctories entirely suspended, death.

In a cow there was observed, two hours after eating, dilatation of pupils, the conjunctivæ were injected, and the carotids beat violently. There were general convulsions, loud respiration, salivation, and purgation. According to Pott the milk of affected cows is of an unpleasant taste.

\section{REFERENCES.}

$4,16,39,57,68,73,81,128,141,151,157$, $161,190,203,205,213,257$.

Garden Nightshade (Solanum nigrum L.). This species is described as "one of the widest spread weeds over every part of the globe, excopt the extreme north and south; varying so much in warmer regions as to have been described under more than forty names" (Bentham and Hooker). In the same way there can be no doubt that, though it must always be regarded as poisonous, this plant varies considerably in toxicity according to soil, climate, and general condition of growth. For this reason the plant may sometimes be eaten in con- 
siderable quantities without ill effects, while in other cases it will undoubtedly prove poisonous.

Children have been poisoned by the berries, but may on occasion eat them with no other ill effect than a stomach ache, or, if eaten in excess, sickness and purging. The berries "have even been used instead of raisins for plum puddings with no effects out of the ordinary" (Ewart). The plant has also been used in Queensland and elsewhere as a substitute for spinach. In several cases the plant has proved fatal. Gohier gave 3 kilogrammes $\left(6 \frac{1}{2} \mathrm{lb}\right.$.) of the green plant to a horse and observed no serious symptoms. Cases of poisoning are recorded for calves, sheep, goats and pigs (Chesnut and Wilcox). According to Lehmann, Schraber and Haller, the berries are poisonous to ducks and chickens. Over thirty years ago the death of a number of cattle in Victoria was recorded as being due to poisoning by this weed.

Though cases of poisoning of stock are rare, partly perhaps because the plant is a weed of arable land and partly because animals are likely to avoid it unless starved, Solanum nigrum must be regarded as a poisonous plant, any examples of which may prove toxic. The downy and more prostrate form has been considered the most poisonous.

The "Wonderberry," said to be a hybrid between Solanum guineense and $S$. villosum, which are probably varieties of $S$. nigrum, cannot in England be distinguished from the last named, the fruits of which appear to be edible in some countries and poisonous in others. Greshoff found that fruits of the "Wonderberry" contained more Solanine than the wild English S. nigrum or the Canadian form known as the "Huckleberry," and hence they should not be eaten.

Toxic Principle. The Garden Nightshade, in particular the berries, contains the alkaloidal glucoside Solanine, of which the formula is considered doubtful. Solanine is readily converted into sugar and the poisonous Solanidine. It was isolated from the berries in 1821, and though decidedly active in sufficient quantity is not a violent poison. A small quantity of Solanine is present in the stem and berries, but these are probably less poisonous than green potatoes (p. 54).

Symptoms. The symptoms of poisoning are apparently much the same in man and animals: "Stupefaction; staggering; loss of speech, feeling, and consciousness; cramps and sometimes convulsions. The pupil is generally dilated."

\section{REFERENCES.}


Bittersweet (Solanum Dulcamara L.). Some doubt exists in regard to the toxic character of this common denizen of the hedge-row, some persons regarding the berries as harmless and others as poisonous. Possibly the plant varies in toxicity. Floyer states that 30 berries killed a dog. Though stock rarely touch the plant there seems to be no doubt that it is poisonous, stem, leaves, and berries containing the toxic alkaloid found in S. nigrum and the potato (q.v.), and it is especially possible that poisoning may follow the ingestion of the berries. Johnson and Sowerby (1861) say that the leaves are narcotic, causing nausea and giddiness, and that the fruit is equally harmful, though no fatal cases then seemed to be recorded. Gillam records (Vet. Record, 1906) a case of poisoning of sheep. An anonymous writer in the Mark Lane Express (July 24, 1911) states emphatically that this plant is very poisonous, and that he has known 14 per cent. of the sheep on a farm to be killed by it in a year, while his veterinary surgeon had had 40 cases that season, some proving fatal.

Toxic Principle. Like S. nigrum, the stems, leaves, and berries of Bittersweet contain Solanine. The berries are stated by Esser to contain 0.3 to 0.7 per cent. of Solanine. The stems also contain the glucoside Dulcamarin $\left(\mathrm{C}_{22} \mathrm{H}_{34} \mathrm{O}_{10}\right)$, which imparts a bitter taste to the plant, but which has not been fully studied.

Symptoms. In the case recorded by Gillam (see above) the symptoms observed in sheep were small intermittent pulse, temperature $104^{\circ} \mathrm{F}$., quickened respiration, staggering gait, dilated pupil, and greenish diarrhoea. The symptoms appear to be the same in the case of cattle (Farmer and Stockbreeder, July 10, 1911).

\section{REFERENCES. \\ $4,16,40,50,52,73,81,141,147,203,213,257$.}

The Potato (Solanum tuberosum L.). Though potato haulm is more or less commonly utilised on the Continent as a green fodder, and has been so used in England, yet there are good grounds for the general belief that it is not a suitable food for stock. The tubers may in general be eaten with impunity, but, under certain conditions, cannot be regarded as blameless, since they have caused serious injury. There are certainly records of injury to man from eating Potatoes, and accidents with animals have occurred more commonly. "Greened" tubers, and tubers with young shoots appear to be the chief cause of accidents, and, as regards live stock, usually when fed raw.

Cornevin knew of no case of poisoning in man, and considered that 
this was probably because man (1) eats only the part poorest in the toxic principle (see below), (2) does not eat the skin, (3) always cooks the tubers, and (4) rarely subsists only on potatoes for a considerable time. He found accidents among animals, however, not rare. In fact, eliminating cases possibly due to changes caused by weather, cryptogams, and ferments, he found poisonings every year unquestionably due to Solanine, chiefly among cattle. Cows will eat the haulm without trouble in times of scarcity of green fodder, but to the detriment of their health if such feeding is prolonged.

Macfadyen showed some time since that old sprouted Potatoes, even after boiling, are poisonous to horses. In 1896 eleven horses died from eating in most instances small quantities of spoiled and somewhat sprouted Potatoes, and two test-horses fed on the Potatoes died. In this case, however, it was conjectured that the poison was probably some organic substance generated by the bacteria or fungi growing on the Potatoes.

Chesnut and Wilcox (1901) recorded the death of six pigs due to eating sprouted uncooked Potatoes; after cooking the potatoes did not cause poisoning. With sufficient boiling most of the poison appears to remain behind in the water and might be thrown away.

Cases of poisoning of stock by Potatoes appear to have occurred more or less frequently in Germany. Two such cases were noted in the Berliner Tierärztliche Wochenschrift in 1909, in one of which 64 cows developed symptoms of poisoning after being fed on a large quantity of raw tubers, while in the other instance two cows became ill after eating Potato parings-which, as shown below, contain more Solanine than the "flesh."

In the case of two children who died, F. W. Stoddart, Public Analyst of Bristol, after a post-mortem in one case, gave a very guarded opinion that death was probably due to Solanine poisoning, due to eating raw Potato peel, but was not confident. A most interesting case of severe but not fatal poisoning is described in The Lancet (1899). No less than 56 soldiers in Berlin were badly affected, until the supply of Potatoes was stopped, but the men recovered.

Pammel (1911) states that some persons cannot eat Potatoes because poisonous to them, but such persons must be extremely rare, and hypersensitive to minimum quantities of Solanine, which is almost if not quite absent in the "flesh" of Potatoes.

Toxic Principle. The Potato plant, like the other species of Solanum mentioned above, contains Solanine, which occurs not only in the 
hauln, but in the flowers and fruits, and in the peel of the tubers. Solanidine also occurs ready-formed in the young sprouts of potatoes to the extent of 1.5 per cent. (Allen). In the case of the soldiers poisoned in Berlin analysis demonstrated the presence of Solanine to the extent of 0.038 per cent. in boiled tubers and 0.024 per cent. in raw tubers, and on an average every man who fell ill had 0.3 gramme of the alkaloid, a sufficient quantity to produce toxic results. Esser (1910) states that in nidsummer the haulm contains 0.0925 per cent. of Solanine but late in summer only 0.0374 per cent. In the tubers the alkaloid occurs in the inner layers of the peel to the extent of 0.0124 per cent., red or pink varieties containing rather more than yellow sorts. The same authority says that damp soils tend to a higher percentage of Solanine than dry soils ${ }^{1}$, and that nitrogenous manuring as compared with potash tends to an increase of Solanine. In fresh spring shoots 1.5 per cent. of the alkaloid has been found, and the percentage is especially high in tubers which have been "greened" by long exposure to light. As already stated it is the greened tubers which appear to be the chief cause of accidents. Tubers with young shoots are richer in poisonous alkaloids than those which have not yet been sprouted; such tubers when fed raw to stock may on occasion induce poisoning, unless fed only in small quantities.

Writing in 1887 Cornevin remarked that Solanine, though neither very active nor very abundant in Potatoes, nevertheless causes accidents, as it is cumulative, or, to be more exact, is eliminated slowly.

Symptoms. In poisoning by potato haulm, Cornevin records constipation, loss of appetite, rise in temperature, accelerated circulation, normal respiration, salivation, tumefaction of eyelids, eyes watery, conjunctivæ injected, and hair erect. The skin is covered with scabs which exude matter, the skin being cracked. These scabs are found especially on the scrotum of male cattle and the udder of female cattle, but also in the caudal region and round the anus. An examination of the mouth shows places on the upper jaw which are devoid of mucus and are purulent at the centre, the mucus round the edges being swollen. The posterior members are similarly but not so badly affected. Movement of these members seems to cause the animal much pain. Defecation is frequent, the fæces being liquid and dark in colour. The animals are recumbent for a considerable time with the posterior members stretched out. In the worst cases there is pronounced emaciation.

1 On the other hand, potatoes grown in a dry sandy soil are stated to contain more Solanine than those grown in other soils. 
According to Friedberger and Fröhner (vide Pammel) animals affected by potato tops show symptoms resembling those of foot-andmouth disease.

According to Pott the berries cause colic and foul smelling diarrhœa in cattle. A German veterinary surgeon after feeding the green plant observed symptoms of delirium, paralysis, and flatulence. In other cases trembling and uncertain gait, with paralysis of the spinal cord, have been observed in cows.

In poisoning by tubers there is depression, loss of appetite, cessation of lactation, gritting of teeth, profound prostration, with a remarkable somnolence, but no dilatation of the pupils. The animals remain recumbent, with closed eyes, and refuse to get up. Respiration is somewhat retarded, and the pulse is small and accelerated. There are digestive disturbances, tympanitis, diarrhœa succeeds constipation, and there is vomiting (where possible). The poisoning is usually fatal.

Where a large quantity of sprouted Potatoes has been fed the prostration becomes paraplegia, with loss of sensibility, stupefaction, and death. Where there is prolonged ingestion of a large quantity of unsprouted tubers there is prostration, intestinal irritation, rapid emaciation and death in marasmus after an illness of from one to three weeks (Cornevin).

Pott states that potatoes diseased with wet rot, when fed raw, cause digestive troubles, bloating, diarrhœa, abortion, and decrease in milk yield, with fatal results in some cases. Potatoes diseased with dry rot cause constipation in sucking pigs, and a "fishy" butter from cow's milk.

Lander notices two cases of poisoning of horses by tubers. In the first case the symptoms were a small and weak pulse, normal temperature and loss of co-ordination in movements; complete loss of appetite, excessive thirst, but inability to drink; mydriasis, stertorous breathing, suspension of peristalsis, and slight tremors over the crural muscles. In the second case there was a rapid and feeble pulse, temperature $103^{\circ} \mathrm{F}$, intense congestion of the mucous membranes, and very fœid diarrhœa, terminating fatally.

In poisoning of horses after receiving large quantities of raw Potatoes, Pott records boil-like swellings on the skin, loss of hair, diarrhœa, inflammation of the stomach and intestines, skin irritation, and swollen fetlocks and hocks.

In reference to the horses mentioned above (p. 55) it is stated that an affected animal seems dull, and dies within twelve hours after being 
first observed, without evincing any sign of pain. The first symptoms in ten cases were weakness and loss of power over the limbs.

In cows the symptoms (Müller) are loss of appetite, bloating, diarrhœa, staggering, dilatation of pupils, convulsions, loss of sensation and paralysis. In many cases, however, these symptoms do not appear, but instead there are outbreaks on the skin of the hind legs similar to those in foot-and-mouth disease. Pott mentions abortion as a symptom. After the ingestion of green Potato parings by dairy cows be remarks catarrh of the stomach and intestines, and bad milk and cheese; consumption of diseased Potato parings resulted in the flow of hard mucus from the mouth, the legs being badly swollen, and covered with scabs, and the mouth and body covered with boils. Symptoms of paralysis were noticed after feeding dirty Potato parings to four cows and four bulls, and one cow died.

In the case of the cows already referred to (p. 55) as poisoned in Germany, it was remarked as a noticeable feature in both instances that there was the appearance of eczema on the hind limbs, causing lameness.

A case in which pigs were fed on uncooked, sprouted Potatoes is noticed by Chesnut and Wilcox; there was slowly progressing paralysis, which became complete after about 24 hours, increased salivation, and a regurgitation of the stomach contents. According to Pott death may result in pigs. The symptoms given by Lander for poisoning in pigs are loss of appetite, dullness, exhaustion, imperceptible pulse, watery diarrhœa, low temperature and comatose condition.

In the case of the poisoned soldiers the symptoms were those of acute gastro-enteritis; rise in temperature to $103^{\circ} \mathrm{F}$; headache, colic, diarrhœa, general debility; in some cases vomiting, in others nausea only; several men fainted, and one had convulsions; the majority were drowsy and apathetic; but all recovered.

REFERENCES.

$4,16,19,57,73,81,128,130,14 \mathrm{~J}, 170,190$, 196, 203, 204, 205, 213.

Deadly Nightshade (Atropa Belladonna L.). This plant has long been known to be exceedingly poisonous, all parts containing a toxic principle. Both man and domestic animals may be poisoned, though the latter are very unlikely to touch the plant. As regards man, children are most likely to be affected, owing to the attractive character of the large bright black berries. Domestic animals appear to be rarely poisoned and are less affected than man, and in any case the susceptibility 
of various species-and even individuals of the same species-is very variable. Human beings are most susceptible, followed by the cat and dog; the horse is much less so; and the pig, goat, sheep, and rabbit are little susceptible to poisoning, even on eating the root-the most poisonous part (Cornevin). Gohier and others have given over $2 \mathrm{lb}$. of the green plant to horses without ill effects, and this repeated on three days did not cause marked pathological troubles. Hertwig considered large ruminants to be more sensible than horses to the action of Belladonna. It appears to be agreed that small ruminants are very slightly susceptible to this plant. Birds are considered almost insensitive, while rabbits may be fed for weeks on the leaves without poisoning, as also sheep, goats, and pigs. Horses and cattle are more sensitive but nevertheless resistant. The poison is no doubt quickly removed by the kidneys, since ordinary injection of Belladonna causes the usual symptoms. It is stated that the flesh of rabbits and birds which have eaten the plant and have been slaughtered apparently healthy is poisonous to man.

One berry can induce symptoms of human poisoning, and a child died after eating only three berries. Mortality in human cases of poisoning by Belladonna is given by Kanngiesser as 10 per cent.

Toxic Principle. Deadly Nightshade is the source of drugs widely used in medicine, and its properties as regards man have been extensively studied. The principal substance present is the alkaloid Hyoscyamine $\left(\mathrm{C}_{17} \mathrm{H}_{23} \mathrm{O}_{3} \mathrm{~N}\right)$, readily converted into Atropine $\left(\mathrm{C}_{17} \mathrm{H}_{23} \mathrm{O}_{3} \mathrm{~N}\right)$; Scopolamine or Hyoscine $\left(\mathrm{C}_{17} \mathrm{H}_{21} \mathrm{O}_{4} \mathrm{~N}\right)$, and in smaller quantity Apoatropine, and Belladonine are also present.

All parts of the plant contain the toxic alkaloids, but in unequal degree. The total quantity of the alkaloids is largest in the roots ( 0.4 to 1 per cent.), which in the fresh state contain no Atropine, but only Hyoscyamine; the leaves and fruits contain less of the alkaloids, and cultivated plants have been found to be poorer $(0 \cdot 26$ per cent. $)$ than wild $(0 \cdot 4$ per cent). The root has been found to be five times as toxic as the berries. Drying does not destroy the poisonous properties.

Symptoms. In quantities which are not fatal the symptoms are nausea, dilatation of pupils, muscular weakness, stumbling, falling, and rising only to fall again. These are followed by vertigo, frenzy, and coma (more rarely). There is a slight slackening in respiration, and an increase in the rapidity of the heart's action. Dysury and constipation are observed.

In fatal quantities the symptoms are more intense and make their 
appearance more rapidly. The nausea is accompanied by vomiting, and there is almost complete loss of sight. Sensitiveness is at first increased but later diminishes and gradually disappears; complete incoordination of movements; increase in the heart's action but a gradually weakening pulse; stertorous, painful respiration; decrease in temperature. There is repeated urination at the commencement of the poisoning, and then dysury. At the approach of death there are muscular trembling and clonic contractions. This phase of convulsions is short but very clear in some cases: other cases do not leave the deep coma in which they are plunged (Cornevin).

In regard to cattle, the following symptoms are given by Müller: Injury to sight, dilatation of pupils, constipation, later bloody evacuations, pain in hind limbs, rapid pulse, difficult breathing, restlessness, frenzy and finally paralysis.

\section{REFERENCES.}

$4,16,61,73,81,128,138,143,151,157,161,190,205$. 


\section{CHAPTER V}

\section{SCROPHULARINEE.}

Foxglove (Digitalis purpurea L.). The Foxglove has been recognized as poisonous for centuries, and one of its trivial names is Dead Men's Bells-a name suggestive of the consequences of taking it. It is the source of the well-known drug; and cases of human poisoning have been very common, though by no means always fatal-indeed, Esser says "seldom resulting in death." Animals are not known to touch this plant, but it may possibly be included in rough meadow hay, though only one case, in which two cows and a horse became ill after eating hay containing dry foxgloves, has come to notice (Veterinary Record, 1906). Cornevin, however, experimented on animals, and found the following amounts of fresh leaves capable of causing death in the animals specified:-

$\begin{array}{llrll}\text { Horse } & \ldots & 120-140 \text { grammes } & (4 \text { to } 5 \text { oz. }) \\ \text { Ox } & \ldots & 160-180 & & (5.5 \text { to } 6.5 \mathrm{oz} .) \\ \text { Sheep } & \ldots & 25-30 & , & (0.88 \text { to } 1 \text { oz. }) \\ \text { Pig } & . & 15-20 & , & (0.5 \text { to } 0.7 \mathrm{oz} .)\end{array}$

The weight of dried leaves would be only one-fourth of these figures.

All parts of the foxglove are poisonous, but especially the seeds, and the leaves are more active before than after the flowering period. Cultivated varieties are stated to be less toxic than the wild species. The effects of poisoning may terminate fatally in a few hours, or if small quantities are taken regularly the poison may be cumulative and induce chronic poisoning.

Toxic Principle. The foxglove contains several poisonous glucosides, investigated by Kiliani, Schmiedeberg, Cloette, Bourquelot, Herzig, and others. The following substances are toxic: Digitalin $\left(\mathrm{C}_{35} \mathrm{H}_{56} \mathrm{O}_{14}\right.$ or $\left.\mathrm{C}_{36} \mathrm{H}_{58} \mathrm{O}_{14}\right)$ in the seeds and leaves; Digitonin $\left(\mathrm{C}_{54} \mathrm{H}_{92} \mathrm{O}_{28}\right.$ or $\left.\mathrm{C}_{55} \mathrm{H}_{94} \mathrm{O}_{28}\right)$ in the seeds; Digitalein, only in small quantity; Digitoxin $\left(\mathrm{C}_{34} \mathrm{H}_{54} \mathrm{O}_{11}\right)$ in the leaves; and Digitin. The toxic property of the foxglove is not lost on drying or boiling. 
Symptoms. Digitalis is an active heart poison, and causes nausea, pressure in the region of the stomach, with diminished pulse, darkening of the field of vision, dizziness, buzzing in the ears, and usually dilated pupils.

According to Pammel the symptoms in animals are dullness, lassitude, loss of appetite, nausea, flatulence, diarrhœa; infrequent, full pulse (reduced $6-10$ beats in the horse); and contracted pupils. In fatal cases these symptoms are followed by severe colic and tympanites; rapid, feeble, dicrotic, irregular or intermittent pulse (120-140 in horses), while the heart may be heard and felt beating wildly and strongly, and a systolic blowing murmur can frequently be detected. This is due to mitral or tricuspid regurgitation caused by irregular contraction of the columnæ carnæ. The pulse is imperceptible because of the failure of the heart to fill the vessels. The extremities are cold, the eye is protruding, and salivation occurs. Bloody diarrhœa is very often present and the urine may be suppressed. The breathing finally becomes difficult and death ensues within a few hours, or as late as several days.

The following account of the symptoms of poisoning in various animals is collected by Lander:-

Horses. On the first day sleepiness, swollen eyelids, dilated pupils, injected conjunctivæ, considerable swelling in submaxillary space; respiration normal, temperature $103.5^{\circ} \mathrm{F}$; ; pulse full, between 65 and 75 , very intermittent, being occasionally normal; the second heart sound frequently obliterated. On the next day laboured breathing, head immensely swollen, tongue greatly enlarged and protruding, pulse 80 and most erratic, temperature very slightly up, great restlessness. Respiration became more difficult and stertorous, tongue and buccal membranes livid, jugular standing out.

A mare experimentally poisoned showed on the third day dullness and loss of appetite; fourth day nauseated; nose, mouth, and ears cold; abdomen blown, with colicky pain, and occasional pawing; pupil somewhat contracted, pulse firm at axilla and heart, but not perceptible at jaw; at 4.30 p.m. she was down, much pained, and attempting to roll; pulse 82 , but unequal; fifth day, pulse, imperceptible at jaw, about 120; respiration 25, and very much laboured: lips retracted and saliva dripping from the mouth; enormous abdominal tympanites, and much pain; rapid sinking: died sixth day.

Cows. Fed erratically, breathed hard, lay down after feeding. Pulse almost imperceptible, contracted pupil, and excessive urination.

Pigs. Languid and sleepy: refused to eat or drink, attempting to 
vomit and repeatedly passing small quantities of fæces. Urination was scanty and strained.

In a case of poisoning among horses to which Müller refers the animals had an exhausted appearance, there was loss of appetite, increasing thirst, often also colic, and later diarrhœa, urination often in great quantity, and staggering. Some of the animals died after a few days in convulsions.

\section{REFERENCES.}

$4,16,73,76,79,81,161,170,187,190,203$, $204,205,213,229,252,257$.

Lousewort (Pedicularis, sp.). Two species of lousewort are involved, $P$. palustris $\mathrm{L}$. and $P$. sylvatica L., and though both are regarded as poisonous the extent to which they are so is not well known. They have an unpleasant smell and sharp taste, and are in general refused by all classes of stock. P. sylvatica may be eaten when young (Cornevin). Lindley says that both plants are acrid, but are eaten by goats. $P$. palustris is regarded by Pott as an acutely poisonous plant, especially for sheep. A decoction of these plants was formerly used against lice, and hence the trivial name.

Toxic Principle. Very little appears to be known about the poisonous principle, but, like Rhinanthus and Melampyrum, they have been found to contain the glucoside Rhinanthin (see p. 96).

Symptoms. The plants are held to be emetic and purgative; to cause inflammation of the digestive tract, and to cause anæmia in cattle. Brugmann stated (vide Cornevin) that if, pressed by hunger, animals eat $P$. palustris, the first consequence is hæmaturia. Muiller also notes hæmaturia.

\section{REFERENCES.}

$73,76,81,190,203,213$.

\section{POLYGONACEÆ.}

Docks (Rumex sp.). In general it is probable that but little harm is done by species of Rumex, but owing to the fact that Common Sorrel (R. Acetosa L.) and Sheep's Sorrel (R. Acetosella L.) contain acid oxalates they may on occasion prove injurious. Instances have been recorded in which children have suffered from eating the leaves of the former species in considerable quantity, and both species have been accused 
by veterinary surgeons of poisoning horses and sheep, some sheep even dying. Pammel states that the Curled Dock (R. crispus L.) induces nausea, watery brown frecs, copious urination, dry spasmodic cough, and perspiration; but no record of the death of animals has been found.

In regard to $R$. Acetosella it is stated that in the horse a condition may be produced resembling drunkenness, with vacillating gait, salivation, muscular tremors, dilatation of pupils, relaxation of sphincters, and a feeble, slow, and intermittent pulse: then convulsive contraction of lips, retraction of the eyeball, accelerated and stertorous breathing, extreme dilatation of the nostrils, tetanic contraction of the muscles of the neck, back, and limbs, abundant sweating and falling. In bad cases after a period of extreme exhaustion, these symptoms are repeated, and death occurs in convulsions (Cornevin).

The acid oxalates seem especially harmful to sheep, causing loss of appetite, cxhaustion, small and scarcely perceptible pulse, rapid breathing, and constipation, and in many cases severe diarrhœa, uncertain gait, and sometimes death (Müller).

The milk of affected cows is with difficulty made into butter (Pott). REFERENCES.

73, 14I, 190, 203, 233.

Polygonum sp. Several species of Polygonum are said to have poisonous properties. The chief among them is Buckwheat ( $P$. Fagopyrum), the grain of which is widely grown as a food for both man and live stock. This plant, particularly the flowers, has given rise to a well-known rash in man, cattle, sheep, and pigs, with congestion and tumefaction-especially of the head and ears. There is also nervous disturbance, with agitation and hallucination-sheep, for example, may butt against objects. The affection of the nervous centres may lead to fatal results, which have followed in cattle, sheep, and pigs. Little is known of this so-called Fagopyrism, but after analytical and spectroscopical researches on the colouring matter of the tegument Kurt concluded that it is due to the chlorophyll.

Persicaria ( $P$. Persicaria L.) and Water-pepper ( $P$. hydropiper L.) are also stated to be harmful, though the former has been considered a nutritious plant and has been given to horses and cattle as a green food.

Both species, however, are said to cause a rash, and to contain injurious narcotic substances. Persicaria is stated by Müller to have caused inflammation of the bladder and the digestive tract in pigs, and 
Water-pepper to have caused hæmaturia; fatal results have followed. Pott records similar symptoms. In regard to Persicaria it should be noted that it varies considerably in general form, and may possibly vary also in acridity. Bentham and Hooker state of $P$. hydropiper that "the whole plant is more or less acrid or biting to the taste."

REFERENCES.

$17,19,73,190,201,213$.

\section{THYMELACER.}

Mezereon (Daphne Mezereum L.) and Spurge Laurel (D. Laureola L.). Both of these species are acrid and poisonous, and cases of the death of horses due to the spurge laurel are recorded by Lander. In general, however, animals will not eat the plants, and indeed, in one of the cases mentioned by Lander the dried leaves were administered for worms. Should they touch these plants most animals would probably refuse them on account of their bitter taste. The berries are tempting to children, and Pratt says "Death has resulted from eating but a few of these berries (D. Mezereum); and Dr Christison relates a case of a child, in Edinburgh, who died from eating them, while another is recorded by Linnaeus of a young lady to whom twelve of the berries were given as a medicine in intermittent fever, and who soon died in consequence of their corrosive poison. Four berries produced thirst, sense of heat in the mouth and throat, and also fever, in a man who ate them; and they are proved to be poisonous to dogs and foxes." Blyth states that 30 grammes ( $1 \mathrm{oz}$.) of the powdered bark is a lethal dose for a horse, but smaller doses of the fresh leaves may be deadly (Pammel).

Toxic Principle. All parts of these plants are acrid and poisonous, especially the bark and berries. They contain the bitter, astringent, and poisonous glucoside Daphnin $\left(\mathrm{C}_{30} \mathrm{H}_{34} \mathrm{O}_{19}\right.$-or $\mathrm{C}_{15} \mathrm{H}_{16} \mathrm{O}_{9}$ according to Van Rijn), an acrid resin (Mezerein), and a vesicating fatty oil. (Pott remarks that Daphnin is believed to be harmless, but that Mezerein has poisonous effects.) Drying does not destroy the poisonous property.

Symptoms. The Daphnes are severely purgative, cause burning in the mouth and throat, and in severe cases have narcotic effects and give rise to convulsions.

Lander gives the symptoms as intense colic, constipation, followed by dysentery and copious evacuations of fæces streaked with mucus, blood, and intestinal epithelium. Drowsiness between the spasms. 
According to Müller there is inflammation of the stomach and intestines (with colic, vomiting, severe diarrhœea, passing of blood), inflammation of the kidneys (with strangury, bloody urination), and in many cases nervous symptoms (weakness, giddiness, and convulsions).

In a case observed by Lander, in the horse, there was abdominal pain, staggering gait, anxious countenance, laboured breathing, pulse 80 , temperature $103 \cdot 2^{\circ} \mathrm{F}$., bowels normal. On the following day there was excessive purgation, pulse 120 , temperature $104 \cdot 2^{\circ} \mathrm{F}$, and death occurred at mid-day.

REFERENCES.

$73,76,81,130,141,170,190,203,213,216,240$.

\section{EUPHORBIACE屟.}

Spurges (Euphorbia sp.). Many species of Spurge must be regarded as acrid, purgative, and poisonous. Live stock are not likely to touch them, owing to the acrid effect of the milky juice on the mouth.

The Caper Spurge ( $E$. Lathyris L.) contains an acrid, emetic, and highly purgative milky juice, and the fruits have commonly been employed by country folk as a purge, and also as a pickle, though they are dangerous and should not be so used. Pratt records a case in which five women ate the pickled fruits with boiled mutton, and all suffered severe pain and burning in the stomach, and showed other symptoms attendant on irritant poisoning-and though all recovered the illness was severe. Used in this manner, indeed, they have given rise to serious cases of human poisoning. Only very young animals are said to eat it, but cattle in the United States are said to be "quite resistant to its influence, but they are sometimes overcome." According to Chesnut goats eat this plant extensively, and it is said that their milk then possesses all the venomous properties.

Petty Spurge (E. Peplus L.) is somewhat similar to the Caper Spurge in poisonous properties, and fatal poisoning has occurred through a boy eating it.

Sun Spurge (E. Helioscopia L.) is similarly poisonous to the preceding species. It has caused fatal poisoning to a boy who ate it. In Germany cows were poisoned through pasturing in stubble in which the plant was growing, but there were no deaths.

Toxic Principles. The milky juice of these spurges contains highly acrid poisonous substances, which have not been individually and fully investigated. Drying may reduce the toxicity but does not eliminate it. 
Symptoms. As regards $E$. Lathyris Chesnut says that on the skin the juice causes redness, itching, pimples, and sometimes gangrene. The seeds when eaten inflame the mouth and stomach, cause vomiting and intense diarrhœa, and if the illness is serious, nervous disorders, unconsciousness, collapse, and death.

The Euphorbias have an acrid effect on the mouth, and severe poisoning may follow their use as aperients-burning mouth, swelling tongue, stomach pains, cold skin, vertigo, fainting or syncope, and even death in two or three days (Esser).

Similar symptoms are given by Cornevin, who states that the Euphorbias have an irritating effect on the mucous membrane, especially at the back of the mouth. In from three quarters of an hour to two hours after eating the plant, or even longer, there is painful vomiting, followed by diarrhœic evacuations, with a lowering of the temperature. If the quantity ingested has been sufficient there appear also nervous symptoms, vertigo, delirium, muscular tremors, and respiratory and circulatory troubles which disappear after abundant sweating if the poisoning is not fatal. If it is fatal the symptoms of superpurgation and enteritis predominate, but are accompanied by nervous symptoms and circulatory disorders.

Müller gives in addition loss of appetite, piteous whining (in goats), groaning, colic and tympanites; and Pott, bloating, fever, palpitation of the heart, and loss of consciousness. Cows gave a reddish or sharptasting milk. Milk of affected goats caused diarrhœa in human beings.

REFERENCES.

$19,52,53,73,81,82,130,141,190,213,216$.

Dog's Mercury (Mercurialis perennis L.) and Annual Mercury (M. annua L.). These two species may be taken together as they have similar poisonous properties, and closely resemble one another, though the former is a perennial and the latter an annual. The plants have a somewhat unpleasant odour, and live stock are not likely to take them unless pressed for readily available green food. The loss of one cow and severe illness of four others was recorded by Blackhurst in the Veterinary Journal in 1896; Güssow mentioned the loss of cows in the Farmer and Stock Breeder Yearbook, 1907; the loss of horses fed on herbage cut from a hedge and containing $M$. perennis was recorded in the Journal of the Royal Agricultural Society in 1898; the loss of sheep was recorded by Henslow. As regards man, Ray records a case in which a family of five persons suffered severely from eating $M$. annua fried 
with bacon. Fishermen ate it with soup and all were seriously ill an hour later, with symptoms of irritant narcotic poisoning; two children died the next day. Cornevin saw $M$. annua used, after boiling, as a food for pigs, without ill consequences, in the east of France. This is believed to be due to the poison being volatile and destroyed by heat or boiling; hence in hay the plant is harmless, though Pott says that even in hay stock avoid it.

Toxic Principle. The poisonous properties are said to be due to Mercurialine, Oil of Euphorbia, a volatile toxic alkaloid. Esser states that the stem and leaves of $M$. annua contain Tiimethylamine, which may perhaps be a decomposition product of Choline, a poisonous base.

Symptoms. Both plants are emetic and dangerously purgative, causing irritant and narcotic symptoms. Veterinary observation has shown that the poison is cumulative, and that it is usually after the weed has formed part of the food for 7,8 , or 10 days that symptoms first appear. In the case recorded by Blackhurst (see above) the cows suffered from inflammation of the digestive tract, with severe purging and loss of blood. The secretion of milk entirely stopped. One cow died, but three recovered in about four days. The fifth was not convalescent for three weeks and then had a permanently curved and injured neck, the muscles being subsequently found rich in fibrous tissue, and the last three joints partially anchylosed. Rabbits were tested by feeding two on the leaves, two on the stems and roots, and two on the ground seeds mixed with oatmeal; the first two were unaffected, but the other four died in a few hours, showing drowsiness and suffering, while the post-mortem showed gastritis.

The digestive and urinary tracts are affected. There is indigestion with slight bloating, then colic of varying intensity, and at first diarrhœa which may give place later to constipation; hæmaturia; micturition is frequent, painful, and the urine is blackish and bloody; dullness, weakness, loss of appetite and refusal of food; the heart beats very strongly, the pulse is rapid, and the mucous membrane of the eye is reddishyellow in colour. There is no modification of respiration (Cornevin).

According to Müller, however, the symptoms at first include constipation and later severe and bloody diarrhœa.

In cattle Pott states that $M$. annua causes inflammation of the stomach and intestines, bloody urine, paralysis of bladder, fœtid diarrhœa, abortion, and bluish coloured milk deficient in fat. Müller states that there is occasionally blood in the milk. According to Lander there is in cows excessive bloody purgation, cessation of lactation, temperature 
$105^{\circ} \mathrm{F}$., pulse 90 , and increased respiration. The illness is protracted over several weeks, the animals being comatose after the first symptoms.

REFERENCES.

$73,81,112,130,146,170,190,205,213,255$.

Box (Buxus sempervirens L.). Farm live-stock may occasionally have the opportunity of browsing on box, or clippings may be thrown to them with other green herbage from gardens. Care should be taken that clippings are otherwise disposed of. All parts of the plant are bitter and have been proved to be poisonous. The bitter taste tends to prevent animals eating sufficient of the plant to cause serious injury. Pigs have died a day after eating the leaves. Horses also were killed by eating 750 grammes (1.6 lb.) of the foliage.

Toxic Principles. Faure found in the bark and leaves of box the toxic alkaloid Buxine, but it was believed that there were other toxic substances, since analysis showed the leaves to be less rich in Buxine than the bark, while they are three times as active. Other substances occurring in box are Parabuxine, Buxinidine, and Parabuxinidine.

Symptoms. Small amounts have an emetic and purgative action; with average amounts, there are, in addition, nervous symptoms, lameness, muscular tremors, vertigo, then a period of coma. Large amounts cause death with intense abdominal pains, dysenteric flux, tenesmus, convulsions, respiratory and circulatory troubles.

Pigs are chiefly affected after eating the leaves, exhibiting great thirst, uncertain gait and delirium, while death occurs within twentyfour hours.

Pott gives the general symptoms as sickness, diarrhœa, giddiness, stupefaction, convulsive movements, and colic.

REFERENCES.

$4,16,73,128,190,205,213,235$.

\section{AMENTACEÆ.}

The Oak (Quercus sp.). Injury to stock from the Oak has been due in the first place to the leaves, and in the second to the acorns. In regard to the leaves no injury appears to have been recorded in Britain, but Cornevin devotes attention only to poisoning by the leaves, which in special circumstances have caused serious accidents to animals which 
have eaten them. In France, cattle taken to the forests for grazing purposes browse on the young shoots and leaves of the oak, and after some days there arises a trouble long known as Mal de Brou or Maladie des Bois, which may end fatally, sometimes even in 24 hours (see Symptoms below). A case was also reported from Nebraska in 1903, ten head of cattle having apparently died from eating oak leaves, the trimmings from trees. The stomachs were full of the leaves, and the intestines had the appearance of being burned in places. There was no evidence of impaction. When the cut branches were removed no more cattle were lost.

Serious losses have been caused through the ingestion of acorns by young cattle not over about two years old, the years 1808, 1870, 1884, and 1900 being especially noteworthy in this respect. Cattle over three years old have seldom been affected, while sheep and pigs, if not immune to "acorn poisoning," are but slightly affected. Müller, however, states that horses, cattle, sheep, and goats are affected; 9 quarts (10 litres) taken in four days were sufficient to cause poisoning in the case of a bullock. It is believed by some observers that half-ripe acorns - e.g. acorns which may drop owing to drought-are more injurious than thoroughly ripened acorns.

Some authorities appear to be of the opinion that "acorn poisoning" is not actually poisoning, but a serious form of indigestion. If this be so the symptoms must be regarded as exceedingly severe. There is no doubt that "acorn poisoning" is not well understood, but a great deal has been observed and written on the subject, and there is clear evidence that acorns may reasonably be held to be poisonous. It must be pointed out, however, that the poisoning does not usually follow on the consumption of acorns in small quantities, but is commonly due to full meals of acorns taken in periods when there is a dearth of herbage. By proper preparation and storage acorns have been converted into a most useful food for horses, cattle and sheep (Jour. Bd. Agric., Sept. 1914 and Feb. 1916, and Leaflet No. 291 of the Bd. Agric., The Food Value of Acorns, Horse-Chestnuts and Beech Mast). In Germany it has been found that acorns fed to fowls caused diminished egglaying, which finally ceased, while the yolks of eggs laid were discoloured a dirty brown (Jour. Bd. Agric., Dec. 1915, p. 902).

Toxic Principle. The facts as to acorn poisoning and oak-leaf poisoning are not clearly known, and the actual toxic substance is similarly not certainly known. It is probable, however, that it consists of Tannin, or substances which give rise to Tannin. 
Symptoms. In relation to Maladie des Bois due to leaves, Cornevin gives the symptoms as loss of appetite; less (and more difficult) rumination; constipation, which increases; lying down, animals looking at their flank as in colic, followed by rising and attempts to urinate, with passing of rosy-coloured liquid in jets; loss of milk production, which may drop to nothing; fever, trembling, enfeebled condition.

Three or four days after the commencement of illness rumination is completely suspended; there is stamping of the feet, colic, retracted stomach, pulse hard, heart agitated, accelerated respiration, violent muscular shocks, and frequent urination. The urine is always dark in colour, but varies from clear red to dark black, nut-brown being usual. Cases are only serious when a foetid, frothy, and abundant dysentery succeeds constipation, in which case there is rapid emaciation and death.

Usually the course of the illness is not rapid; but occasionally thene is immediate and bloody urination with violent colic and sometimes intestinal hæmorrhage, death occurring in 24 hours.

In poisoning by acorns there is progressive wasting, entire loss of appetite, diarrhœa, discharge of an excessive quantity of pale urine, sore places inside the mouth, discharge from the nostrils, and also from the eyes, which are always sunken, giving the animal a peculiar haggard expression. There is no fever; on the contrary, the temperature is commonly below normal, though in some cases stated to be above normal.

Müller remarks on the severe constipation, followed by dysenteric diarrhœa, caused by acorns, especially when eaten in the half-ripe condition, horses, cattle, sheep, and goats being affected.

The experimental poisoning of a young steer and a young sheep by fully ripe acorns was described in 1871 (Jour. R.A.S.E., 1871). In the steer the symptoms were a semi-conscious condition, weak pulse, pallid membranes, cold surface of body, torpid bowels, slow breathing, twitchings of muscles, and a disposition to maintain a recumbent position. Inflammation was entirely absent. The symptoms increased in severity day by day; there ensued a copious flow of colourless urine; a mucopurulent discharge from the eyes and nostrils. No impairment of health followed the feeding of acorns to the sheep.

Thorburn (Veterinary Journal, Feb., 1902) mentions loss of appetite, grunting, disinclination to move, prostration, icy coldness of extremities, very rapid emaciation (this sometimes was particularly noticeable), pulse very small and weak (in some cases almost imperceptible), temperature high $\left(105^{\circ}\right.$ to $\left.107^{\circ} \mathrm{F}.\right)$ ) and constipation succeeded by watery diarrhœa. 
Brookes and Yeomans described (Veterinary Journal, 1912) an instance in which 30 animals were affected and 9 died. The chief symptoms were a dull and depressed appearance, entire absence of appetite and rumination, a weak feeble pulse, subnormal temperature and disinclination to move. Three cases showed a mucous and bloodtinged discharge from the nostrils and anus, and these all died, one eight days after being seen and the other two the day afterwards. Obstinate stoppage was noticeable in all cases, and the fæces were inky black, stinking and very thick. Yeomans observed similar symptoms of acute digestive disturbance; later the eyes had a sunken appearance, diarrhœa set in, the fæces being dark coloured, offensive and bloodstained. The temperature was at first normal and later subnormal, and in fatal cases death took place in from 3 to 7 days.

REFERENCES.

$4,13,20,26,29,70,73,130,144,190,240,255$.

\section{CONIFERA.}

The only Conifer which commonly causes poisoning of live-stock is the Yew, but injury might more frequently occur were it not for the fact that Conifers generally are unpleasant to the taste, and are hence avoided by stock. Many species, however, contain Tannin, Resins and Gums, Volatile Oils, and an acrid substance which may cause inflammation of the digestive and urinary tracts, while Tanret found in the young shoots of Picea the bitter glucoside Picein $\left(\mathrm{C}_{14} \mathrm{H}_{18} \mathrm{O}_{7} \mathrm{H}_{2} \mathrm{O}\right)$; Kawalier and Thal found the intensely bitter glucoside Pinipicrin $\left(\mathrm{C}_{22} \mathrm{H}_{36} \mathrm{O}_{11}\right)$ in Pinus sylvestris, Thuja occidentalis and Juniperus Sabina; and Kubel isolated Coniferin or Abietin $\left(\mathrm{C}_{16} \mathrm{H}_{22} \mathrm{O}_{8}\right)$, a slightly bitter glucoside found in Abies excelsa, A. pectinata, Pinus strobus, Larix europcea and other conifers. It is not clear, however, whether these substances are at all poisonous. It is quite possible that if eaten in quantity the foliage of some Conifers may induce poisonous symptoms and even death in the animals concerned. It is noteworthy, however, that according to Pott the needles of Picea excelsa, Abies pectinata, Larix europcea, and Pinus sp. are, in the mountainous districts of Steiermark, Kärnten, and Tyrol, extensively fed to cattle and sheep, usually as a supplementary food, either fresh or dried and ground up-chiefly perhaps as an appetiser, and in small quantities as a dietetic; Juniperus sp. are similarly utilised in some districts. It is not known to what extent the foliage may be 
fed without harmful consequences, but Pott states that large quantities can cause hæmaturia and similar effects, and hence only small quantities should be used, and even so may impart a bad flavour to the milk of cows. All green needles frequently cause digestive troubles.

A case has recently (January, 1916) been reported to the author in which a Douglas Fir was cut down and a small branch about $4 \mathrm{ft}$. long was flung over into a field. Two sheep nipped off the bark and nearly died, but both vomited and recovered. The farmer reporting this experience recalls that over 30 years ago, after a gale, a lot of trees were blown down in a small plantation, and in severe weather the sheep ate the bark to such an extent that 80 of them aborted, while of the ewes which did not eat the bark none aborted, so that it would appear that the bark of Scotch Fir and Spruce was to blame for the loss.

The foliage of the Yew (see below) is well known to be dangerously poisonous to stock, and has caused many losses.

In regard to Cupressus the only cases of poisoning which have been traced are recorded in The Journal of the Board of Agriculture (October, 1905). These cases were reported as follows:-

"Two instances have recently come before the Board in which the death of cattle has been attributed to the poisonous effects of Cupressus macrocarpa and $C$. nootkatensis. In one case four bullocks died, and on the internal organs being forwarded by the owner to the Royal Veterinary College, Professor McFadyean reported that from the inflamed condition of the fourth stomach and from the description of the symptoms he had little doubt that the cause of death was irritant poison. Some pieces of Cupressus macrocarpa were found in their stomachs, and in default of any other explanation it was suggested that this plant might have some poisonous properties.

"In another case three heifers are stated to have suffered from irritant poison; one of them died, but the other two recovered on removal to another field. The veterinary surgeon in this case also attributed the death to a Cupressus (C. nootkatensis) growing by the side of the field.

"The Board have no information as to the poisonous properties of these two species, nor can any record be found of any similar case which would tend to confirm the suspicion that they are poisonous to cattle."

REFERENCES.

$4,16,76,144,213,252$.

Yew (Taxus baccata L.). As stated above, the Yew is the only British conifer that is likely to prove seriously poisonous to live stock. 
It has unfortunately caused the death of many horses and cattle, while asses, mules, deer, pigs, rabbits, and pheasants have also been poisoned. Many cases of fatal human poisoning have also occurred. For example, the poisoning of a horse, and of cattle, horses, and deer were mentioned respectively in 1885 and 1893 (Jour. Roy. Agric. Soc.). "Through eating the poisonous leaves of a Yew tree, four cross-bred cattle were found dead in a shrubbery at Elmswell, near Driffield" (Daily Mail, 13th Dec., 1913). Many cases of poisoning and death of animals due to eating the foliage direct from the trees have been recorded in the veterinary journals - e.g. the death of 15 cattle in The Veterinary News, 7th Dec., 1912. Tegetmeier recorded the death of pheasants due to Yew leaves and seeds (The Field, 11th Nov., 1893). On the other hand many cases have been recorded in which fatal results have not followed the ingestion of the leaves, and it appears that the lower branches of Yew trees in parks are constantly cropped by cattle without ill effects. (Trans. Chem. Soc., 1902 ; Jour. Bd. Agric., 1903).

The bark, leaves, and seeds are all poisonous, the leaves usually being the parts eaten. Henslow states that of 32 cases of Yew poisoning 9 were due to the berries and the remainder to the leaves, while 20 of the 32 cases were fatal. In $1879 \mathrm{R}$. Modlen published a circumstantial account of children poisoned at Oxford by the fruits, and demonstrated that the arillus or scarlet mucilaginous cup surrounding the ripe seed is not poisonous, but that the seeds are so. Apart from idiosyncrasy of appetite stock are perhaps more likely to eat the dark green foliage of the Yew in winter or during scarcity of green fodder than at other times. The old leaves or shoots are the most poisonous parts.

By experiments with autumn and winter leaves Cornevin found that the following quantities would be necessary to kill various animals:-

\begin{tabular}{|c|c|c|c|c|}
\hline Horse & $\cdots$ & $0.2 \mathrm{lb}$. & 10 & weight \\
\hline Ass and Mule & & $0: 16 \mathrm{Ib}$. & , & " \\
\hline Cow and Sheep & & 1.0 lb. & ״, & , \\
\hline Goat ... & .. & l.2 lb. & ". & $"$ \\
\hline Pig & $\cdots$ & $0.3 \mathrm{lb}$. & ", & ", \\
\hline Rabbit & .. & $2.0 \mathrm{lb}$. & ", & ," \\
\hline
\end{tabular}

Other authorities, however, quote much lower quantities as necessary to kill the horse and ox, and Pott says that in the case of horses 150 to 180 grammes $(0.33$ to $0.4 \mathrm{lb}$.) is sufficient to cause death in one-quarter to one-half an hour, without previous symptoms. Eaten by an animal on a full stomach a small quantity of Yew may cause little or no dangerous results. 
Toxic Principle. The researches of Marmé pointed to the alkaloid Taxine $\left(\mathrm{C}_{37} \mathrm{H}_{52} \mathrm{NO}_{10}\right)$ as the toxic substance. Later investigations of Thorpe and Stubbs confirmed this view, and it is generally agreed that this substance is the toxic principle, though doubts as to its being the only poison have been expressed. Taxine has a bitter taste, is a heart depressant, and may cause death from suffocation. The yew also contains a considerable quantity of Formic Acid, and the acrid, irritant volatile Oil of Yew.

Thorpe and Stubbs (Trans. Chem. Soc., 1902) found in the fresh leaves of the common Yew from 0.1 to 0.18 per cent. of Taxine. In an investigation of the Irish Yew ( $T$. baccata var. fastigiata) Moss found Taxine present as follows:-

Leaves from female tree, fresh $\quad$. $\quad \ldots \quad 0.596$ per cent.

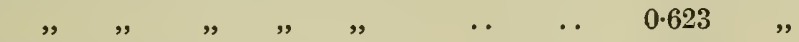

Seeds from fruit of same tree .. $\quad$. $\quad \ldots \quad 0.079 \quad$,

Another female tree-leaves .. $\quad$. $\quad \ldots \quad 0.323 \quad$,

" ", seeds .. $\quad . . \quad \ldots \quad 0.082 \quad$,"

In the leaves of the male common Yew Moss found 0.082 per cent. of Taxine, or less than one-half the quantity found by Thorpe and Stubbs.

Symptoms. The Yew is irritant and narcotic, and the poison is not cumulative, but on the other hand rapidly effective, so that animals may die apparently suddenly, no previous symptoms having been observed.

When small quantities only have been taken the closest attention is necessary to discern the symptoms, which simply consist in a little excitement with a slight rise in temperature.

With larger (but not fatal) quantities the first symptom, excitement, is more pronounced and is followed by nausea, and (where possible) vomiting. There is a pronounced slackening of respiration and circulation, the pulse being small, slow, and difficult to perceive, and the movement of the flanks very slow; sensibility is diminished. There is a fall in temperature, the skin and extremities being cold. The head is lowered, the eyes are closed and there is decubitus. In some cases pregnant animals have aborted. In the horse there are muscular tremors and frequent urination. In cattle and sheep rumination is suspended and there is more or less pronounced tympanites, with eructation, nausea, and sometimes vomiting. Pigs bury the head in the litter and sleep, their sleep being interrupted from time to time by nausea and groaning; or the animals rise, stagger about, and lie down again. 
With fatal quantities the foregoing symptoms may be followed by coma, with death in two hours or more after the poisoning, but more generally and usually in horses, asses, and mules (but also in cattle) there is no period of coma, the excitement is less pronounced and often unobserved, and death appears very sudden. The animals stop, shake their heads, respiration is modified, there is falling, and death (sometimes with convulsions) results from cessation of the heart's action (Cornevin).

The symptoms given by Müller are roaring, torpidity, stupefaction, laboured breathing, convulsions and death in from ten minutes to an hour in the worst cases; or where the course of poisoning is slower, there is salivation, nausea, vomiting, bloating, retardation of pulse and respiration, great giddiness and stupefaction, diabetes and hæmaturia.

The rapidity of the poisoning is confirmed by cases noted in the veterinary journals. Lander shows that the effects often only appear in cattle when chewing the cud; whilst quietly chewing, they drop as if shot. In some examples the animal died while eating the plant, or was found to have fallen and died suddenly and without evidence of a struggle. The animal in some cases will stop suddenly whilst working, start blowing and trembling, stagger, fall on its haunches, then on its side, and die quietly. Death occurs in about five minutes with symptoms resembling apoplexy. A colt died after 16 or 17 hours; the plant was taken on a full stomach, but paralysis of the alimentary system with stoppage of digestion immediately ensued.

In the case of pheasants there was acute inflammation of the small intestines (Tegetmeier).

\section{REFERENCES.}

$4,16,49,73,81,84,100,128,130,141,144,161$, $170,189,190,205,213,239,240,256$.

\section{AROIDEEE.}

Cuckoo Pint (Arum maculatum L.). The well-known Cuckoo Pint, or Lords and Ladies, is to be regarded as highly poisonous, and children have died from eating the berries. Animals have exceptionally eaten the plant, but no record of death has been found, as it does not appear to be taken in sufficient quantity. Cornevin records that pigs have eaten the roots, and suffered in consequence, though the results were not fatal. All parts of the plant are poisonous, though the virulence is lost on drying. The plant is acrid, and emits a disagreeable 
smell when bruised. In Gerarde's Herball the following passage occurs : "The most pure and white starch is made from the rootes of the Cuckowpint; but most hurtfull for the hands of the laundresse that hath the handling of it, for it choppeth, blistereth, and maketh the hands rough and rugged, and withall smarting." In Dorset the tuber-like corms have been macerated in water, dried and powdered, and eaten under the name Portland Sago or Portland Arrowroot, the poisonous property being dissipated.

- Toxic Principle. The Cuckoo Pint does not seem to have received much attention in this connection, but the poisonous principle is believed to be a Saponin.

Symptoms. The juice acts as an irritant when in contact with the mucous membrane. When a pig has eaten several roots rich in sap, the mouth and tongue redden and tumefy, there is salivation, and swallowing is difficult on account of the inflammation at the back of the mouth. Introduced in small quantity into the digestive tract it acts as an irritant and purgative, and sometimes causes vomiting. Severe intestinal pains, excitement, some muscular contraction of the limbs, rocking of the head, and superpurgation with tenesmus are also symptoms which have been observed. The intestinal pains continue for some days and the appetite is small. Cornevin states that animals never take a sufficient quantity to cause fatal poisoning, but according to Lander, if a dangerous quantity is taken, convulsions, exhaustion, and death from shock may possibly follow the foregoing symptoms.

A case in which a horse was poisoned through a wound being washed with a decoction of arum leaves is cited by Müller. There was much local swelling, trembling, and rapid breathing, and the heart beat strongly; the animal died on the third day.

REFERENCES.

$73,81,130,141,170,190$. 


\section{CHAPTER VI}

\section{DIOSCORIDEXE.}

Black Bryony (Tamus communis L.). The stem and foliage of Black Bryony are apparently harmless, being browsed by sheep and goats with impunity, but the scarlet fruits are decidedly poisonous and the starchy root is acrid and purgative.

Toxic Principle. This is probably the glucoside Bryonin, which occurs in Bryonia dioica (p. 35).

Symptoms. Cornevin, in citing experiments on animals, states that small quantities of the fruits cause uneasiness, somnolence, and difficult locomotion. Larger quantities cause vomiting, intestinal pains, and paralysis of hind quarters. Death is rapid. Müller, however, remarks that paralysis of the hind quarters and convulsions may result from small quantities, large quantities causing in addition inflammation of the stomach and intestines.

\section{REFERENCES.}

$73,190$.

\section{LILIACEÆ.}

Herb Paris (Paris quadrifolia L.). Owing to its habitat-damp woods-it is unlikely that stock will eat this plant, but it may be possible where fields border open woods in which it grows. No records of stock poisoning have been met with, but cases of poisoning in man are recorded, one due to eating a considerable number (30 to 40$)$ of the berries, and symptoms of poisoning in a child four years of age who had eaten a few berries. In smaller quantities they are very poisonous to poultry. All parts are stated to be poisonous, especially the berries. Fatal poisonings are nil, or very rare if recorded.

Toxic Principle. Walz isolated the glucoside Paridin; and Esser states that the toxic property is due to a Saponin,--the bitter irritant glucoside Paristyphnin $\left(\mathrm{C}_{38} \mathrm{H}_{64} \mathrm{O}_{18}\right)$, which is convertible into Paridin $\left(\mathrm{C}_{16} \mathrm{H}_{28} \mathrm{O}_{7}+2 \mathrm{H}_{2} \mathrm{O}\right)$ and sugar. 
Symptoms. The plant is emetic, purgative, intensely acrid, and narcotic. Poisoning up to the present only appears to have been recorded in fowls, the symptoms being intense local inflammation, narcotic effects, vomiting, colic, diarrhœa, stupefaction, convulsions, and paralysis (Müller).

\section{REFERENCES.}

$4,16,73,76,81,130,141,190$.

Lily-of-the-Valley (Convallaria majalis, L.). This beautiful plant is only likely to induce poisoning of domestic animals at very rare intervals, as it occurs wild in only a few woods from Moray southwards, being, however, abundant in some districts. All parts are stated to be poisonous, especially the flowers. It has an acrid, bitter taste. Few cases of poisoning are recorded. Sheep and goats are believed to eat the leaves with impunity. The extract is so poisonous that four drops injected into the blood stream sufficed to kill a dog in ten minutes (Cornevin). The leaves have been known to kill geese and fowls.

Toxic Principle. All parts of the plant contain the bitter poisonous glucoside Convallamarin $\left(\mathrm{C}_{23} \mathrm{H}_{44} \mathrm{O}_{12}\right)$, the glucoside Paridin $\left(\mathrm{C}_{16} \mathrm{H}_{28} \mathrm{O}_{7}+2 \mathrm{H}_{2} \mathrm{O}\right)$, and the glucoside Convallarin $\left(\mathrm{C}_{34} \mathrm{H}_{62} \mathrm{O}_{11}\right)$-the first a dangerous purgative, and the last a cardiac poison resembling Digitalis. Convallamarin is a very poisonous crystalline substance, with at first a bitter and afterwards a sweetish taste.

Symptoms. The action of this plant on the animal organism is not yet clearly known, but it is stated to have marked emetic and purgative action. Taken in moderate quantities a period of retardation of the heart and lung action is followed by a period in which the heart action is intermittent, and there are stoppages in respiration, and vomiting. Taken in large quantities, the first of these periods is extremely short, the pulse soon becomes rapid and small, respiration is quickened, and the heart action ceases (Cornevin).

Pott observes that the leaves cause stupefaction, convulsions, and death after a few hours in the case of geese. He cites a case in which ten fowls ate the leaves and nine died.

\section{REFERENCES.}

$52,73,76,81,190,203,205,213$.

Meadow Saffron (Colchicum autumnale L.). The Meadow Saftron, Autumn Crocus, or Naked Ladies, as it is variously named, occurs in 
meadows in many districts in England and Wales. All parts are poisonous, both in the green state and when dried, as it possibly may be, in hay. It has caused extensive losses of live stock, and the greatest care should be taken to eradicate it from grass land. The leaves and seedvessels are produced in spring, and the flowers from August to October -and it is at these two periods that cases of poisoning by this plant are most frequent, though, as stated, it may be included in hay. Many horses, cattle, and pigs have been killed by Meadow Saffron, though cattle commonly avoid it. Sheep and goats are belicved to be very slightly affected. Children and fowls died at Schorren (Canton Berne) from eating the seeds, and there have been many cases of human poisoning due both to eating the seeds and the bulbs. In Staffordshire, Mr. J. C. Rushton reported some years ago ${ }^{1}$ that in one year a farmer lost seventeen milking cows; in 1908 he lost seven calves; and in 1909 he lost a number of sheep and cows. It was then discovered that the field in which the animals grazed contained "any quantity of Meadow Saffron and Water Hemlock," and this was the cause of the losses. Horses and cattle are more commonly poisoned than other domesticated animals. Johnson and Sowerby record the case of a woman who ate the corms in mistake for onions at Covent Garden, and died; and state that deer and cattle have been killed by the leaves. Kanngiesser notes that this species is the most toxic of German plants, and that in cases of human poisoning the mortality is 90 per cent., children being chiefly affected. Cornevin's experiments showed that 8 to 10 grammes of green leaves per kilogramme of live weight-say 3 to $5 \mathrm{lb}$. for an average cow-was sufficient to kill ruminants; while 30 centigrammes of corms per kilogramme of live weight sufficed to kill pigssay $4 \frac{1}{2} \mathrm{oz}$. for a pig of $200 \mathrm{lb}$. live weight. Barret and Remlinger (Veterinary Journal, 1912, p. 306) record the sudden illness of 31 out of 51 cattle, and 5 of them died.

The toxic principle is cumulative, that is, small quantities of the plant eaten regularly may result in poisoning, owing to the poison being slowly eliminated by the kidneys. Indeed, cases have been recorded in which the poison has been secreted and eliminated in the milk of cows and so has caused poisoning of both calves and infants.

Toxic Principle. Meadow Saffron contains in all parts the acrid, poisonous alkaloid Colchicine $\left(\mathrm{C}_{22} \mathrm{H}_{25} \mathrm{NO}_{6}\right)$ stated by Esser to occur to the extent of 0.2 per cent. in the corms, 0.4 to 0.6 per cent. in the secd coats, but only traces in the leaves. Hertel obtained 0.38 to 0.41 per cent. of

1 Staffordshire Weekly Sentinel, Aug. 21st, 1909. 
alkaloid from the seeds, Farr and Wright from 0.46 to 0.95 per cent., and Carr and Reynolds 0.12 to 0.57 per cent.; the U.S. Pharmacopœia, 1905, required a Colchicine content of 0.45 per cent. in the seeds, and 0.35 per cent. in the corms (Allen).

Symptoms. After small, but not fatal doses there is loss of appetite, suppression of rumination, salivation, light colic, diarrhœa and voiding of small quantities of urine. Blood has been observed in the milk of affected cows. Larger and fatal quantities cause total loss of appetite and sensation, stupefaction, loss of consciousness, dilatation of pupils, unsteady gait, and even paralysis of limbs, sweating, severe colic, and bloody diarrhœa, strangury and bloody urination; rapid, small, and finally imperceptible pulse, laboured breathing; and death in from one to three days. Where recovery takes place it is very slow (12 to 14 days according to Cornevin).

Cornevin draws attention to the fact that, as the symptoms do not occur until several hours after ingestion, by which time the poison must be partly distributed, the poison is very dangerous and difficult to combat, attempts at vomiting or evacuation, whether spontaneous or caused therapeutically, having little chance of ridding the organism of the poison. Cornevin's account of the symptoms shows that at first there is abundant salivation, with constriction of the throat, and dysphagia; then nausea with vomiting; colic; abundant, repeated and diarrhœic evacuations, which at the end become dysenteric with painful tenesmus; abundant urination; short, accelerated and difficult respiration, with inco-ordination in the thoracic and abdominal movements. The circulatory functions are modified only in fatal cases, when the pulse is small and intermittent towards the end. There is finally a notable drop in temperature, shown by the coldness of the skin. Death occurs in from 16 hours to 6 days after ingestion. During the last few hours the animals are stretched at full length and are incapable of getting up. There may be prolapsus of the rectum; the eye is deeply sunk; sensibility is deadened and death is due to stoppage of respiration.

In the horse, there are spasmodic movements of the hind-quarters and excessive excitement of the urinary genital organs. In cattle there is cessation of rumination, grinding of teeth, dryness of muzzle, ptyalism, groaning, painful colic, dysentery, deeply sunken and watery eyes, anus wide open, and evacuation of very fœtid, blackish, glareous matter round the excrement. In cows there may be suppression of milk, and abortion. In the pig there is abundant salivation and vomiting, and 
the animal keeps its snout buried in the litter. There is also extremely fœtid diarrhœa, with dysentery.

\section{REFERENCES.}

$4,16,27,73,81,128,130,141,148,151$, $190,192,203,217,255$.

\section{GRAMINEE.}

Darnel (Lolium temulentum L.). The grass known as Darnel, of the same genus as rye-grass, has been recognized for centuries as a harmful species, and it is considered by some authorities that it is really the tares of Scripture which the enemy sowed among the wheat. Its effect on eyesight was known to the ancients ${ }^{1}$, and its objectionable character was noted by Shakespeare:-

"Want ye corn for bread?

I think the Duke of Burgundy will fast

Before he'll buy again at such a rate:

'Twas full of darnel: Do you like the taste?" -1 Henry VI, Act III, Se. 2.

Its effect when mixed with flour was also referred to by Gerarde (1597): "The new bread wherein Darnell is, eaten hot, causeth drunkenness; in like manner doth beere or ale wherein the seede is fallen, or put into the mault."

Before the seeding stage is reached Darnel seems to be quite suitable as a food for stock, only the seed or grain being poisonous, and this not invariably so. The chief danger perhaps is that the grain may not be thoroughly removed from cereal grains, and may thus find its way into bread or cereal stock foods. Though it has caused many cases of human poisoning, fatal results seem to be rare: Dr. Taylor could record no fatal case up to 1859. Darnel mixed with barley caused the poisoning of pigs (Veterinarian, 1842). Johnson and Sowerby (1861) state that Darnel has in several cases proved fatal to horses and sheep.//The same authorities quote a case in which 80 inmates of Sheffield Workhouse were attacked by violent vomiting and purging from the use of oatmeal containing Darnel. At the Veterinary School at Lyons a horse was

1 E.g. Ovid says "Let the fields be elear of darnel that weakens the eyes." In Plautus' comedy, The Braggart Soldier, one servant says to another, " 'Tis a wonder that you are in the habit of feeding on darnel with wheat at so low a price." "Why so?" "Because you are so dim of sight." [Agric. Jour. Union of S. Africa, Jan. 1914, p. 82.] 
killed by giving it 2 kilogrammes $(4.4 \mathrm{lb}$.) of Darnel. Cornevin concluded that the amounts of Darnel necessary to kill certain animals would be as follows:-

$\begin{array}{lllll}\text { Horse .. } & \ldots & \ldots & 0.7 \mathrm{lb} \text {. per } 100 \mathrm{lb} \text {. live weight. } \\ \text { Ruminants } & \ldots & \ldots & 1.5 \text { to } 1.8 \mathrm{lb} \text {. per } 100 \mathrm{lb} \text {. live weight. } \\ \text { Poultry } & \ldots & \ldots & 1.5 \text { to } 1.8 \mathrm{lb} \text {. , } \\ \text { Dog .. } & \ldots & \ldots & 1.8 \mathrm{lb} . & \text {, }\end{array}$

He found pigs very little affected. As regards man 30 grammes ( $1 \mathrm{oz}$.) of the flour appear to be about the most that can be taken without showing dangerous symptoms.

The presence of Darnel flour in flour of the cereal grains may be determined by an examination of the starch granules, which are given by Cornevin as only 5 to $8 \mu$ in diameter (compared with 25 to $45 \mu$ for rye), simple in general, but sometimes in groups of 2 to even 5, polyhedral or partly rounded, with a nucleus or fusiform nucleal cavity, and readily coloured blue with iodine; they resemble those of maize but are only about one-eighth the size.

Toxic Principle. The grains only are harmful, and contain the narcotic alkaloid Temuline $\left(\mathrm{C}_{7} \mathrm{H}_{12} \mathrm{~N}_{2} \mathrm{O}\right)$, which Hofmeister showed to be a strong nerve poison, and which is said to occur to the extent of 0.06 per cent. in the seeds. Other authorities impute the toxic property to Loliine, while Smith states that the toxic principle is Picro'oxin. In relation to the grain fungal hyphæ have usually been found, though not invariably, 20 to 30 per cent. of the plants sometimes being free from it. The fungus (Endoconidium temulentum) is propagated vegetatively by means of mycelium. It appears to live symbiotically in the maturing grain, and perhaps to a slight extent renders possible the assimilation of nitrogen from the atmosphere; but Freeman observed that though generally stimulating to the Darnel, it is occasionally injurious to it. Esser sums it up by saying that according to most authorities who have investigated Darnel the fungus alone contains the toxic substancethe Temuline-and hence the grains in which the fungus does not occur should be harmless. The fungus is found in Darnel grain in all countries-Chile, Brazil, S. Africa, Persia, Spain, France, Sweden, Germany, etc. So far as can be ascertained there have been no feeding experiments to determine the difference in toxic character between fungus-infested and fungus-free grains. The dangerous properties are said to be most pronounced in wet seasons.

Symptoms. In France Darnel is called Ivraie, because, when brewed with barley, it acts as a narcotic intoxicant. 
Darnel poisoning induces giddiness, drowsiness, uncertain gait, and stupefaction (Müller), and, in the older animals, vomiting, convulsions, loss of sensation and death (Pott).

The symptoms in the horse are dilatation of pupils, vertigo, uncertain gait, and trembling. The animal falls, the body is cold and the extremities are stiff, respiration is laboured, the pulse is slow and small, and there are convulsive movements of the head and limbs. There is rapid enfeeblement, and death may occur within thirty hours.

In pigs, foaming, convulsions and paralysis have been observed; the stomach and intestines were inflamed and the lungs congested.

REFERENCES.

$4,16,73,81,106,128,130,141,190,203,204$, $205,213,233,235,254$.

\section{EQUISETACE正.}

Horsetails (Equisetum sp.). A very great deal has been written on the subject of Equisetosis or Equisetum poisoning, and even at the present day opinion is divided as to which species are poisonous and to what extent. From the time of Linnæus there has been uncertainty as to the species, which has generally been given as $E$. arvense. Two German papers, by Weber and Lohmann respectively, published by the German Agricultural Society in 1903 and 1904, have done much to remove doubt on the matter, but cannot be said to have settled the question absolutely. These two papers seem to have been overlooked by some recent writers on the subject, but Lohmann's appears to be the most authoritative paper yet written. Both are referred to below.

It seems to be definitely proved that certain species of Equisetum really are poisonous, hesitating statements notwithstanding. Chesnut and Wilcox state that there are cases of poisoning of both horses and sheep by $E$. arvense in the United States, though they are not common, and the opinion is expressed that "the plant, if deleterious, is evidently so only on account of its harsh scouring action in the mouth and intestinal tract." On the other hand Rich and Jones record poisoning of horses by $E$. arvense in hay, but while adding that horses seem to develop a depraved appetite for the weed, they state that they have no evidence that horses grazing upon the green plant are poisoned. Güssow's experience has been that cattle do not suffer any inconvenience at all 
from this species, or only very slight disturbance of the digestive organs, but that horses are conspicuously subject to fatal poisoning by it. Examination of hay on which a considerable number of poisoned horses were fed revealed in every case the presence of $E$. arvense. When the food was changed, horses, if not too seriously affected, made rapid recovery. (Treatment suggested is to change to easily digested food, give a sharp purgative, and follow by small doses of nux vomica three times a day.) Pammel says that in recent years a disease of horses in Vermont has been attributed to hay and fodder containing the weed; that it is proved by experiment that when ingested in sufficient quantity $E$. arvense is capable of causing fatal poisoning in horses, and is at times the cause of extensive losses; and that young horses are most susceptible, while grain-fed horses are less susceptible than others. He adds that sheep are supposed to be slightly affected, but cattle eat hay in which it occurs in large proportion with impunity.

Coming to the two German reports, it is stated by Weber (1903) that $E$. palustre contains a specific poison for cattle and other ruminants, but sheep and goats are able, owing to their fine muzzles, to separate it in fodder, and hence suffer less. Horses and pigs, he says, seem to suffer very little. Young animals and stock, from districts where the species does not occur, suffer more than those from places where it occurs-the latter appearing to learn early to avoid it.

Lohmann conducted feeding experiments with guinea-pigs with $E$. arvense, E. palustre, E. pratense, E. sylvaticum, E. maximum, and $E$. heleocharis (not British). He also fed $E$. arvense and $E$. palustre to horses, cattle, sheep, pigs, and geese in considerable quantities for many days on end; and made experiments with aconitic acid on guinea-pigs and horses. The feeding experiments with guinea-pigs showed that of the species named only $E$. palustre and to a less extent $E$. sylvaticum are poisonous plants (to guinea-pigs). With the large domestic animals the experiments showed $E$. arvense to be a harmless plant, and $E$. palustre to be really injurious to cattle but avoided by other stock. Lohmann considers that the many statements in the literature agree in part with this result, and that the divergent observations may be traced to various causes, among which perhaps an abnormal chemical composition of the weed fed plays a principal part.

In this connection, however, the American results must be carefully borne in mind, and $E$. arvense must not too hastily be regarded as blameless.

Toxic Principle. It was for some years believed that the apparent 
toxic symptoms induced by Horsetails were due to Silica or to Aconitic acid-the latter a substance found by $\mathrm{Matz}$ and Ludwig. The conclusion come to by Weber, however, was that the poisoning by $E$. palustre is of an organic character, not due to silica. The young shoots, which contain little silica, were found in general to be much more poisonous than the old plants, which contain much silica. It was long since found by Wiggers that dried plants of $E$. palustre contained 8.88 per cent. of silica, but all species contain this substance in greater or less degree, and it varies considerably in amount, even in the same species. The feeding experiments conducted by Lohmann, with certain species of Equisetum, and the observed symptoms of illness after the consumption of some of them, particularly $E$. palustre, serve to show that the ill effects are neither to be attributed to greater or less digestibility, nor to the silica present. Neither are the aconitic acid and other organic substances, in part found in previous investigations, responsible for the poisoning. However, an active compound named Equisetine, a substance belonging to the alkaloid group, was isolated; this occurs usually, perhaps only, in E. palustre, at any rate in sufficient quantity to be dangerous to animals. Lohmann then, following up the investigations of Paucerzynski, Matz, Meyer, Weber and others, ascertained definitely that $E$. palustre contains an alkaloidal nerve poison, to which the name Equisetine was given, and the experiments were held to decide that this is the poisonous substance in this species. (As stated above, $E$. arvense was held to be harmless.)

Symptoms. At first, excitement and anxiety, followed by uncertainty of movement, reeling and staggering; paralysis of hind limbs at least, falling, possibly general paralysis, insensibility to external irritants, unconsciousness, and coma. Pulse accelerated, appetite at first normal, but in course of time great disturbance of nutrition; sugar in the urine. Course sometimes very acute, death occurring in a few hours, but sometimes protracted (two to eight days), and at times even chronic (one to several weeks).

In caltle, after excessive eating, continuous diarrhœe is characteristic, with paralysis; while, if the food be persisted with, cachexia and hydræmia combined with weakness bordering on paralysis make their appearance (Friedberger and Fröhner, via Pammel). In addition to cachexia, Pott also mentions colic, stoppage, bloody urination, abortion, and loss of teeth.

Young animals appear to succumb sooner than older ones, while grain-fed animals are more resistant than others. Referring to $E$. 
arvense Pammel says it produces paralysis of the rear extremities, and when death occurs spasms are noted. In relation to the poisoning of horses by the same species in hay Rich and Jones note unthriftiness, the animal appearing thin and the muscles wasted. In from two to five weeks, according to the age of the horse and the manner of feeding, the animal begins to lose control of the muscles, and there is swaying and staggering, though the eye is bright and the appetite good. If the plant is regularly ingested the horse loses the power of standing, becomes nervous, struggles to rise, the legs become more or less rigid, and at times all the muscles of the body seem convulsed. Even in this condition one well-nursed patient lived two weeks. The horses are generally willing to eat, although unable to rise, but become sore and tired from struggling, finally dying from exhaustion. Life is much prolonged by turning from side to side three or four times in twenty-four hours, thus preventing congestion. The pulse is slow till near the end, when it is rapid and weak; the temperature is below normal at first, but when the animal is down there is fever; the extremities are usually cold; and the lining membrane of the mouth, nose, and eye becomes pale.

Of Equisetum sp. Stebler and Schroeter say that they induce diarrhœa in cattle, which become poor, and in cows the milk yield is checked or ceases. Weber also refers to the effect on milk yield of $E$. palustre, which he says causes the milk of affected cows to become watery, poor in fat, and gives rise to a greasy, unappetising butter, while the yield may soon quite fail.

\section{REFERENCES.}

$2,20,57,111,176,203,204,213,220,221,222,237,260,261$.

\section{FILICES.}

Bracken (Pteris aquilina L.). The Bracken, Brake Fern, or "Fern" is of very considerable importance to farmers for four reasons: (1) It is a most pernicious weed; (2) it forms an excellent litter for stock and treads down into good manure; (3) it is said to have been successfully converted into silage; but (4) it has been accused of poisoning cattle.

In regard to possible poisonous properties, it must be said that the facts are at present somewhat uncertain, but a number of authorities clearly regard the Bracken as poisonous. (a) Muiller (1897) records the poisoning of horses which ate it for some weeks with chaff-and some 
died. (b) Chesnut and Wilcox (1901) say that cases of poisoning of horses and cattle have been reported from England and a few localities in the United States. (c) Pott states that when eaten in quantity by cattle Bracken causes hæmaturia, and in horses nervous symptoms (brain trouble), sometimes with fatal effects. (d) Pammel also remarks on the believed poisonous character of this plant. (e) In view of its suspected poisonous character feeding experiments were conducted by the Board of Agriculture and Fisheries with a large quantity of Bracken, but the results were negative, yielding no experimental proof of the plant being poisonous. One animal-a heifer-consumed $60 \mathrm{lb}$. of Bracken between Aug. 14 and Aug. 20, and after two meals containing about $30 \mathrm{lb}$. of Bracken showed only symptoms of indigestion. After the $60 \mathrm{lb}$. there were no symptoms of illness. It has been thought possible that the so-called Bracken poisoning is due to Potentilla Tormentilla $(q . v$.$) .$

In 1893 Storrar dealt with the question and expressed the view that any disorder due to Bracken was probably not a toxic effect but a digestive trouble simply (Jour. Comp. Path., 1893).

Toxic Principle. Continental authorities say that Bracken contains the poisonous Pteritannic acid, which is identical with the Filicic acid of the Male Fern (Aspidium filix-mas).

Symptoms. In the cases of horses which died Miiller gives the symptoms as timidity, slower movement or action, loss of balance, dilated pupils, reddening followed by yellowing of the conjunctivæ, and slowing of the pulse.

Pammel notes Bracken as an astringent and anthelmintic, and also says it causes enteritis, spasms, and paralysis.

REFERENCES.

$10,25,57,190,203,204,213$.

\section{FUNGI 1 .}

Ergot (Claviceps purpurea). This fungus, parasitic on rye and a number of grasses, has long been known to induce distinct poisonous effects on man and domestic animals when ingested in sufficient quantity.

Ergot must be regarded as a cause of abortion in cows, though somewhat divergent views have been expressed as to the facts, some

1 Poisonous parasitic fungi generally are not dealt with in this volume, but ergot is included because it is widely distributed and perhaps the best known, while its effects have been fully studied. 
authorities considering the belief well founded, while others consider that there is little ground for it. It is quite clear, however, that when taken in sufficient quantity Ergot induces serious poisoning of domestic animals. Horses have died in two or three days from eating ergoted hay and wild rye. Extensive outbreaks of ergotism have occurred in the United States, and serious losses have been recorded in the Central and Western States. Ewart remarks that "a comparatively small number of fresh Ergot grains suffice to injure or kill a horse, cow, or sheep." The effects of the poisoning of animals will be found under Symptoms below.

Toxic Principle. Ergot of rye is used in medicine. It contains 0.20 to 0.25 per cent. of Ergotinine. In the British Pharmaceutical Codex, 1911, the grains (sclerotia) of Ergot (see Frontispiece) are described as longitudinally furrowed, 1 to $4 \mathrm{~cm}$. long, slender, curved, tapering to both ends; they break with a short fracture, and are somewhat triangular in transverse section; they have a characteristic and disagreeable odour and taste, are dark violet to black in colour, and whitish within. Ergot contains the physiologically active alkaloid Ergotoxine or Hydroergotinine $\left(\mathrm{C}_{35} \mathrm{H}_{41} \mathrm{O}_{6} \mathrm{~N}_{5}\right)$, also known as amorphous Ergotinine, and, when formerly obtained in an impure state, as Comutine and Ecboline. It is the hydrate of the crystalline base Ergotinine $\left(\mathrm{C}_{35} \mathrm{H}_{39} \mathrm{O}_{5} \mathrm{~N}_{5}\right)$. There are also other physiologically active constituents derived from amino-acids.

Symptoms. In man Ergot has induced two types of epidemic ergotism, caused by the prolonged use of ergoted rye bread. The two forms are rarely or never found together. One is a gangrenous form characterized by agonizing pain in the extremities, followed by dry gangrene of the peripheral parts of the body. The second type of ergotism is much more rare-a nervous epidemic characterized by paroxysmal epileptiform convulsions.

Owing to the fact that at the outset ergotism causes irritation in the hands and feet it is termed "Kribbelkrankheit" in Germany.

The three substances noted above as isolated by Kobert are stated to cause poisoning - the first producing inflammation of the serous and mucous membranes, disintegration of the red blood cells, and widespread ecchymoses; the second excites the central nervous system and causes general convulsions; and the last induces gangrene.

In one case a horse ate ergoted hay: next day the left hind leg was stiff, and moist with cold sweat; on the second day it was badly swollen and gangrene of all the tissues became apparent, and after the skin of 
the leg and a considerable part of the muscular tissue had sloughed off the animal died on the third day. In other cases horses showed symptoms twenty-four hours after eating ergoted hay: fatigue, indisposition to work, cold sweat, particularly on the neck, paralysis of the tongue and muscles concerned in swallowing, and then generalized paralysis, very slow and deep respiration, subnormal temperature, normal pulse at first and then weaker till scarcely distinguishable, death in six or eight hours (Chesnut and Wilcox).

According to Pammel ergotism manifests itself among animals chiefly in the chronic form, the poison being acquired in small amounts and accumulation taking place slowly. Two distinct forms of the disease are recognized, the spasmodic and gangrenous. "Symptoms referable to the digestive tract, such as nausea, vomiting, colic, diarrhœa, or constipation occur in both forms. Pregnant animals very frequently abort."

"In the spasmodic type of the disease, symptoms due to overstimulation of the central nervous system appear. These are tonic contraction of the flexor tendons of the limbs, anæsthesia of the extremities, muscular trembling, general tetanic spasms, convulsions and delirium. Death usually occurs from secondary causes."

"Gangrenous ergotism is characterised by coldness and anæsthesia of the extremities, followed ultimately by dry gangrene of these parts. The effects of this dry gangrene are often very serious and amount to sloughing of the feet, tips of the ears, tip of the tail, shedding of the hair, teeth, etc. Death takes place from exhaustion.

"Acute poisoning is characterized by vomiting (in dogs), profuse salivation, dilatation of the pupils, rapid breathing and frequent pulse. The animal cries out, has convulsive twitchings, staggering gait, paraplegia, intense thirst and coma, terminating in death."

In an extensive outbreak of ergotism in the United States in 1884 Law and Salmon reported as a prominent symptom ulceration of the mucous membrane of the tongue and mouth cavity, this and lesions on the extremities giving the appearance of foot-and-mouth disease. Affected animals showed weakness, dullness, and paralytic conditions of certain groups of muscles. When in pregnant animals the uterus is acted upon, labour pains occur, and the fœtus is expelled. The straining in those cases is often very painful and may be so severe that prolapsus of the uterus or even the rectum is the result. When Ergot produces gangrene, it usually affects the extremities, like the lower parts of the legs, the ears, tail or teats in cattle, and the comb, wattles, toes, wings or tongue of poultry. It is preceded by redness, coldness, and painful 
swelling of the parts affected. After a while sensibility of the dying region is lost and the line of demarcation between it and the living tissue becomes manifest. The dead portion commonly dies and is cast off. In some cases the gangrene is accompanied by symptoms of a septic nature.

"The possible result of the poisoning depends largely on the amount of Ergot taken and on the severity of the symptoms produced thereby. When small amounts are taken and only a slight dullness or digestive disturbance results the outlook may be quite favourable. Even Ergot abortion with rather severe symptoms usually is followed by recovery, but in the gangrenous cases, fatal terminations are common. The animals which through this cause have lost one or more parts are not only crippled, but septic or embolic complications may lead to a fatal termination. Paralytic cases do not permit of a favourable prognosis, especially if muscle groups containing important functions are involved." (N. Dakota Exp. Sta. Rept.)

REFERENCES.

$1,4,13,16,35,57,81,82,128,154,161,203,242,251$. 


\section{CHAPTER VII}

\section{PLANTS SUSPECTED OF BEING POISONOUS.}

A very large number of plants have at various times been suspected of possessing poisonous properties and causing harm to live stock. Of these it is quite probable that many are in practice entirely harmless, but some must be included as possibly deleterious, complaints having been made which vary in gravity from a slight irritation to causing death.

Purging Flax (Linum catharticum L.). It is perhaps doubtful whether this plant is really poisonous unless taken in considerable quantity by animals - as it is quite unlikely to be. It may, however, be included here, as it is stated to contain a glucoside which is purgative and which on fermentation yields prussic acid.

Furze or Gorse (Ulex europaus L.). In view of the fact that Gerrard isolated from the seeds of Gorse the alkaloid Ulexine, which is identical with Cytisine (p. 27) and that the alkaloid is also contained in less quantity in the bark of young shoots, this plant has been suspected of possessing toxic properties. Experiments $(179)^{1}$ with the alkaloid definitely showed it to be a nerve and muscle poison, 3 milligrammes having killed a chloroformed cat with convulsions in three minutes, though the animal could be kept alive as long as artificial respiration was kept up. As, however, Gorse has long been used very widely and in considerable quantities as a fodder the percentage content of the alkaloid must in general be exceedingly small, and no harmful effects need be feared from the consumption of the cut and bruised plant. Possibly the seeds might prove injurious if eaten in quantity.

Melilot (Melilotus sp.) may at times cause injury. Ewart (82) writes: "All the species contain Cumarin, a volatile odoriferous principle, which in excess produces a disinclination to locomotion, paralysis and ultimately fatal symptoms. No harm is to be apprehended if the amount present does not exceed 10 per cent. of the herbage."

Silver Weed (Potentilla Anserina L.). This well-known and elegant little weed is scarcely likely to be eaten to any extent by farm stock,

1 Reference to Bibliography. 
though it may possibly be taken occasionally on roadsides. It has not been proved to be poisonous, but Pott states that it has a strongly constipating effect (213).

Tormentil (Potentilla Tormentilla L.). In relation to supposed bracken poisoning (see p. 87) in regard to which experiments were conducted by the Board of Agriculture and Fisheries, Tormentil occurred in several instances with the bracken in localities where this plant was reported to cause poisoning. Two feeding experiments in which the weed was fed to heifers gave negative results. In a further case, however, 4 or $5 \mathrm{lb}$. wire collected from a field where sick animals were grazing, and fed to a heifer; it appeared to be the cause of rise of temperature (to $106^{\circ} \mathrm{F}$.), diarrhœa, and the passing of a considerable quantity of blood in the fæces for three days, after which the animal improved. It was, however, slaughtered, and lesions were found similar to those found in animals dying in the field from so-called bracken poisoning. Though the plant was suspected, results generally were not held to prove that it was the cause of poisoning (25). According to Van Rijn the root of Tormentil contains a considerable quantity of Chinovic acid $\left(\mathrm{C}_{32} \mathrm{H}_{48} \mathrm{O}_{6}\right.$ ?).

Wall-Pepper (Sedum acre L.) is regarded as emetic and purgative, but to lose the harmful properties on drying.

Sundews (Drosera sp.) are reputed to be poisonous to sheep, but no evidence has been found.

White-Rot or Marsh Penny-Wort (Hydrocotyle vulgaris L.) is stated to have caused inflammation of the digestive tract, and hæmaturia; and to contain a toxic substance Vellarin (213).

Wild Parsnip (Pastinaca sativa L.). This plant has often been supposed to be poisonous, but Pammel shows that in Iowa the plant is quite harmless, as it appears to be in Britain.

Devil's-Bit (Scabiosa succisa L.) is stated by Moir to have caused injury to cattle in one instance (Vet. Record, 1899), causing salivation, gritting of the teeth, twitching of facial muscles, and slightly protruded, abraded, swollen and sensitive tongue. An experiment on cattle showed the plant to induce violent inflammation of the mouth and tongue.

All-Heal (Valeriana officinalis $\mathrm{L}$.) is not likely to be eaten by stock in sufficient quantity to cause poisonous symptoms, though it is stated to contain the poisonous Valerianic acid and Oil of Valerian. According to Chevalier (vide Henry) this plant contains an alkaloid not yet fully characterised.

Canadian Erigeron (Erigeron canadensis L.), sporadic in England, is suspected in America. It contains an oil, chiefly a terpene $\left(\mathrm{C}_{\mathbf{1 0}} \mathrm{H}_{16}\right)$. 
It has an acrid taste, causes smarting of the eyes, soreness of throat, aching of extremities, and colic; and irritation to people handling it (203).

Mayweeds (Anthemis sp.). It is not at all clear whether these plants are more than irritant in character, and they are so very common and widely distributed that there would probably be more evidence if they were poisonous. A. Cotula is regarded as suspected by Smith and Halsted, while Ewart says that it is obnoxious to stock on account of its unpleasant flavour, and if eaten by them in time of scarcity is apt to give their flesh, milk, or butter an unpleasant flavour. Güssow states that this species blisters the mouth and nostrils of animals. In his investigations at Kew, Greshoff found that the seeds of $A$. Cotula and $A$. arvensis contain much hydrocyanic acid. (He further found that the cyanogenetic glucoside from $A$. aetnensis Schouw. and A. chia L. belongs to the amygdalin type, giving off hydrocyanic acid and benzaldehyde on hydrolysis. "The strong odour of benzaldehyde may even be observed on grinding the seeds with water. Species of Anthemis contained from 0.15 down to 0.03 per cent. of hydrocyanic acid.")

Cat's-Ear (Hypochoris radicata L.). No record of poisoning of Cat's Ear has been found, but it may be mentioned here, since Ewart says of it: "It contains a bitter, milky sap, which makes it unpalatable though not entirely poisonous. . . . . An exclusive diet of this weed could not help but injure stock eventually."

Dodders (Cuscuta sp.), when parasitic on clovers and fed as fodder or hay, have been suspected of causing digestive troubles in horses and cattle in the United States. Müller records a case of poisoning of young pigs by $C$. europaca, with inflammation of the intestines and nervous symptoms. Barbey determined the presence of the glucoside Cuscutin in C. Epithymum.

Viper's Bugloss (Echium vulgare L.) is suspected of being poisonous; according to Friedberger and Fröhner it causes slavering (see also Cynoglossum).

Hound's Tongue (Cynoglossum officinale L.). To what extent this plant is actually poisonous is not clear, but with some other members of the order (Echium vulgare, Anchusa officinalis), it contains the two alkaloids Consolidine and Cynoglossine-the former of which paralyses the central nervous system and the latter the peripheral nerves. (Greimer, 1900: vide Henry).

According to Hooker, Hound's Tongue is narcotic and astringent, and Smith includes it as a simple vegetable irritant, causing nausea and purging. No records of actual poisoning of animals have been found. 
Broom-rape (Orobanche minor Sutt.) has been suspected, and according to Boitel is liable to cause violent colic when it occurs in considerable proportion in clover and is ingested with it (73). On the other hand, in a case noted by Stapledon, in which Broom-rape (O. minor) had completely overrun the aftermath on a farm near Fishguard, two-year-old cattle devoured the plant with apparent relish and cleared off most of it in a few days after being turned in. The farmer stated that he saw no trace of colic or other ill effects. (Jour. Bd. Agric., September, 1916.)

Great Mullein (Verbascum Thapsus L.). Though it does not appear to be touched by farm live-stock the Great Mullein must be mentioned here. The leaves and flowers have been used medicinally as an emollient and pectoral, while the seeds possess narcotic properties and serve to stupefy fish (73). Pammel states that the plant causes irritation, but is probably not very poisonous to stock.

Toadflax (Linaria vulgaris Mill.). Cornevin describes Toadflax as acrid and poisonous, but says that stock reject it, and he could record no accidents to animals. In his full and excellent account of this weed, Kraus says it is regarded as poisonous, or suspected of being so, but that according to most accounts it is not harmful to cattle (168). Leunis regards it as suspicious on account of its acridity. Some German authorities say it is willingly eaten by cattle, but it is generally believed to be avoided, and owing to its disagreeable odour and acrid taste this view is probably correct. The plant has not been exhaustively studied, and while Smith gives the toxic principle as Oil of Snapdragon and the resin Gratiolin, it may be observed that Toadflax contains the glucoside Linarin $\left(\mathrm{C}_{64} \mathrm{H}_{56} \mathrm{O}_{40}\right)$.

Figworts (Scrophularia nodosa L. and S. aquatica L.). These plants are not likely to be eaten by animals, but Cornevin states that the former is strongly emetic and purgative, and that in excess it may cause superpurgation ending in death. Müller says that the two species have respectively caused poisonous symptoms in a cow and a sheep; in the case of the cow there were loss of appetite and symptoms of paralysis. From $S$. nodosa Walz extracted a bitter, crystalline substance, Scrophularine.

Yellow Rattle (Rhinanthus Crista-galli L.). When grass land is put under the plough Yellow Rattle present may re-appear in a cereal crop as a semi-parasite, and its seeds may later be ground up with the grain, imparting a reddish or violet-brown colour and an unpleasant taste to the flour and even bread made from it. It is strongly suspected 
of being poisonous, like Pedicularis and Melampyrum, but it is by no means clear how far it may prove harmful to stock. It is believed by some people to impart a bad taste to the butter made from the milk of cows grazing on infested pastures. Lehmann ate without harm 35 grammes (about $1 \frac{1}{4} \mathrm{oz}$.) of the seeds made into a cake and cooked; and during four days he gave a rabbit 1238 grammes $(2 \cdot 7 \mathrm{lb}$.) of the fresh plant with half-ripe seeds, without apparent injury (73).

In some poor pastures it occurs in excessive quantity, and would appear to be only very slightly poisonous, or would have attracted wider attention. It is possibly only poisonous after being eaten for a prolonged period, as in the case of Lolium temulentum, and Lathyrus sativus. The seeds contain the bitter-sweet glucoside Rhinanthin $\left(\mathrm{C}_{29} \mathrm{H}_{52} \mathrm{O}_{20}\right)$, which is suspected of having poisonous properties.

Cow-Wheat (Melampyrum arvense L.). It seems clear that CowWheat is at least not poisonous unless eaten in very considerable quantities - amounts in fact which in practice are most unlikely to be eaten. The seeds may occur in cereal grains, and hence be ground up into meal. As they are said to contain a glucoside analogous to Rhinanthin, have a bitter taste and peculiar odour, and impart a violet coloration to flour, their presence in cornfields is most undesirable. According to Pammel this plant induces sleepiness and colic.

Ground Ivy (Nepeta Glechoma Benth.) is, according to Schaffner, poisonous to horses. It contains a volatile oil and bitter principle, as also does Catmint ( $N$. Cataria). In a case which came before the Board of Agriculture and Fisheries in 1906 three horses became ill with symptoms of poisoning, and the only weed found in the lucerne they were getting was Ground Ivy, and this was suspected but not proved to be the cause. In a further case, reported in 1909, eleven horses were believed to have been poisoned by this weed, and in one of the dead horses scarcely any food but Ground Ivy was found, and to it the veterinary surgeon in attendance attributed death. During preceding years several horses had died in the locality (Ely), owing, it was believed, to poisoning by the same weed. The losses, however, were not proved to be due to this plant.

In the Veterinary Journal (October, 1914, p. 515) poisoning of horses by this weed was noted (after Ferenczhazsy in the Recueil de Médecine Vétérinaire). The author observed nine cases of intoxication due to the weed, though it is stated that it "has occasioned no trouble in cattle and sheep that consumed it." The symptoms in horses were 
"anxious look, dyspnca, salivation, sweating, dilatation of the pupils, cyanosis, signs of pulmonary œdema." Two horses died. In 1913 similar cases were observed by other owners, and terminated fatally.

Hooker states that $N$. Glechoma is "bitter and aromatic, formerly used for beer, occasionally for tea."

Orache (Atriplex sp.). So far as known these plants are not poisonous, but it may be stated that Greshoff found the seeds of five species, and the leaves of two species, to contain a Saponin.

Nettles (Urtica sp.). Nettles are not generally regarded as poisonous otherwise than as causing painful nettle rash on the bare skin, but Urtica dioica L. is stated to have caused the death of dogs (Berliner Tierärztliche Wochenschrift, 1909).

Yellow Flag (Iris Pseud-acorus L.). The wild Flag was noted by Linnæus as dangerous to cattle, but no case of actual poisoning has been found in the literature. The plant is stated to have marked emetic and purgative properties, and Cornevin remarks that in Belgium intense gastro-enteritis is attributed to it. It contains the glucoside Iridin $\left(\mathrm{C}_{24} \mathrm{H}_{26} \mathrm{O}_{13}\right)$.

Narcissus sp. Various Narcissi (e.g. N. pseudo-narcissus, N.poeticus, and others) have been regarded as irritant to the hands. They would rarely if ever be eaten by live-stock in Britain, but it is stated that on the Continent many poisonings of cattle, goats, and pigs have been recorded, not infrequently ending in death after two or three days. The Narcissi are strongly narcotic, emetic, and purgative, and cause dilated pupils. Pott states that they cause inflammation of the digestive tract, and convulsions, sometimes with fatal results; and according to Pammel N. poeticus induces intense gastro-enteritis. N. pseudonarcissus contains the alkaloid Narcissine $\left(\mathrm{C}_{16} \mathrm{H}_{17} \mathrm{O}_{4} \mathrm{~N}\right)$, which with cats causes nausea and purgation (Henry).

Common Fritillary (Fritillaria Meleagris L.). The Fritillary or Snake's Head occurs only in a few places in England, and truly wild perhaps only rarely in southern and eastern counties-not in Scotland or Ireland. No definite case of poisoning has been found in the literature, but the plant is stated to be poisonous. It contains the bitter alkaloid Imperialine $\left(\mathrm{C}_{35} \mathrm{H}_{60} \mathrm{NO}_{4}\right)$, which is a heart poison.

Bog Asphodel (Narthecium ossifragum Huds.) has by some been regarded as a poisonous plant, and Muiller says that the poisoning of cows has been recorded, and also that a cat died after drinking the milk of an affected cow. The toxic property is believed to be the glucoside Narthecin. 
Molinia caerulea, Moench. A short account by Pott shows that when forming the principal part of moorland pasture grasses, and hence extensively eaten, this grass causes brittleness of the bones of stock, and in sheep chlorosis and wool eating. It also induces hrematuria, but if free from parasitic fungi (e.g. Claviceps microcephala) and not covered with microscopic, sharp crystals, is quite harmless if only eaten as a secondary or incidental fodder. This grass seems to be very poor in lime (Immendorf, 1898), and Schulze and Castoro found the internodes of the stem to contain a considerable quantity of a pentosan (Xylan). It is poor in nutritive constituents. The harm done is due perhaps in part to this fact, and in part to more or less accidental or occasional constituents (as 0.046 per cent. of lead oxide in a case of the var. altissima near some lead works). Plants said to be occasionally similarly harmful are Juncus sp., Nepeta Glechoma, and Hieracium Pilosella. 


\section{CHAPTER VIII}

\section{THE EFFECTS OF PLANTS ON MILK.}

A number of poisonous plants have a considerable influence on the milk yield of animals which eat them, reducing it in volume or in fat content, or imparting to it an unpleasant flavour which renders it unfit for human consumption, and even affecting the butter made from it. Other plants not actually poisonous also affect milk by "tainting" it, and must therefore be considered harmful otherwise than as mere weeds. Still others affect milk by causing it to be stained with blood, and in some cases the toxic principle of the plant concerned is even stated to have rendered the milk poisonous. It will be useful to give here a brief account of milk-affecting plants, though it is probable that there may be others which are not mentioned.

The plants best known in this connection are the Garlics (Allium oleraceum L., A. ursinum L., A. vineale L., and others), which impart to milk a strong "oniony" flavour. These plants also seriously affect the flesh of animals which eat them, even rendering it unfit for consumption. A case came before the author several years ago in which a considerable number of sheep had eaten a quantity of Allium ursinum, which was growing in a field in which they had been grazing for some days. The meat was so strongly tainted that, as the owner (a butcher) stated, it was quite unfit for sale. The only thing to be done was to pasture the sheep elsewhere for a time.

Pott notes that species of Ranunculus give rise to reddish or bitter milk (Mölkereizeitung, 1897), while Caltha palustris causes loss of milk production in cows.

Ranunculus repens imparts a strong unpleasant flavour to the milk of cows that have eaten it, and the butter made from such milk is distinctly bitter in taste (Güssow).

Ranunculus sceleratus causes a falling-off in milk-yield. (Cornevin.) Alliaria officinalis Andrz, imparts an oniony flavour to milk. 
Achillea Millefolium L. is stated to impart its bitter taste and strong odour to dairy products when eaten by cows. It contains an alkaloid, Achilleine $\left(\mathrm{C}_{20} \mathrm{H}_{38} \mathrm{O}_{15} \mathrm{~N}_{2}\right)$ having a peculiar odour and bitter taste.

Chrysanthcmum Leucanthemum has also been suspected of imparting a bad flavour to butter.

According to Pott the milk of cows eating Oxalis Acetosella is with difficulty converted into butter.

The poisonous principle of Colchicum autumnale is stated to find its way into the milk of animals consuming it, and Muiller states that the milk of goats which have eaten it has caused the poisoning of infants.

Muiller states that a cat died after drinking the milk of a cow suffering from poisoning by Narthecium ossifragum.

Mercurialis annua is said to cause milk to be thin, "blue," and poor in fat; while in a case already mentioned (p. 68) M. perennis entirely stopped the secretion of milk.

According to Chesnut, goats may eat quantities of Euphorbia Lathyris, and it is said that their milk then possesses the poisonous properties of the plants. Ingestion of other Euphorbias appears to have the same effect.

Cornevin remarks that Melampyrum arvense is considered to influence cows to produce more milk.

According to some authorities species of Equisetum check milk production or cause it to cease, and $E$. palustre is stated by Weber to cause the milk of affected cows to become watery, poor in fat, and give rise to a greasy and unappetising butter, while the yield may soon quite fail.

The ingestion of the foliage of the oak (Quercus sp.) is stated by Cornevin to induce Maladie des Bois, with reduction or entire loss of milk production (see p. 69). Acorns have also affected milk production, and a case is recorded (The Dairy, 1913) in which it is stated that cheese made from the milk of cows which had fed on acorns developed a sharp acid flavour when about four weeks old, though the texture was good. It is not clear, however, how it was proved to be due to the acorns.

In one case recorded a reddish tinge was observed in the milk of a cow suffering from Rhododendron poisoning (p. 46), and in general reduced milk production appears to occur.

In addition to the foregoing, there is good authority for saying that the following plants may impart a disagreeable flavour to milk, and in many cases the butter made from it:- 
Anthemis arvensis $\mathrm{L}$.

Anthemis Cotula L.

Artemisia Absinthium L.

Conium maculatum L.

Hyoscyamus niger $\mathrm{L}$.

Matricaria Chamomilla L.

Pinguicula vulgaris $\mathrm{L}$.

Senebiera didyma Pers.

Sium angustifolium $\mathrm{L}$.

Sium latifolium $\mathbf{L}$.

Tanacetum vulgare $\mathrm{L}$.

Thlaspi arvense $\mathrm{L}$.
(Corn Chamomile).

(Stinking Mayweed).

(Wormwood).

(Hemlock).

(Henbane).

(Wild Chamomile).

(Butterwort).

(Lesser Wartcress).

(Lesser Sium).

(Water Parsnip).

(Tansy).

(Penny Cress).

(See also Index "Milk, plants affecting," p. 117.)

\section{PLANTS WHICH CAUSE MECHANICAL INJURY.}

There are a number of plants which, while not necessarily physiological poisons, may induce injuries of a severe character when taken by animals, and by causing festering may bring about septic poisoning. For example the sharp pointed fruits of Stipa pinnata and Nardus stricta may cause injury to the skin and mouth, piercing the palate and causing inflammation, and when eaten may even perforate the wall of the intestine and cause death; and the awned glumes of species of Bromus or the spikelets of Hordeum may injure the gums, causing inflammation, ulceration, sores, the formation of pus, and loss of teeth. The Bromus and Hordeum, also, together with over-matured "heads" of Trifolium incarnatum, may give rise to phytobezoars or balls in the stomach of horses and cattle $(60,119)$. The sharp pointed fruits of Erodium cicutarium may cause local irritation by working into the wool of sheep. Aira caespitosa may also cause injury to the mouth of stock.

A case is recorded in New South Wales in which cattle and horses ate Shepherd's Purse (Capsella Bursa-pastoris). The cattle were unaffected, but the horses scoured, though most of them soon recovered when removed from the cultivated paddock containing the weed. Two young horses, however, showed signs of colic, became bloated, and died. It was then found that they contained balls of fibrous material (one weighed $1 \mathrm{lb} .9 \frac{1}{2} \mathrm{oz}$.) which consisted to the extent of nearly 50 per cent. of fibres from Shepherd's Purse, and death was due to simple mechanical obstruction of the bowel (155).

Chickweed (Stellaria media) has been found to cause digestive disorder 
in lambs and sheep when eaten in large quantities (48), and has caused the death of many a lamb. It would appear to be due entirely to the formation of large lumps of the weed in the stomach, and subsequent fermentation (Farmer and Stockbreeder, Mar. 16, 1908).

According to Cornevin, Black Bindweed ( $P$. Convolvulus L.) may prove injurious, owing to the occurrence of the hard, trigonous, and pointed "seeds" in cereal grains. Galtier published facts which show that oats which contain too many of the "seeds" may, by prolonged use, occasion a more or less serious enteritis, which is sometimes fatal, particularly when the grain is fed to greedy horses which scarcely grind their food (73). The fruits or "seeds" of Knot-weed (Polygonum Aviculare L.) may similarly prove injurious, and probably the seeds of other plants. 


\section{CHAPTER IX}

\section{CLASSIFICATION OF POISONS.}

The classification of poisonous plants according to their effects is a somewhat difficult process, since more than one prominent symptom may be produced by the same plant. Two classifications, however, may be given as examples, the first that of Blyth, and the second that of A. B. Smith. These must be regarded as essentially applicable to human beings, though serving more or less as a guide in case of poisoning of farm live-stock.

\section{Blyth's Classification (after Pammel).}

A.-Poisons causing death immediately or in a few minutes: Prussic acid, cyanides, oxalic acid, and occasionally strychnine.

B. - Irritant Poisons, with symptoms chiefly pain, vomiting, and purging: Ergot, digitalis, colchicum, yew, laburnum.

C.-Irritant and Narcotic Poisons, with symptoms of an irritant nature, with more or less cerebral indications: Oxalic acid or oxalates.

D.-Poisons more especially affecting the Nervous System :

1. Narcotics.-Symptoms: insensibility, which may be preceded by more or less cerebral excitement. Opium.

2. Deliriants.-Delirium, for the most part, a prominent symptom: Belladonna, hyoseyamus, stramonium, and other Solanaceae, Lolium temulentum, Oenanthe crocata, poisonous fungi.

3. Convulsives.-Almost every poison bas been known to produce convulsive effects, but the only true convulsive poisons are the alkaloids of the strychnine class.

4. Complex Nervous Phenomena.-Aconite, digitalis.

\section{A. Bernhard Smith's Classification.}

\section{A.-Poisons acting on the Brain.}

1. Narcotics.-Symptoms: Giddiness; dimness of sight; contracted pupils; headache; noises in the ears; confusion of ideas, and drowsiness, passing into insensibility.

British Plants included: Papaver somniferum. 
2. Deltriants. - Symptoms : Spcctral illusions; delirium; dilated pupils; thirst and dryness of the mouth; incoordination. Occasionally, though rarely, there are paralysis and tetanoid spasms.

British Plants included: Datura Stramonium, Hyoscyamus niger, Solanum Dulcamara, Solanum nigrum, Atropa Belladonna, Lolium temulentum.

3. INEBrIANTS.-Symptoms: Excitement of ccrebral functions and of the circulation; loss of power of coordination and of muscular movements, with double vision; leading to profound sleep and deep coma.

British Plants included: Pinus pinaster, Pinus larix, Artemisia maritima, Artemisia Absinthium.

\section{B.-Poisons acting on the Spinal Cord.}

Convolsives.-Symptoms : Clonic (intermittent) spasms, extending from above downwards. Opisthotonos very violent; but trismus (lock-jaw) rare. Swallowing spasmodic. Death, usually, in less than three hours, or rapid recovery.

British Plants included: none.

\section{C.-Poisons acting on the Heart.}

1. Depressants.-Symptoms: Vertigo; vomiting; abdominal pain; confused vision; convulsions; occasional delirium; paralysis; syncope; sometimes asphyxia.

British Plants included : Conium maculatum, Cytisus Scoparius.

2. Asthenics.-Symptoms: Numbness, and tingling in the mouth; abdominal pain; vertigo; vomiting; purging; tremor; occasional delirium; paralysis; dyspnœa, ending in syncope.

British Plants included: Prunus laurocerasus, (Phaseolus lunatusimported cattle food), Lathyrus aphaca, Rumex Acetosa, Aconitum Napellus, Actaea spicata, Delphinium consolida, Digitalis purpurea, Convallaria majalis, Colchicum autumnale.

\section{D. - Vegetable Irritants.}

1. Purgatives.-Symptoms : Abdominal pain; vomiting and purging; cramps; strangury and tenesmus, followed by collapse, and sometimes accompanied by drowsiness, and slight nervous symptoms.

British Plants included: Sambucus nigra, Sambucus Ebulus, Helleborus viridis, Helleborus fœtidus, Caltha palustris, Linum catharticum.

2. Aвortrves.-Symptoms : Nausea; vomiting; stupor; polyuria; sometimes tenesmus. Abortion may or may not occur; cons.

British Plants included : Juniperus Sabina (cultiv. in Britain), Claviceps purpurea; Ruta graveolens (cultiv. in Britain).

3. Irritants wTth Nervous Symptoms.-Symptoms: Abdominal pain; vomiting and purging; dilated pupils; headache; tetanic spasms; occasional convulsions; sometimes rapid coma.

British Plants included: Oenanthe crocata, Ocnanthe Phellandrium, Oenanthe fluviatilis, Cicuta virosa, Aethusa Cynapium, Sium angustifolium, Taxus baccata, Cytisus Laburnum, Paris quadrifolia, Mercurialis perennis. 
4. StMrple IrRItants.-Symptoms : Burning pain in the throat and stomach; thirst; nausea; vomiting; tenesmus; purging; dysuria; dyspnœea and cough occasionally. Death through shock; convulsions; exhaustion; or starvation due to injury to throat or stomach.

British Plants included : Arum maculatum, Daphne Laureola, Daphne Mezereum, Narcissus moschatus, Narcissus poeticus, Scilla bifolia, Galanthus nivalis, Hyacinthus nonscriptus, Fritillaria meleagris, Clematis Vitalba, Anemone nemorosa, Anemone appenina, Ranunculus aquatilis, R. Flammula, R. Ficaria, R. auricomus, R. sceleratus, R. acris, R. bulbosus, Aquilegia vulgaris, Bryonia dioica, Ligustrum vulgare, Asarum europæum, Saponaria officinalis, Valeriana officinalis, Agrostemma Githago, Doronicum Pardalianches, Impatiens noli-me-tangere, Erysimum cheiranthoides, Cynoglossum officinale, Arctostaphylos Uvaursi, Tamus communis, Euonymus europæus, Rhamnus catharticus, Glaucium luteum, Roemeria hybrida, Papaver Rhoeas, Chelidonium majus, Sedum acre, Sedum album, Drosera rotundifolia, Linaria vulgaris, Iris Pseudacorus, Iris foetidissima, Buxus sempervirens, Crocus sativus, Euphorbia Peplis, E. pilosa, E. Helioscopia, E. platyphylla, E. hiberna, E. portlandica, E. Paralias, E. Peplus, E. exigua, E. Lathyris, E. amygdaloides, Urtica dioica, U. urens, U. pilulifera, Viscum album, Lepidium latifolium.

5. Simple Irritants When TAKen IN LARGe QUANTITIES.-Symptoms: Burning pain in throat and stomach, vomiting; purging; difficulty in swallowing. Recovery usual.

British Plants included : Sinapis alba, and S. nigra. 


\section{BIBLIOGRAPHY}

1. Aderhold, R. Úber das Mutterkorn des Getreides und seine Verhütung Kais. Biol. Anst. f. Land. und Forstw., Flugblatt No. 21.

2. Agricultural Journat, Union of S. Africa, July, 1913.

3. Agricultural Gazette of New S. Wales, Oct. $2,1913$.

4. Allen's Commercial Organic Analysis. Vols. vi. and vir, 1913.

5. ANALYST, August, 1906.

6. Armatage, G. The Sheep Doctor, 1895.

7. Atrisson, V. T. Action of Poisons. Special Report, Diseases of Cattle and on Cattle Feeding. U.S. Dept. Agric., Bur. An. Ind., 1896.

8. - Poisons and Poisoning. Special Report, Diseases of Cattle, rev. by L. Pearson. U.S. Dept. Agric., Bur. An. Ind., 1908.

9. AuLd, S. J. M. (See Dunstan, W. R.)

10. BAILEY, F. M. Weeds and Suspected Poisonous Plants of Queensland, 1906.

11. - and Gordos, P. R. Plants reputed Poisonous and Injurious to Stock, 1887.

12. BaNG, B. Cases of Poisoning from Rape-seed Cakes. Ugeskr. Landm., 1897. Abs. in Exp. Sta. Rec., 9, p. 994.

13. BARGER, G., and CARR, F. H. Note on Ergot-Alkaloids. Phar. Jour., 23, p. 257.

14. BaUme, M. Poisoning by Oenanthe crocata. Archiv. des Mal. Mentales, 1881, No. 3. Abs. in Ed. Vet. Rev., 4, p. 704.

15. Becker, T. C. (See Witthads, R. A.)

16. Beilsters, F. Handbuch der Organischen Chemie. 3 Bd. Hamburg and Leipzig, 1897.

17. Bentham ANd Hooker. British Flora, 1908.

18. Berge, Fr., and RIECKe, V. A. Giftpflanzenbuch, 1845.

19. Beritiner Tierarztuiche Wochenschrift. Var. issues.

20. Bessey, C. E. Poisonous Weeds. Rept. Nebraska Agr. Exp. Sta., 16, pp. 14-62.

21. Blankinshir, J. W. The Loco and other Poisonous Plants in Montana. Agric. Coll. Exp. Sta., Montana, Bul. 45, 1903.

22. Blytн, A. W. Poisons: Their Effects and Detection. 4th Ed., 1906.

23. — Old and Modern Poison Lore, 1884.

24. — and Вцчтн, M. W. Poisons. Rev. Edn., 1906.

25. Board of Agric. and Fisheries. Ann. Rept. Proc. Dis. Anim. Acts for 1910 (Cd. 5606, 1911).

26. L Leaflet, No. 13. Acorn Poisoning.

27. — " No. 222. Meadow Saffron.

28. — " No. 251. Some Common Weeds (Corn Cockle).

29. — " No. 291. Food Value of Acorns, Horse-Chestnuts and Beech Mast. 
30. Boeck, H. von. (See BöHar, R.)

31. Boеrm. Cicutoxin. Archiv. f. exp. Path. u. Pharmakol., 5, 279-310.

32. Bömy, R., NAUNyn, B., and BofCK, H. von. Handbuch der Intoxicationen. Ed. 15 of the German Ed. of Ziemssen's Cyclop.

33. Brandt, J. F., and Ratzeburg, J. F. C. Deutschlands phan. Giftgewächse in Abbildungen $u$. Beschreibungen, 1838.

34. Breteat. (See Cazeneuve.)

35. British Pharmacedtical Codex, quoted in Pharm. Jour., Aug. 29, 1911.

36. BrüHL, J. W., in col. with E. HJelt and O. Aschan. Die Pflanzen Alkaloide. Braunschweig, 1900.

37. BRÜNNICH, J. C. Hydrocyanic Acid in Fodder Plants. Jour. Chem. Soc., 1903, 788-796.

38. BuLLetin of the Imperial Institute, 1903, 1905, 1906.

39. - 1911, (Datura, Hyoscyamus).

40. Boll. Agric. Intelligence and Plant Diseases. Inter. Instit. Agric. Aug.-Oct., 1911, p. 2099 (Solanum Dulcamara).

41. Bulltard, P. Histoire des Plantes vénéneuses et suspectes de la France, 1798, Ed. 2.

42. Callsen, J. Ueber die Alkaloide der Samen von Lupinus angustifolius und von Lupinus perennis, var. polyphyllus. Archiv. der Phar., 237, 566-595.

43. Canadian Dept. Agric., Ottawa. Farm Weeds of Canada. 2nd Ed., 1909.

44. CARR, F. H. (See Bargir, G.)

45. Carruthers, Wr. Aethusa Cynapium. Jour. Roy. Agric. Soc., England, $63: 280$.

46. Lychnis Githago. Id., 63: 279.

47. - Ranunculus bulbosus. Id., 63: 279 .

48. - Stellaria media: Is it Poisonous ? Id., $64: 308$.

49. — and Others. Yew Poisoning. Id., Ser. III, 3: 698.

50. Cazeneuve, P., and Bretead, P. Sur la Solanine. Compt. Rend., tome 128,1899 , p. 887.

51. Chemist and Druggist. Var. issues.

52. Chesnut, V. K. Principal Poisonous Plants of the United States. U.S. Dept. Agric., Div. Bot., Bull. 20, 1898.

53. - Thirty Poisonous Plants of the United States. U.S. Dept. Agric. Farmers' Bull. 86, 1898.

54. - Preliminary Catalogue of Plants Poisonous to Stock. Ann. Rept. Bur. An. Ind., U. S. Dept. Agr., 15: 387-420.

55. - Some Common Poisonous Plants. Year Book, U.S. Dept. Agr., 1896.

56. - Some Poisonous Plants of Northern Stock Ranges. Id., 1900.

57. — and Wrcox, E.V. Stock Poisoning Plants of Montana. U.S. Dept. Agr., Div. Bot. Bull. 26, 1901.

58. Coale, R. D. (See Remsen, I.)

59. Colun, Eug. Traité de Toxicologie végétale, 1907.

60. Colville, F. V. Crimson Clover Hair Balls. Circ. U.S. Dept. Agr., Div. Bot., $8: 4$.

61. Comptes Rendus. No. 147, 1906 ; 150, 1910; \&c.

62. Cooke, M. C. Seven Sisters of Sleep. London, 1860. 
63. Connevin, Ch. Des Plantes Vénéneuses, 1887.

64. - Sur l'empoisonnement par quelques espèces de Cytisus. Compt. Rend., 1886.

65. Cusminy, A. R. Phariuacology, 1898.

66. Ueber das Ricinusgift: Areh. f. exper. Path. u. Pharm., 1898.

67. Czapek, F. Biochemie der Pflanzen, 1905.

6S. Daily Mrrror, Dec. 13, 1910 (Hyoseyamus poisoning).

69. Die Futterumtel des Handels, 1906.

70. Die landwitscilaftliche Versuchs-Stationen, Lxxir, 1 and 2, p. 93.

71. Dietrich, D. N. F. Deutschlands Giftpflanzen, 1826.

73. Drxon, W. E. Manual of Pharmacology. 4th Ed., 1915.

74. Doeltz, J. C. Neue Versuche und Erfahrung der einige Pflanzengifte, 1892.

75. Duchesse, E. A. Répertoire des Plantes Utiles et des Plantes Vénéneuses du Globe. Brussels, 1846.

76. Dunstan, W. R. Glucosides, 1913.

77. Henry, T. A., and Auld, S. J. M. Cyanogenesis in Plants, Proc. Roy. Soc., Vol. 72, 1903; B. Vol. 79, 1906; B. Vol. 79, 1907.

78. - and Umsey, C. I, Contributions to Our Knowledge of the Aconite Alkaloids; II, The Alkaloids of the true Aconitum Napellus; III, Formation and Properties of Aconine and its Conversion into Aconitine. Jour. Chem. Soc., 1892.

79. Eden, R. T. Digitalis and its Cumulative Action. Ther. Gaz., 6: 89.

80. Erdmann, K. G. Sammlung und Beschreibung der Giftpflanzen. Dresden, 1797.

81. Esser, P. Die Giftpflanzen Deutschlands, 1910.

82. Ewart, J. Weeds, Poison Plants and Naturalized Aliens of Victoria, 1909.

83. FALCK, F. A. Lehrbuch der praktischen Toxikologie, 1880.

84. Field, The. Var. issues.

85. Flückioer, F. A. Pharmakognosie der Pflanzenreiche, 1881-2.

86. - and Hanbury, D. Pharmacographia, 1879.

87. Friedberger, F., and Fröhner, E. Veterinary Pathology. Ed.6. 1:731; $2: 702$.

88. Fröhner, EuaEn. Lehrbueh der Toxicologie für Tierärzte, 1910.

89. - (See Fried berger, F.)

90. Gardener's Chronicle. Var. issues.

91. Gruman, J. F. Conium maculatum. Jour. belge d'homoeopathie, 1899.

92. Grmlette, J. D. On Datura Poisoning. Brit. Med. Jour., 1903.

93. Glover, G. H. Larkspur and Other Poisonous Plants. Agric. Exp. Sta., Colorado, Bull. 113, 1906.

94. — Poisonous Weeds. Agr. Exp. Sta., Colorado, Bull. 137, 1909.

95. Gmelin, J. F. Abhandlung von den giftigen Gewäehsen, 1775.

95. - Allgemeine Geschichte der Pflanzengifte, 1775.

97. Godet, C. Les Plantes vénéneuses du Canton de Neuchâtel, 1864.

98. Goeppert, H. R. Ueber die giftige Pflanzen Schlesiens, 1832.

99. Gordon, P. R. (See Batley, F. M.)

100. Grandeau, L. Poisoning of Cattle by Yew Tree Leaves. Jour. d'Agric. Prat. I, 229-230, 1894. 
101. Greshoff, M. Phytochemical Investigations at Kew. Bull. Misc. Infor. Roy. Bot. Gardens, Kew, No. 10, 1909.

102. - Distribution of Prussic Acid in the Vegetable Kingdom. Rept. Colonial Museum Haarlem, Holland, 1906.

103. Gressler, F. G. L. Deutschlands Giftpflanzen, 1897.

104. Grönlund, Chr. Danske Giftplanter. Copenhagen, 1874.

105. Guardia, J. Poisonous Plants and their Poisons. Bull. Pharm., 1893.

106. Guerin, P. The Probahle Cause of the Poisonous Effect of the Darnel, Lolium temulentum. Bot. Gaz. 28.

107. Gutgnard, L. Le haricot à acide cyanhydrique (Phaseolus lunatus). Rev. Vit., 1906.

108. - Recherches physiologiques sur la greffe des plantes à acide cyanhydrique. Ann. sc. Nat., ser. 9, Bot. 6, 261-305.

109. - A Study of Beans yielding Hydrocyanic Acid. Rev. Vit., 26.

110. - Sur la greffe des plantes à acide cyanhydrique. Compt. Rend. Acad. Sc. Paris, 1907.

111. Güssow, H. T. Canad. Ex. Farms Rept. 1912 (Equisetum arvense).

112. Cattle Poisoning by Plants. Farmer and Stockbreeder Year Book. 1907.

113. - Injurious Fodder and Poisonous Plants. Jour. Roy. Agric. Soc., England, 1907.

114. HAAS, P., and HILl, T. G. The Chemistry of Plant Products, 1913.

115. Halenke, A., and Kling, M. Landw. Versuchs.-Stat., vol. 64.

116. HaLLE, J. S. Die deutsche Giftpflanzen, Berlin, 1784-1795.

117. Halsted, B. D. The Poisonous Plants of New Jersey. Rept. Bot. Dept., N. J. Agr. Coll. Exp. Sta., 1894 (1895), pp. 401-419.

118. Hanbury, D. (See Flǘckiger, F. A.)

119. Harshberger, J. W. A Review of our Knowledge of Phytobezoars. Jour. Com. Med. \& Vet. Arch., 19 : 143.

120. Hartman, G. Mechanische Vergiftungen. Berlin, 1896.

121. HARLeY, J. Aethusa Cynapium, St Tho nas' Hospital Reports, n.s. 1873.

122. HEBERT, A. Recherches sur la présence de l'acide cyanhydrique chez diverses plantes. Bull. de la Soc. chim. de Paris, 1896.

123. Hedrick, U. P. Cicuta, a Plant that Poisons Cattle. Bull. Oreg. Agr. Exp. Sta., $46: 12$.

124. Hein, Heinrich. Deutschlands Giftpflanzen. Hamburg. 1880.

125. Hendrick, J. Poisonous Beans. Trans. Highland and Agric. Soc., 1907.

126. Henkel, Alice. Weeds Used in Medicine. U.S. Dept. Agric. Farmers' Bull. 188, 1904.

127. Henry, T. A. (See Dunstan, W. R.)

128. _ The Plants Alkaloids, 1913.

129. - On the Occurrence of Prussic Acid and its Derivatives in Plants.

Sci. Progress, No. 1, July, 1906.

130. Henslow. Rev. G. Poisonous Plants in Field and Garden, 1901.

131. - The Uses of British Plants traced from Antiquity to the Present Day, 1905. 
132. Herissey, H. Ueber das Prulaurocerasin. Arch. der Phar., 245: 463-469.

133. Hroger, A. (See Huseman, A.)

134. Hill, T. G. (See HaAs, P.)

135. Huseman, A., Hiloer, A., and Huseman, Th. Die Pflanzenstoffe in chemischer, physiologischer und toxieologiseher Hinsieht. Berlin, 1883.

136. Index Phytochesucus. I. C. Ritsema \& Sack, Amsterdam, 1905.

137. JACkson, J. R. Poisonous Indian Peas. Phar. Jour., 76: 521-22.

13S. JARRESBERICHT ü. d. Fortsehritte auf dem Gesamtgebiete der AgrikulturChemie, 3te Folge, XIV, 1911 (1912).

139. Johnson, CH. British Poisonous Plants. London, 1856. [Ed. 2, ?1866].

140. C. P., and Sowerby, J. E. Useful Plants of Great Britain. London [? 1865].

141. - Cr., Johnson, C. H., and Sowerby, J. E. British Poisonous Plants, 1861.

142. Jones, L. R. A. (See Rich, F. A.)

143. Jour. Agricultural Research. Vol. 1., No. 2, Nov., 1913.

144. Jour. Board of Agriculture. Var. issues.

145. Jour. Roy. Aoric. Soc., Exgland. Annual Rept. of Consulting Botanist for 1899, Poisonous Plants investigations-including Ranunculus acris, R. parviflorus, R. Ficaria etc., etc., 1899, pp. 678-688.

146. Water Dropwort and Dog's Mereury (1898), p. 561.

147. - Bitter Sweet or Woody Nightshade (1905), p. 164.

148. - Meadow Saffron (1897), p. 742.

14\%. Jour. Soc. Chem. Indostry, May 15, 1908.

150. JणCH, K. W. Die Giftpflanzen. Augsburg, 1817.

151. Kannatesser, Fr. Die akuten Vergiftungen, 1911.

152. Karstex, G. (See Strasburger, E.)

153. KAUPP, B. F. Aconite Poisoning. Am. Vet. Rev., 30:454-56.

154. Keeler, D. D. Poisoning by Ergot. Am. Vet. Rev. 38: 25l-2.

155. Kellermans, W. A. 'Poisoning by Shepherd's Purse. Bot. Gaz., 20: 325-6.

156. Kerver, J. S. Deutschlands Giftpflanzen. Hanover, 1798.

157. Kerver, A., and Oltver, F. W. Nat. History of Plants, 1902.

158. Kioxka, H. Grundriss der Toxikologic. Leipzig, 1901.

159. Kuño, M. (See Halenke, A.)

160. Knolle, F. A. G. Plantas venenatas umbelliferas. Leipzig, 1771.

161. Ковевт, E. R. Compendium der praktischen Toxicologie, 1912.

162. - I,ehrbuch der Intoxicationen, 1893.

163. - Lebrbuch der Intoxicationen. II. Bd., 1906.

164. Kraus, C. Das gemeine Leinkraut. Arb. d. deut. landw. Gesell., Heft $166,1909$.

165. Kreutzer, K. J. Oesterreiches Giftgewächse, 1838.

166. Krocker, Dr. Zur Lupinenkrankheit der Sehafe. Landw. Jahrb., 9: 27-35

167. Kubixgi, A. Plantae venenosae Hungariae, 1842.

168. Konkel, A. J. Handbuch der Toxicologic, Jena, 2 Vols. 1899 and 1901.

169. Lambert, L. (See Noel, Charles.)

170. LANDER, G. D. Veterinary Toxicology, 1912.

171. Leather, J. W. Cyanogenesis in Plants. Ag. Jour. India, I, 220-225. 
172. Lemmann, K. B., and Mori, R. Ueber die Giftigkeit u. Entgiftung der Samen von Agrostemma Githago. Archiv. f. Hyg., 9: 257 (Bot. Gaz. 14: 233).

173. LehmaNN, Otтo. Giftpflanzen mit besonderer Berücksichtigung der wirksamen Stoffe, 1882.

174. Lewin, L. Lehrbuch der Toxicologie. Ed. 2.

175. Ltadtard, A. Poisoning of Horses by Snow Drop. Am. Vet. Rev., 30: 298.

176. Lohmann, C. E. J. Ueber die Giftigkeit der deutschen Schachtelhalmarten. Arb. d. deut. landw. Gesellschaft, Heft 100, 1904.

177. Lubenad, Dr. On Poisoning from Foods. Centrbl. f. Bakt., 1906, I. Abt., Orig., xL., 433.

178. McCarthy, Gerald. The Poisonous Plants of North Carolina. Bull. N.C. Agr. Exp. Sta. (St. Bd. Agric.), $22: 48$.

179. MacDougall, R. S. On Lathyrus sativus . . . and Allied Leguminous Plants. Jour. Bot. Soc. Edin., Dec., 1894.

180. Matden, J. H. Native Plants Poisonous to Stock. Agr. Gaz. N. S. Wales, $6,57-58$.

181. Plants reported to be Poisonous to Stock in Australia. Id. 12, $637-666$.

182. MARCHLEWSKI, L. (See CHUNCK.)

183. Marsh, C. D., and others. Larkspur or "Poison Weed." U.S. Dept. Agric. Farmers' Bull. 531, 1913.

184. Mrlch-Zirtung, 23 (1894), p. 6. Poisoning of Swine from feeding Rye Meal containing Corn Cockle Seed.

185. Mrquel, F. A. W. De Nord-Nederlandsche vergiftige Gewassen, 1838.

186. MrtLacher, W. Toxicologisch oder forensisch wichtige Pflanzen, 1904.

187. Moeller, J. Digitalis and Verbascum. Phar. Post., 37:677-680.

188. Mori, R. (See Lehmañ, K. B.)

189. Moss, R. J. The Taxine in Irish Yew. Sci. Proc. Roy. Dublin Soc., vol. XII (N.S.), No. 10, 1909.

190. MÜLLER, G. Landwirtschaftliche Giftlehre. 1897.

191. Müller, Georg, and Kradse, C. Ueber die Giftwirkung der Anemone nemorosa. Archiv. für wissenschaftliche u. praktische Thierheilkunde, $23,326-335$.

192. MUELLer, KarL. Colchicum autumnale. Die Natur., $44: 550$.

193. Nadnyn, B. (See BöHm, R.)

194. Nebraska. 16th Ann. Rept., Agric. Exp. Sta., Univ. Nebr., 1903, pp. 14-94.

195. New Zgaland Dept. Agric. Ann. Repts., 1904. Ragwort Poisoning.

196. Jour. of Agric., 15th Sept., 1913, 301.

197. Noez, Charles. Contributions à l'étude médicale de l'Anemone Pulsatilla. Nancy, 1897.

198. - and LAMBERT, L. Recherches expérimentales sur l'Anemone Pulsatilla. Arch, inter. de phar., 1897.

199. Noll, F. (See Strasburger, E.)

200. Nonn, J. A. Veterinary Toxicology, 1907.

201. Oliver, F. W. (See K ERner, A.)

202. Opwyrda, R. J. (See Praag, L. van.) 
202 b. Orfila, M. J. Traité de Toxicologie, Ed. 5, 2 v. Paris, 1852.

203. Pammel, L. H. Manual of Poisonous Plants, 1911. (Contains a list of 1097 references to Poisonous Plant Literature.)

204. Poisonous and Medical Plants of Missouri. Bul. 14, Missouri Stato Bd. Hort.

205. Parkinson, S. T., and Russell, E. J. A List of Plants Poisonous to Stock. Jour. S. E. Agric. College, Wye, Kent, No. 16, 1907.

206. Patek, Johans. Die Giftpflanzen, 1866-67.

207. Peters, A. T. (Seo Sturdevant, L. B.)

208. Pfaff, Franz. Ivy Poisoning and its Treatment. Bull. Rov. Bot. Gardens, Kew, 1903, 15-16.

209. Pharmaceutical Journal. Var. issues.

210. Pictet, A. La Constitution chimique des Alcaloïdes Végétaux, $2^{\text {me }}$ Ed., 1897.

211. Plugge, P. C. Andromedotoxin-haltige Ericacen. Arch. der Pharm., $229: 552-554$.

212. Giftiger Honig von Rhododendron ponticum. Arch. der Pharm., $229: 554-56$.

213. Pотт, EmL. Handbuch der tierischen Ernährung und landwirtschaftlichen Futtermittel, II. Bd., 1907.

214. Power, F. B., and Totix, F. Chemical Examination of Aethusa Cynapium. Wellcome Chem. Res. Laboratories, No. 58, 1905.

215. PraAg, L. VAN, and OPWYRDa, R. J. Leerbuch voor practische giftleer, 1871.

216. Pratr, Anve. The Poisonous, Noxious and Suspected Plants of our Fields and Woods [?1887].

217. Ratri, Professor. On Colchicum Poisoning. Phar. Jour. and Trans., m, 6: 47 (abstr. from Lancet).

218. Ratzebura, J. F. C. (See Brandt, J. F.)

219. Remsen, I., and Coale, R. D. Am. Chem. Jour., vi, 1884, p. 50.

220. RICE, W. S. Equisetum Poisoning. Am. Vet. Rev., 26: 944-951.

221. Rrch, F. A. Poisonous Equisetum. Proc. Am. Vet. Assoc., 1902.

222. — and Jones, L. R. A. Poisonous Plant: the Common Horsetail. Bull. Vt. Agr. Exp. Sta., 95: 187-192.

223. Rrchet, C. Les poisons convulsivants. Arch. inter. de phar., 4: 293-309.

224. Rrecke, V. A. (See Berge, Fr.)

225. Rothera, A. C. H. Reputed Poison Plants. Jour. Dept. Agr. Victoria, Nov., 1910.

226. Russell, E. J. (See Parkinson, S. T.)

227. Schenck, H. (See Strasburger, E.)

228. SCHIMPFKY, RICHARD. Deutschlands wichtigste Giftgewächse in Wort und Bild, nebst einer Abhandlung über Pflanzengift, 1893.

229. Schmedeberc, O. On Digitalin. Archiv. Exp. Path., 16: 149.

230. SchünemanN, H. Die Pflanzenvergiftungen, 1891.

231. Schonck, E., and Marchlewski, L. Ann. d. Chem., 278, 354.

232. Sitzbericht K. Acad. Wiss. (Vienna), Math. Naturw. Kl., 121 (1912)

I, No. 1-3.-Abs. Exp. Sta. Record, xxrx, p. 133.

233. Sмrтн, A. B. Poisonous Plants of All Countries, 1905.

234. Sowerby, J. E. (Sce Jomnson.) 
235. Strasburger, E., Noll, F., Schenck, H., and Karsten, G. Text Book of Botany. 3rd Eng. Ed. Rev. by W. H. LANG. 1908.

236. Stтввs, G. (See Thorpe, T. E.)

237. Sturdevant, L. B., and Peters, A. T. The Poisoning of Horses by the Common Horse-tail Weed. Rept. Neb. Agr. Exp. Sta., 19: 111-115.

238. Tasmanta, Agric. and Stock Dept. Hemlock. Bull. No. 22, 1911.

239. Thorpe, T. E., and Strbbs, G. Yew Poisoning, Trans. Chem. Soc., 81 (1902).

240. Tronpe, T. E. A Dictionary of Applied Chemistry, 1912.

241. Trans. Chem. Soo., 1902.

242. 1907, p. 337.

243. Treub, M. Nouvelles recherches sur le rôle de l'acide cyanhydrique dans les plantes vertes. Ann. Jardin bot., Buitzenborg, Ser. II, 6: 79-106.

244. Toczek, F. Behandlung der Vergiftungen mit Pflanzenstoffen. Handb. d. Spec. Therap. innerer Krankh. 2: 234-334, 1894.

245. Totin, F. Chemical Examination of Oenanthe crocata. Wellcome Chem. Res. Laboratories, No. 132, 1911.

246. - (See Pow ER, F. B.)

247. Umney, C. (See Dunstan, W. R.)

248. U.S. Dept. Agric. Experiment Station Record. Var. issues.

249. - See (7), (8), (52-57), (60), (126), and (183).

250. VAN Es, L., and WaLdron, L. R. Some Stock Poisoning Plants of North Dakota. N. Dak. Agr. Coll. Exp. Sta., Bull. 58, 1903.

251. VAN RiJN, J. J. L. Die Glykoside, 1900.

252. Verschaffelt, E. Bepaling der werking van vergiften op planten, Afd. $\mathrm{d}$. $\mathrm{k}$. Akad. v. Welensch. Amst. 12: 855-9, 1903-4.

253. Veterinarian. Var. issues.

254. Veterinary JoURnaL. Var. issues.

255. Veterinary News. Var. issues.

256. VETERINARY RECORD. Var. issues.

257. Vicat, P. R. Histoire des Plantes vénéneuses de la Suisse. Yverdon, 1776.

258. WaLdron, L. R. (See VAN Es, L.)

259. WALSH, L. H. South African Poisonous Plants. 1909.

260. Weber, C. A. Der Duwock (Equisetum palustre). Arb. d. deut. landw. Gesell., Heft 72, 1902.

261. Wiedmann, Fr. Zur chemischen Charakteristik der Familie der Papaveraceen. Munich, 1901.

262. Wrlcox, E. V. (See Chesndt, V. K.)

263. Wrison, P. Rhododendron Poisoning in a Goat. The Veterinarian, 70: 639-640.

264. Winslow, Kenecm. Veterinary Materia Medica and Therapeutics. 1902.

265. Wrtthads, R. A., and Becker, T. C. Medical Jurisprudence, Forensic Medicine and Toxicology. Vol. 4., 1896.

266. Wunchmans, F. Deutschlands Giftpflanzen. 1833.

267. Zeitschr. Anal. Chem., 1905, No. 44.

(See also various references in the text.) 


\section{INDEX}

Abies excelsa 72

- pectinala 72

Abietin 72

Achillea Millefolium 100

Achilleine 100

Aconine 15

Aconitic acid 86

Aconitine 11, 15

Aconitum Niapellus 10, 14, 15, 103, 104

Acorns $70-72,100$

Actaea spicata 104

Aethusa Cynapium 39, 104

Agrostemma Githago 3, 6, 8, 19, 105

Agrostemma-Sapotoxin 21

Agrostemmin 21

Aira caespitosa 101

All-Heal 93, 105

Alliaria officinalis 19,100

Allium sp. 99

Allyl-isothiocyanate 18

Amentacex 69

Amygdalin 8, 94

Anagallis arvensis 48

Anchusa officinalis 94

Andromedotoxin 47, 48

Anemonal 9

Anemone sp. 9, 11

- appenina 105

- nemorora 9, 105

- pulsatilla 9

- Wood 9

Anemone-camphor (oil of anemone) 9

Anemonic acid 10, 11

Anemonin 10, 11

Annual Mercury 67

Anthemis aetnensis 94

- ariensis 94, 101

- chia 94

- Cotula 94, 101

Apoatropine 59

Aquilegia vulgaris 105

Araliaceæ 43

Arbutin 47, 48

Arctostaphylos Uva-ursi 105

Aroldeæ 76

Artemisia Absinthium 101, 104

- maritima 104

Arum maculatum 76, 77, 105

Asarum europaum 105

Asphodel, Bog 97, 101

Aspidium filix.mas 88
Astragalus bisulcatus 3

Atriplex sp. 97

Atropa Belladonna 4, 5, 8, 50, 52, 58, 103 , 104

Atropine 50, 59

Autumn Crocus 2, 3, 79-82, 100, 104

Azalea sp. 4, 48

- arborescens 48

- indica 48

- nudiflora 48

- pontica 48

Balsamorhiza sagitlata 3

Beans 4, 32, 33, 104

Belladonine 59

Bclladonna, see Deadly Nightshade

Bibliography 107

Bindweeds 49, 102

Bittersweet 54, 104

Black Bindweed 49, 102

- Bryony 35, 78, 105

Bog Asphodel 97, 101

Box 69, 105

Bracken 87, 93

Brake-fern 87, 93

Brassica nigra 18

- Sinapistrum 18, 19

Bromus 101

Broom 27, 104

Broom-rape 95

Bryogenin 35

Bryonia dioica 35, 78, 105

Bryonin 35, 78

Bryony 35, 78, 105

Buckthorn 24, 105

Buckwheat 64

Burma beans 32

Buttercups 8, 10-12, 99, 105

- Acrid 10, 105

- Bulbous 10, 11, 105

- Celery-leaved 10, 11, 99, 105

Butterwort 101

Buxine 69

Buxinidine 69

Buxus sempervirens 69, 105

Caltha palustris 9, 12, 99, 104

Canadian Erigeron 93

Caper Spurge 66, 67, 100, 105

Caprifoliaces 43

Capsella Bursa-pastoris 101 
Caryophyllaceæ 19

Castor Oil Plant 33

Catmint 96

Cats-Ear 94

Celandine, Greater 17, 105

- Lesser 10, 11, 105

Celastraceæ 24

Celery-leaved Buttercup 10, 11, 99, 105

Chaerophyllin 40

Chaerophyllum sp. 37,40

- sylvestre 40

- temulum 40

Chamomile, Corn and Wild 101

Charlock 18

Chelerythrine 17

Chelidonine 17

Chelidonium majus 17, 105

Cherry Laurel 34

Chervils 40

Chickweed 101

Chinovic acid 93

Choline 68

Christmas Rose 13

Chrysanthemum Leucanthemum 100

Cicuta virosa 2, 8, 36, 104

Cicutine 36

Cicutoxine 36

Classification of Poisons 103

Claviceps microcephala 98

- purpurea 8, 88-91, 103, 104

Clematis Vitalba 9, 105

Cockle, Corn 3, 6, 8, 19, 105

Colchicine 80

Colchicum sp. 8, 11, 103

- autumnale 2, 3, 79-82, 100, 104

Compositæ 44

Conhydrine 30,41

Coniceine 41

Coniferæ 72

Coniferin 72

Coniine 30, 39, 41

Conium maculatum 6, 30, 41, 101, 104

Consolidine 94

Convallamarin 79

Convallaria majalis 79,104

Convallarin 79

Convolvulaceæ 49

Convolvulus sp. 49, 102

- arvensis 49

- sepium 49

Com Chamomile 101

Corn Cockle 3, 6, 8, 19, 105

Cornutine 89

Cowbane 2, 8, 36, 104

Cow. Wheat 96, 100

Cress, Penny 101

Crocus, Autumn 2, 3, 79-82, 100, 104

Crocus sativus 105

Crowfoot, Tall 10, 11, 105

Cruciferæ 18

Cuckoo Pint 76, 77, 105

Cucurbitaceæ 35

Cumarin 92
Cupressus macrocarpa 73

- nootkatensis 73

Cuscuta sp. 94

- Epithymum 94

- europaea 94

Cuscutin 94

Cyclamin 49

Cynapine 39

Cynoglossine 94

Cynoglossum officinale 94, 105

Cytisine 25, 27, 92

Cytisus Laburnum 25, 27, 104

- Scoparius 27, 104

- Weldeni 25

Daphne sp. 4, 8

- Laureola 65, 105

- Mezereum 65, 105

Daphnin 65

Darnel 8, 48, 82-84, 96, 103, 104

Datura Stramonium 50, 103, 104

Daturine 50

Deadly Nightshade 4, 5, 8, 50, 52, 58, 103 , 104

Delphinine 11, 14

Delphinium Ajacis 14

- Consolida 14, 104

- Staphisagria 14

Delphinoidine 14

Delphisine 14

Devil's-Bit 93

Digitalein 61

Digitaline 61

Digitalis purpurea 61, 103, 104

Digitin 61

Digitonin 61

Digitoxine 61

Dioscorideæ 78

Docks 63, 64

Dodders 94

Dog's Mercury 67, 68, 100, 104

Doronicum Pardalianches 105

Dropwort, Water 37, 103, 104

Drosera sp. 93

- rotundifolia 105

Dulcamarin 54

Dwarf Elder 43, 104

Ecboline 89

Echium vulgare 94

EIder, Common 43, 104

- Dwarf 43, 104

Endoconidium temulentum 83

Equisetaceæ 84

Equisetine 86

Equisetum sp. 3, 84-87, 100

- arvense $84,85,86,87$

- heleocharis 85

- maximum 83

- palustre 85, 100

- pratense 85

- sylvaticum 85

Erg̈ot 8, 88-91, 103, 104 
Ergotinine 89

Frgotism 89

Engotoxine 89

Ericacen 46

Ericolin 47, 48

Erigeron, Canadian 93

Erigeron canadensis 93

Erodium cicutarium 101

Erysimum cheiranthoides 19, 105

Esparcet, False 3

Euonymin 24

Euопутия europaus 24, 105

Euphorbia sp. 8, 66, 67

- amygdaloides 105

- exigua 105

- Helioscopia 66, 105

- hiberna 105

- Lathyris 66, 67, 100, 105

- Paralias 105

- Peplis 105

- Peplus 66, 105

- pilosa 105

- platyphylla 105

- porilandica 105

Euphorbiaceæ 66

Fagopyrism 64

Ferns 87, 88

Figworts 95

Filices 87

Filicic acid 88

Flag, Yellow 97, 105

Flax, Purging 92, 104

Fool's Parsley 39, 104

Formic acid 75

Foxglove 61, 103, 104

Frangulin 24

Fritillaria Meleagris 97, 105

Fritillary, Common 97, 105

Fungi 88

Furze 92

Galanthus nivalis 105

Garden Nightshade 4, 52, 54, 104

Garlic Mustard 19, 100

Garlics 99

Geraniaceæ 23

Geranium, Wild 3

Githagin 21

Githagism 20

Glaucium luteum 105

Gorse 92

Gramineæ 82

Gratiolin 95

Great Mullein 95

Ground Ivy 96

Gummi hederæ 43

\section{Hedera Helix 43}

Hederin 43

Hellebore, Green 13, 14, 104

- Stinking 13, 104

Helleborein 13
Helleborin 12, 13

Helleborus 8p. 13

- fotidus 13, 104

- niger 13

- viridis 13, 14, 104

Hemlock (see also Water Hemlock) 6, 30, $41,101,104$

Henbane 6, 51, 101, 104

Herb Paris 78, 104

Hieracium Pilosella 98

Hordeum 101

Horsetails 3, 84-87, 100

Hound's Tongue 94, 105

Huckleberry 53

Hyacinthus nonscriptus 105

Hydrocotyle vulgaris 93

Hydroergotinine 89

Hyoscine 50, 51, 59

Hyoscyamine $6,46,50,51,59$

Hyoscyamus sp. 103

- muticus 6

- niger 6, 51, 101, 104

Hyoscypicrin 51

Hypericineæ 22

Hypericum perforatum 22

Hypochaeris radicata 94

Impatiens noli-me-tangere 105

Imperialine 97

Iridine 97

Iris foetidissima 105

- Pseud-acorus 97, 105

Ivraio 83

Ivy 43

- Ground 96

Java beans $4,32,104$

Jervine 12, 13

Jimson Weed 50

Juncus sp. 98

Juniperus Sabina 72, 104

King-cup 12 99, 104

Knot-weed 102

Kribbelkrankheit 89

Laburnum 25, 27, 103

Lactuca scariola 45

- virosa 45, 46

Lactucarium 46

Lactucerin 46

Lactucic acid 46

Lactucin 46

Lactucone 46

Lactupicrine 46

Larix europcea 72

Larkspur 14, 104

Lathyrism 27, 28

Lathyrus A phaca 29, 104

- Cicera 27

- Clymenum 27

- sativus 27, 96

Laurel, Cherry 34, 104 
Laurel, Spurge 65, 105

Lepidium latifolium 105

Lettuce, Wild 45

Ligustrin 49

Ligustron 49

Ligustrum vulgare 4, 49, 105

Liliaceæ 78

Lily-of-the-Valley 79, 104

Lima beans 32

Linaria vulgaris 95, 105

Linarin 95

Linum carthaticum 92, 104

Loco-weed 3

Loliine 83

Lolium temulentum 8, 48, 82-84, 96, 103 , 104

Lords and Ladies 76, 77, 105

Lousewort 63, 95

Lupines 29

- Blue 29

- False 3

- White 30

- Yellow 29

Lupinidine 27, 31

Lupinine 31

Lupinosis 29-32

Lupinotoxin 31

Lupinus sp. 29-32

- albus 30

- angustifolius 29

- luteus 29, 30

Mal de Brou 70

Maladie des Bois 70, 100

Male Fern 88

Marsh Marigold 12, 99, 104

Marsh Penny-Wort 93

Matricaria Chamomilla 101

Mayweeds 94, 101

Meadow Saffron 2, 3, 79-82, 100, 104

Mechanical injury, plants causing 101

Melampyrum sp. $63,95,96$

- arvense 96, 100

Melilot 92

Melilotus sp. 92

Mercurialine 68

Mercurialis annua $67,68,100$

- perennis 67,68, 100, 104

Mercury, Dog's and Annual 67, 68, 100, 104

Methylconiine 41

Mezerein 65

Mezereon 65, 105

Milk, plants affecting 99, 100, 101

- Achillea Millefolium 100

- Acorns 100

- Alliaria officinalis 100

- Allium sp. 99

- Anthemis sp. 94, 101

- Artemisia Absinthium 101

- Caltha palustris 99

- Chrysanthemum Leucanthemum 100

- Colchicum autumnale 80, 81, 100
Milk plants affecting (cont.):

- Conium maculatum 42, 101

- Cytisus Weldeni 25

- Equisetum palustre 87, 100

- Euphorbia sp. 67

- Lathyris 100

- Helleborus sp. 13, 14

- Hyoscyamus niger 52, 101

- Hypericum perforatum 22

- Matricaria Chamomilla 101

- Melampyrum arvense 100

- Mercurialis annua 68,100

- - perennis 68, 100

- Narthecium ossifragum $97 \quad 100$

- Oxalis Acetosella 23, 100

- Pinguicula vulgaris 101

- Quercus sp. 71, 100

- Ranunculus sp. 99

- Rhododendron 47, 100

- Rumex sp. 64

- Senebiera didyma 101

- Senecio latifolius 45

- Sium angustifolium 101

- - latifolium 37, 101

- Solanum tuberosum 57

- Tanacetum vulgare 44, 101

- Thlaspi arvense 101

Molinea caerulea 98

Monkshood 10, 14, 15, 103, 104

Morphine 16

Mullein, Great 95

Mustard, Garlic 19, 100

- Treacle 19

Naked Ladies 2, 3, 79-82, 100, 104

Narcissine 97

Narcissus sp. 97

- moschatus 105

- poeticus 97, 105

- pseudo-narcissus 97

Nardus stricta 101

Narthecin 97

Narthecium ossifragum 97,100

Nepeta Cataria 96

- Glechoma 1, 96, 98

Nettles 97, 105

Nightshade, see Deadly Nightshade and Garden Nightshade

Oak 69-72, 100

Oenanthe crocata 37, 103, 104

- fistulosa 38

- fluviatilis 104

- Phellandrium 38, 104

Oenanthotoxin 38

Oil of Cicuta 36

- Euphorbia 68

- Mustard 18

- Snapdragon 95

- Tansy 44

- Valerian 93

- Yew 75

Oleaceæ 49 
Orache 97

Orobanche minor 95

Oxalis Acclosella 23, 100

Paigya beans 32

Papaver sp. S, 16

- dubium 16

- Rhocas 16, 105

- somniferum 103

Papaveracere 16

Papilionacea 25

Parabuxine 69

Parabuxinidine 69

Paridin 78, 79

Paris quadrifolia 78, 104

Paristyphnin 78

Parsnip, Water 37, 101

- Wild 93

Pasque Flower 9

Pastinaca satiza 93

Peas, Indian 27, 96

- Mutter 27

Pedicularis sp. 63, 95

- palustris 63

- sylratica 63

Penny Cress 101

Penny-Wort, Marsh 93

Persicaria 64

Petty Spurge 66, 105

Phaseolunatin 8,33

Phaseolus lunatus 4, 32, 104

Picea sp. 72

Picein 72

Picrotoxin 36, 83

Pimpernel, Scarlet 48

Pinguicula vulgaris 101

Pinipicrin 72

Pinus larix 104

- pinastre 104

- strobus 72

- sylrestris 72

Pisum satirum 27

Poison Weed 48

Polygonacex 63

Polygonum Aviculare 102

- Convolvulus 102

- Fagopyrum 64

- hydropiper 64,65

- Persicaria 64, 65

Poppies 8, 16, 103, 105

Potato $54-58$

Potentilla Anserina 92

- tormentilla 88, 93

Primulaceæ 48

Privet 4, 49, 105

Protopine 17

Prulaurasin 34

Prunus laurocerasus 34, 104

Pseudoconhydrine 41

Pteris aquilina 87, 93

Pteritannic acid 88

Pulsatilla-camphor 9

Purging Flax 92, 104
Qucrcus sp. 69-72, 100

Radish, Wild 18

Ragwort 44

Rangoon beans 32

Ranunculaces 9

Ranunculus sp. 8, 9, 10, 12, 99

- acer 11

- acris 10, 11, 105

- aquatilis 10, 105

- auricomus 105

- bulbosus 10, 11, 105

- Ficaria 10, 11, 105

- Flammula 10, 11, 105

- lingua 10

- repens 10, 12, 99

- sceleratus 10,11,99, 105

Raphanus Raphanistrum 18

Rhamnaceæ 24

Rhamnetin 24

Rhamnus Catharticus 24, 105

- Frangula 24

Rheadine 16

Rhinanthin 63, 96

Rhinanthus sp. 63

- Crista-galli 95

Rhododendrin 47

Rhododendron sp. 4, 46, 100

- arboreum 47

- californicum 46

- Chrysanthum 46

- cinnabarinum 47

- ferrugineum 46

- hirsutum 47

- maximum 46

- ponticum 46, 47

- punctatum 47

Ricin 34

Ricinine 34

Ricinus communis 33

Roemeria hybrida 105

Rosaceæ 34

Rumex Acetosa 63, 104

- Acetosella 63

- crispus 64

Ruta graveolens 104

St John's Wort 22

Sambuca Ebulus 43, 104

- nigra 43, 104

Sambucine 44

Sambunigrin 44

Saponaria officinalis 19, 105

Saponins 8, 9, 19, 21, 77, 78, 97

Sapotoxin 21

Scabiosa succisa 93

Scarlet Pimpernel 48

Scilla bifolia 105

Scopolamine 50, 51, 59

Scrophularia aquatica 95

- nodosa 95

Scrophularine 95

Scrophularineæ 61 
Sedum acre 93,105

- album 105

Senebiera didyma 101

Senecifolidine $\mathbf{4 5}$

Senecifoline 45

Senecio Burchelii 45

- Jacobea 44

- latifolius 45

Sheep's Sorrel 63

Shepherd's Purse 101

Silica 86

Silver Weed 92

Sinalbin 18

Sinapine 18

Sinapis alba 105

- arvensis, see Brassica sinapistrum

- nigra 105

Sium angustifolium 37, 101, 104

- latifolium 37, 101

Sium, Lesser 101

Smilacin 21

Snake's Head 97

Soapwort 19, 105

Solanaceæ 4, 8, 50, 103

Solanidine 53,56

Solanine $8,53,54,55,56$

Solanum Dulcamara 54, 104

- guineense 53

- nigrum 4, 52, 54, 104

- tuberosum 54-58

- villosum 53

Sorrel, Common 63, 104

- Sheep's 63

- Wood 23, 100

Sparteine 27, 31

Spearwort, Lesser 10, 11, 105

Spindle Tree 24, 105

Spurge Laurel 65, 105

Spurges 66, 67, 100, 105

Staphisagrine 14

Stellaria media 101

Stinking Mayweed 101

Stipa pinnata 101

Sundews 93

Sunflower, Wild 3

Sun Spurge 66, 105

Syringin 49

Syringopicrin 49

Tamus communis $35,78,105$

Tanacetum vulgare 44, 101

Tannin 70

Tansy 44, 101

Taxine 75

Taxus baccata 2, 4, 7, 8, 72, 73-76, 103, 104

Temuline 83

Terpene 93
Thermopsis rhombifolia 3

Thlaspi arvense 101

Thorn Apple 50, 103, 104

Thuja occidentalis 72

Thymelaceæ 65

Toadflax 95, 105

Tormentil 88, 93

Traveller's Joy 9, 105

Treacle Mustard 19

Trifolium incarnatum 101

Trimethylamin 68

Trollius europceus 9

Ulex europous 92

Ulexine 25, 92

Umbelliferæ 2, 36

Urtica sp. 97

- dioica 97, 105

- pilulifera 105

- urens 105

Valeriana officinalis 93,105

Valerianic acid 93

Vellarin 93

Verbascum Thapsus 95

Vetchling, Yellow 29, 104

Viper's Bugloss 94

Viscum album 105

Wall-Pepper 93, 105

Wartcress, Lesser 101

Water Dropwort 37, 103, 104

- Hemlock 2, 8, 36, 104

- Parsnip 37, 101

- Pepper 64, 65

White-Rot 93

Wild Chamomile 101

- Geranium 3

- Lettuce 45

- Parsnip 93

- Radish 18

- Sunflower 3

Wind Flower 9, 105

Wonderberry 53

Wood Anemone 9, 105

- Sorrel 23, 100

Wormwood 101

Xylan 98

Yellow Flag 97

- Rattle 95

- Vetchling 29, 104

Yew $2,4,7,8,72,73-76,103,104$

Zygadenus venenosus 3 


\section{CAMBRIDGE UNIVERSITY PRESS}

CAMBRIDGE AGRICULTURAL MONOGRAPHS

General Editors: T. B. Wood, M.A., and

E. J. Russell, D.Sc.

Inorganic Plant Poisons and Stimulants. By Winifred E. Brenchley, D.Sc., F.L.S., Fellow of University College, London. With I9 illustrations. Royal 8vo. 5 s net.

Plants Poisonous to Live Stock. By Harold C. Long, B.Sc. (Edin.), of the Board of Agriculture and Fisheries. Royal 8vo.

CAMBRIDGE FARM INSTITUTE SERIES

General Editors: Professor T. B. Wood, M.A., and

E. J. Russell, D.Sc.

The volumes of this series are intended to meet the needs of the many Farm Institutes already in existence or about to be formed. They are intended for the average student whose object is to farm, rather than for the exceptional man who wishes to become an agricultural expert.

\section{Now ready}

Farm Accounts. By C. S. Orwin, Hon. M.A. 3s net.

A Student's Book on Soils and Manures. By E. J. RUSSELL, D.Sc. 3s $6 \mathrm{~d}$ net.

Fungoid and Insect Pests of the Farm. By F. R. Petherbridge, M.A. With 54 illustrations. 4 s net.

\section{UNIVERSITY OF CAMBRIDGE SCHOOL OF ,} FORESTRY BULLETINS

\section{The Production and Utilisation of Pine Timber in}

Great Britain. Part I. Production. By E. R. BuRdon, M.A., Investigator in Timber, and A. P. LoNG, B.A., Assistant Investigator.

No. I. Sample Plots of Scots Pine at Woburn. Demy 8vo. Paper covers. Is $6 \mathrm{~d}$ net. (Bulletin, No. I.)

No. 2. Sample Plot of Scots Pine at King's Lynn. Demy 8vo. Paper covers. 9d net. (Bulletin, No. 2.)

\section{THE JOURNAL OF AGRICULTURAL SCIENCE} Edited by

R. H. Biffen, M.A., F.R.S., A. D. HAll, M.A., F.R.S., E. J. Russell, D.Sc., and T. B. Wood, M.A.

Price per volume, consisting of four parts, I $5 \mathrm{~s}$ net in paper covers, I $8 \mathrm{~s} 6 \mathrm{~d}$ net bound in buckram; to subscribers, I 5 s net per volume, post free, payable in advance. The price of each part sold separately is $5 \mathrm{~s}$ net.

\section{Cambridge University Press}

Fetter Lane, London: C. F. Clay, Manager 
Manuring for Higher Crop Production. By E. J. Russel.l, D.Sc., Director of the Rothamsted Experimental Station. With 16 illustrations. Demy 8vo. 3s net.

The Fertility of the Soil. By E. J. Russell, D.Sc. With 9 illustrations. Royal I6mo. Cloth, Is 3 d net. Leather, 25 od net. Cambridge Manuals Series.

Agricultural Geology. By R. H. RASTAll, M.A., late Fellow of Christ's College and Demonstrator of Geology in the University of Cambridge. With 51 illustrations. Demy 8vo. Ios $6 \mathrm{~d}$ net. Cambridge Geological Series.

Rubber and Rubber Planting. By R. H. Lock, Sc.D. With Io plates and 22 figures. Crown 8 vo. 5 s net.

Agriculture in the Tropics. An elementary treatise. By J. C. WILlis, M.A., Sc.D. Second edition, revised. With 3 I plates. Demy 8vo. 9s net. Cambridge Biological Series.

A Manual and Dictionary of the Flowering Plants and Ferns. By J. C. Willis, M.A., Sc.D. Third edition. Crown 8 vo. Ios $6 \mathrm{~d}$ net. Cambridge Biological Series.

The Classification of Flowering Plants. By Alfred Barton Rendle, M.A., D.Sc., F.L.S. Vol. I. Gymnosperms and Monocotyledons. With ${ }_{1} 87$ illustrations. Demy 8vo. Ios $6 \mathrm{~d}$ net. Cambridge Biological Series.

Grasses: a Handbook for use in the Field and Laboratory. By H. Marshall Ward, Sc.D., F.R.S. With 81 figures. Crown 8vo. 6s. Cambridge Biological Series.

Trees: a Handbook of Forest Botany for the Woodlands and the Laboratory. By H. Marshall Ward, Sc.D., F.R.S. Vol. I. Buds and Twigs. Vol. II. Leaves. Vol. III. Flowers and Inflorescences. Vol. IV. Fruits. Vol. V. Form and Habit, with an appendix on Seedlings. With numerous illustrations. Crown 8 vo. 4s $6 \mathrm{~d}$ net each. Cambridge Biological Series.

Botany. A Text-Book for Senior Students. By D. Thoday, M.A., Lecturer in Physiological Botany and Assistant Director of the Botanical Laboratories in the University of Manchester. With 205 illustrations. Crown 8vo. 5s 6d net.

Types of British Vegetation. By members of the Central Committee for the Survey and Study of British Vegetation. Edited by A. G. Tansley, M.A., F.L.S. With 36 plates and 21 figures. Crown 8vo. 6 s net.

Lessons on Soil. By E. J. Russell, D.Sc. With 58 illustrations. Large crown 8vo. Is $6 \mathrm{~d}$ net. Cambridge Nature Study Series.

Weeds. Simple Lessons for Children. By ROBERT Lloyd Praeger. With 45 figures and 3 plates. Large crown 8 vo. Is $6 \mathrm{~d}$ net. Cambridge Nature Study Series.

\section{Cambridge University Press}

Fetter Lane, London: C. F. Clay, Manager 



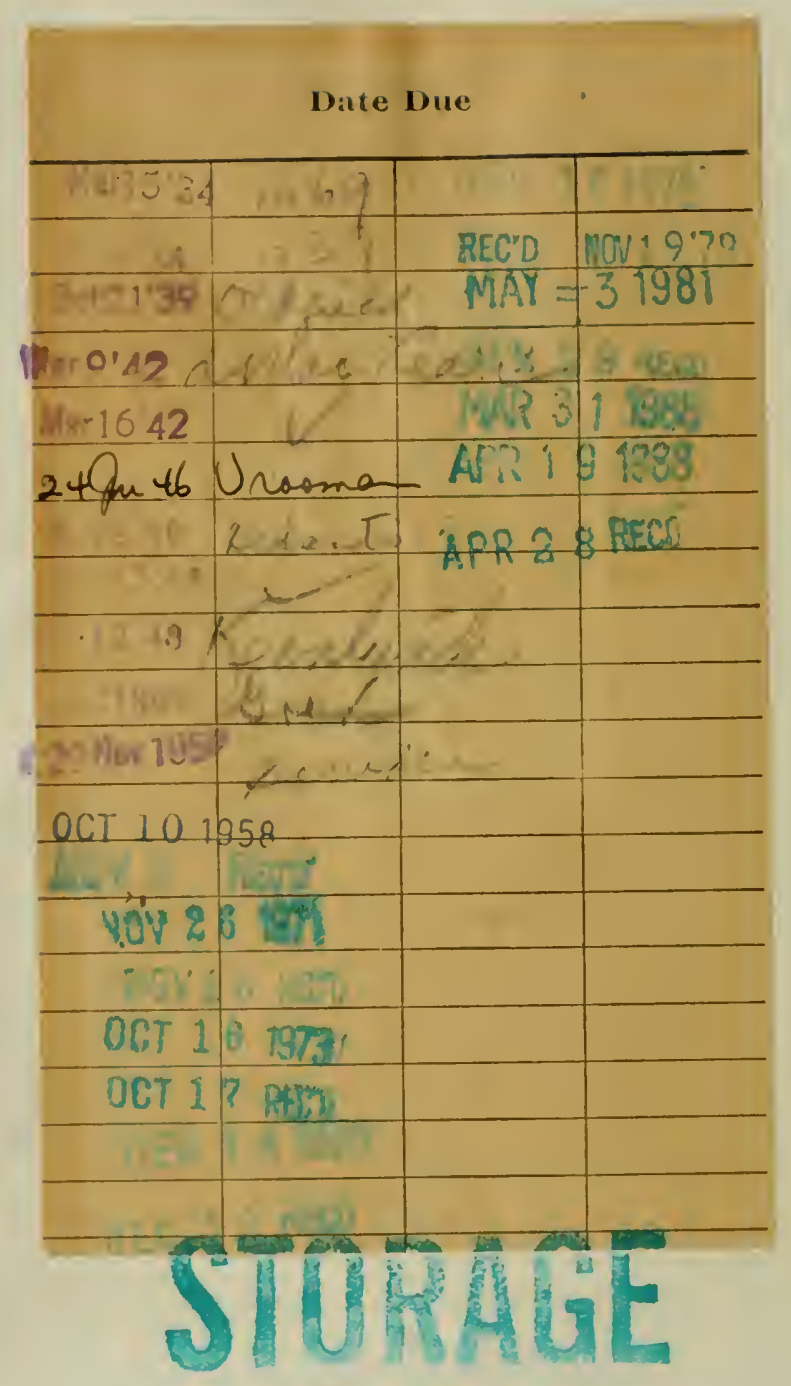




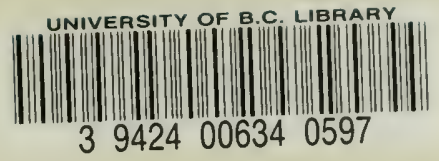

STORAGE 


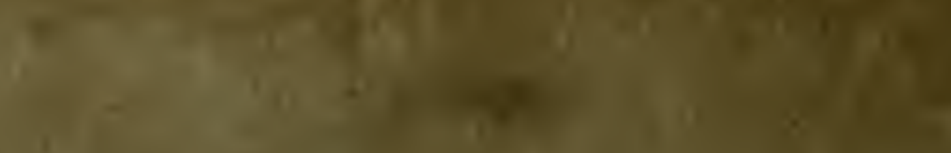

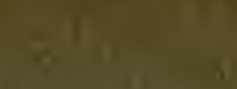

F

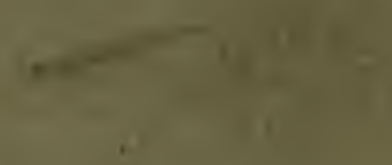

$x=1$

$41 x=$

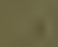

in 